\title{
Essays on Macro-Financial Linkages and Monetary Policy
}

\author{
Raju Huidrom \\ Imphal, India
}

M.A., University of Delhi, 2004

B.A., University of Delhi, 2002

A Dissertation presented to the Graduate Faculty of the University of Virginia in Candidacy for the Degree of

Doctor of Philosophy

Department of Economics

University of Virginia

August, 2014 
C) Copyright by

Raju Huidrom

All Rights Reserved

August 2014 


\begin{abstract}
The financial crisis of 2007-2009 triggered a major recession in the U.S., the fallout of which spilled over to many advanced economies. My dissertation examines three topical questions that emerge from this episode.
\end{abstract}

In the first chapter, "Do Credit Shocks Matter? A Global Perspective", we examine the importance of credit market shocks in driving global business cycles over the period 1988:1-2009:4. We first estimate common components in various macroeconomic and financial variables of the G-7 countries. We then evaluate the role played by credit market shocks using a series of vector autoregressive (VAR) models. Our findings suggest that these shocks have been influential in driving global activity during the latest global recession. Credit shocks originating in the U.S. also have a significant impact on the evolution of world growth during global recessions.

In the second chapter, "Credit Shocks and the U.S. Business Cycle: Is This Time Different?", I examine whether the effects of credit shocks on the U.S. economy show time variation during the Great Moderation period. By estimating a time-varying VAR model with stochastic volatility, I discriminate between two possible sources of time variation: stochastic volatility of shocks and changes in their transmission mechanism. This chapter finds that credit shocks exhibit stochastic volatility: the conditional volatility of these shocks systematically rises during periods of stress to the U.S. financial sector like the 2001 dot-com bust and the 2007 subprime crisis. Adjusted for shock size, I do not find any evidence that the transmission mechanism of credit shocks is time varying. In the specific context of the Great Recession of 2007-2009, I find that credit shocks have a non-trivial role. But, they do not entirely explain the magnitude of this recession.

In the third chapter, "Raising the Inflation Target to Manoeuvre the Zero Lower Bound: The Role of Fiscal Policy", I examine the recent monetary policy proposal that central banks 
should pursue a higher inflation target in view of the recession-induced zero lower bound. Because countercyclical fiscal policy is an alternative macroeconomic stabilization tool at the zero lower bound, this chapter explores how fiscal policy matters when deciding whether or not policy makers should raise the inflation target. I find that the scope for a countercyclical fiscal policy weakens the case for raising the inflation target as a means to mitigate the effects of the zero lower bound. The efficacy of countercyclical fiscal policy during zero lower bound episodes, however, depends on the initial level of government debt - a high initial level of government debt limits that efficacy.

JEL Classification: E32, E44, E52, F44.

Keywords: credit shocks, zero lower bound, fiscal-monetary interactions. 


\section{Acknowledgments}

Words fall short when it comes to expressing my heartfelt appreciation to all who have given me tremendous support and encouragement throughout my Ph.D. program. At the end of this journey, it gives me great pleasure to thank everyone for making it an unforgettable experience.

I owe the greatest gratitude to my advisors Christopher Otrok, Toshihiko Mukoyama, and Eric Young for their constant guidance, encouragement, and most importantly having faith in me. Chris taught me a variety of empirical methods and provided inspirations for all the chapters in this dissertation. I have also greatly benefited from our joint research projects where I got first hand exposure to econometric models, particularly dynamic factor models. I am immensely thankful to Toshi for his dedicated supervision, guidance on research directions, and detailed advice on the presentation of my work. Whenever my research got sidetracked, Toshi was always around to help me move on, which often involved him clocking many car miles for discussions and advising sessions. Eric gave me valuable advice on computation especially related to the global solution method I use in my third chapter. Eric also helped me sharpen my analyses and presentations for which I am very much thankful.

To Mike Gallmeyer of the UVA McIntire School of Commerce, I am grateful that he joined my dissertation committee. I would like to thank Ayhan Kose (then at the Fund and now at the Bank) for his comments and many a session of productive discussions.

To my colleagues - Aaron Butz, Asli Senkal, Bingbing Dong, Daniel Fried, Haiyan Liu, Mike Schreck, and Radu Puslenghea - thank you guys! I cannot express enough thanks for being such great pillars of support and encouragement. I am grateful to Patty Futrell and Debby Stanford of UVA Economics Department for being so helpful and resourceful during all these years. I thank the Bankard Fund for Political Economy and Steer Family Endowed 
Fund for financial assistance while writing this dissertation. For a year spent productively in upstate New York, I thank the library staff at Binghamton University, and my friends there whose good company made the cold weather bearable.

Lastly, I would like to thank my parents and siblings for their constant support, sacrifices, and prayers that helped me see the fruition of this degree. Finally my wife, to whom I owe this dissertation. Without her love, understanding, and support, this dissertation would not have been possible. 


\section{Contents}

1 Do Credit Shocks Matter? A Global Perspective 1

1.1 Introduction . . . . . . . . . . . . . . . . . . . . 1

1.2 Credit Markets and the Business Cycle: A Brief Survey . . . . . . . . . 3

1.3 Database and Methodology . . . . . . . . . . . . . . . 5

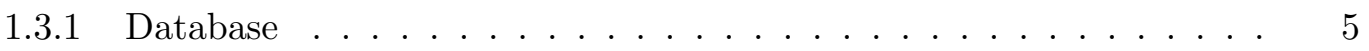

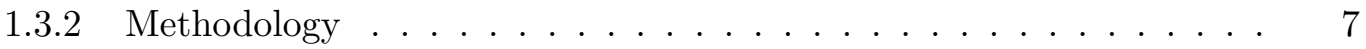

1.4 Credit Shocks and Global Business Cycles . . . . . . . . . . . . . . 11

1.4 .1 Impulse Responses . . . . . . . . . . . . . . . . . . . . . . 12

1.4 .2 Variance Decompositions . . . . . . . . . . . . . . 13

1.4.3 Credit Shocks during Global Recessions . . . . . . . . . . . . . . 14

1.5 The Global Transmission of U.S. Credit Shocks . . . . . . . . . . . . . . 16

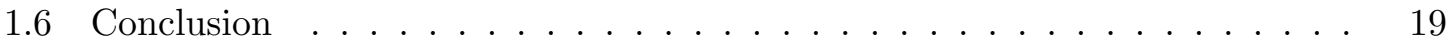

1.7 Figures and Tables . . . . . . . . . . . . . . . . . 21

2 Credit Shocks and the U.S. Business Cycle: Is This Time Different? 28

2.1 Introduction . . . . . . . . . . . . . . . . . . 28

2.2 Theoretical Background . . . . . . . . . . . . . . . . 32

2.3 Related Empirical Work . . . . . . . . . . . . . . . . . . . . . 34

2.4 Methodology . . . . . . . . . . . . . . . . . 35

2.4 .1 Econometric Model . . . . . . . . . . . . . . . . . 35

2.4 .2 Identification . . . . . . . . . . . . . . . 38 
2.4 .3 Database . . . . . . . . . . . . . . . . . . . . . . 39

2.5 Bayesian Inference . . . . . . . . . . . . . . . . . . . . . 40

2.5 .1 Estimation . . . . . . . . . . . . . . 40

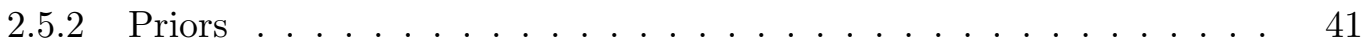

2.6 Results. . . . . . . . . . . . . . . . . . . . . . 44

2.6 .1 Stochastic Volatility . . . . . . . . . . . . . 44

2.6.2 Time Varying Transmission Mechanism _. . . . . . . . . . . 47

2.6.3 Relative Importance of Credit Shocks for Business Cycle Fluctuations 53

2.6.4 Credit Shocks and the Great Recession . . . . . . . . . . 55

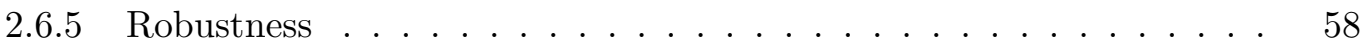

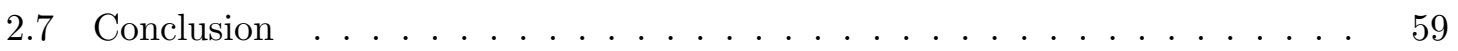

2.8 Figures and Tables . . . . . . . . . . . . . . . . . 61

3 Raising the Inflation Target to Manoeuvre the Zero Lower Bound: The $\begin{array}{ll}\text { Role of Fiscal Policy } & 80\end{array}$

3.1 Introduction . . . . . . . . . . . . . . . . . . . . 80

3.2 Related Literature . . . . . . . . . . . . . . . . . . . 83

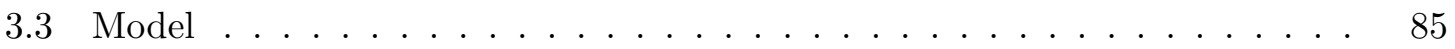

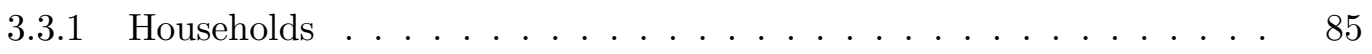

3.3.2 Final Good Producer . . . . . . . . . . . . . . . . . 88

3.3.3 Intermediate Good Producers . . . . . . . . . . . . . . 88

3.3 .4 Government . . . . . . . . . . . . . . . . . . . . 91

3.3.5 Aggregation and Market Clearing Conditions . . . . . . . . . . 93

3.4 Calibration . . . . . . . . . . . . . . . . . 95

3.4 Parameter Values . . . . . . . . . . . . . . . . 95

3.4 .2 Discussion on Equilibrium . . . . . . . . . . . . . . . . . . 97

3.5 Solution Method . . . . . . . . . . . . . . . . 98

3.6 Results. . . . . . . . . . . . . . . . . . . 100

3.6.1 Global Dynamics and Expectational Effects . . . . . . . . . . . 100 
3.6.2 Maneuvering the Zero Lower Bound . . . . . . . . . . . . . . . . . 103

3.6.3 Does the Initial Level of Government Debt Matter? . . . . . . . . . 110

3.7 Conclusion . . . . . . . . . . . . . . . . . . . . . . . . 112

3.8 Tables and Figures . . . . . . . . . . . . . . . . . . . . . . . 114

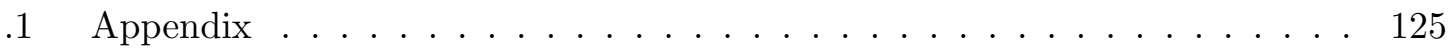

.1.1 Nonlinear Equations . . . . . . . . . . . . . . . . . . . 125

.1.2 Additional Graphs and Tables . . . . . . . . . . . . . 126 


\section{List of Figures}

1.1 G-7 Common Factors and U.S. Specific Variables . . . . . . . . . . . . 21

1.2 Impulse Responses due to a Credit Shock: G-7 VAR . . . . . . . . . . . . 22

1.3 Counterfactual from G-7 VAR: Global GDP . . . . . . . . . . . . . . 24

1.4 Impulse Responses due to a Credit Shock: U.S. FAVAR . . . . . . . . . . 25

1.5 Counterfactual from U.S. FAVAR: US GDP . . . . . . . . . . . . 26

1.6 Counterfactual from U.S. FAVAR: Global GDP . . . . . . . . . . . . 27

2.1 Credit Supply Condition and Economic Activity _ . . . . . . . . . . 61

2.2 Conditional Volatility of Orthogonalized Residuals in Each Equation . . . . 62

2.3 Time Series of Orthogonalized Residuals in each Equation . . . . . . . . . 63

2.4 Impulse Responses: Summary . . . . . . . . . . . . . . . . . . . . . . . 64

2.5 Impulse Response of Output (a) Baseline . . . . . . . . . . . . . 65

2.6 Time-varying vs. Time-invariant Model . . . . . . . . . . . . . . . 66

2.7 Impulse Response of Inflation (a) Baseline . . . . . . . . . . . . . . . 67

2.8 Impulse Response of Interest Rate At Different Horizons . . . . . . . . . . 68

2.9 Impulse Response of Interest Rate At Different Horizons . . . . . . . . . . . 69

2.10 Variance Decomposition . . . . . . . . . . . . . . . . . 70

2.11 Counterfactual: 2007-2009 Recession . . . . . . . . . . . . . . 71

2.12 Counterfactual: 2001 Recession . . . . . . . . . . . . . . . 72

2.13 Stochastic Volatility of credit shocks: Robustness . . . . . . . . . . . 73

2.14 Impulse Response of Output: Alternative Specifications . . . . . . . . . . . 74 
2.15 Impulse Response of Inflation: Alternative Specifications . . . . . . . . . 75

2.16 Impulse Response of Interest Rate: Alternative Specifications . . . . . . . . 76

2.17 Output Counterfactual: 2007-2009 Recession Baseline vs. Model D . . . . . 77

2.18 Impulse Response of Unemployment Rate . . . . . . . . . . . . . . . . 78

2.19 Time Varying Intercept Term in Interest Rate Equation $\ldots . . .78$

2.20 Inefficiency Factors of VAR Parameters . . . . . . . . . . . . . . . 79

3.1 U.K. Macroeconomic Variables . . . . . . . . . . . . . . . . . . . 114

3.2 Policy Rules in the Baseline Specification . . . . . . . . . . . . . 116

3.3 Higher Inflation Target vs. Countercyclical Fiscal . . . . . . . . . . . . . 117

3.4 Components of Govt. Budget Constraint . . . . . . . . . . . . . . 118

3.5 Unconditional Distributions . . . . . . . . . . . . . . . . . . . . 119

3.6 Unconditional Welfare . . . . . . . . . . . . . . . . . . . . . 122

3.7 Conditional Welfare over Baseline Model . . . . . . . . . . . . . . . . . . 122

3.8 Countercyclical Fiscal Policy for Different Levels of Initial Govt. Debt . . . 123

3.9 Countercyclical Fiscal Policy for Different Levels of Initial Govt. Debt . . . 124

10 Global vs. Linear Solution . . . . . . . . . . . . . . . . . 126 


\section{List of Tables}

1.1 Variance Decomposition: G-7 VAR . . . . . . . . . . . . . . . 23

1.2 Variance Decomposition: U.S. FAVAR . . . . . . . . . . . . . 23

2.1 Variance Decomposition . . . . . . . . . . . . . . . . 70

3.1 Baseline Parameter Values . . . . . . . . . . . . . . . . . . . . . 115

3.2 Alternative Model Specifications _. . . . . . . . . . . . . . . . . 115

3.3 Unconditional Moments from Model Simulations . . . . . . . . . . . . . . 120

3.4 Zero Lower Bound Episodes . . . . . . . . . . . . . . . . . . . . . . . . . 121

3.5 Unconditional Welfare . . . . . . . . . . . . . . . . . . . . 121

3.6 Fiscal Variables . . . . . . . . . . . . . . . . . . . . . . . . . 121 


\section{Chapter 1}

\section{Do Credit Shocks Matter? A Global Perspective}

\subsection{Introduction}

The global financial crisis of 2007-2009 that originated in U.S. credit markets rapidly spread across borders and led to recessions in almost all advanced economies. ${ }^{1}$ The global reach and depth of the crisis, which are without precedent in the post-World War II period, have renewed interest in the linkages between the real economy and credit markets, and have triggered an intensive debate about the importance of shocks originating in financial markets for business cycles. Our objective in this paper is to attempt to answer one of the central questions of this debate: do credit shocks matter in driving the global economic activity?

We study this question by analyzing the importance of credit and productivity shocks in explaining business cycles in G-7 countries. Given that there is already a sizeable lit-

\footnotetext{
${ }^{1}$ This is a joint work with Thomas Helbling, Ayhan Kose, and Chris Otrok which is now published at the European Economic Review (April 2011). An earlier version of this paper was presented at the conference on "Advances in International Macroeconomics: Lessons from the Crisis" in Brussels. We are grateful for helpful comments from the editor, Michael Devereux, two anonymous referees, our discussant, Michele Lenza, and conference participants. We would like to thank David Fritz and Ezgi Ozturk for providing outstanding research assistance. The views expressed in this paper are those of the authors and do not necessarily represent those of the IMF or IMF policy.
} 
erature about the importance of productivity shocks, they serve as a benchmark against which we assess the influence of shocks originating in credit markets. We first estimate common components in various macroeconomic and financial variables. We then examine the roles played by credit shocks in explaining global business cycles by employing a set of VAR models. In addition, we study the transmission of credit shocks originating in the U.S. to the global economy using a factor-augmented VAR (FAVAR). Our results suggest that credit shocks play an important role in driving economic activity especially during global recessions.

Our study contributes to a large body of research focusing on the interactions between financial markets and the real economy. In Section 1.2, we briefly summarize the relevant research. As the summary shows, empirical evidence on the linkages between credit market dynamics and the global economic activity is surprisingly limited. Our study addresses this major gap in the literature. To our knowledge, it is the first one to analyze the global implications of shocks originating in credit markets. Another novel aspect of the study is that we derive credit shocks that are not just based on traditional credit spread measures, but also on fluctuations in the volume of credit. Finally, our study extends beyond the general analysis of impulse responses and variance decompositions, and evaluates the role played by credit shocks during recent global recessions. This is particularly important given that the 2007-2009 global recession is associated with widespread dislocations in credit markets.

In Section 1.3, we introduce our database and econometric approach. The database comprises quarterly series of credit, credit spread, default rate, GDP, labor productivity, inflation, and the interest rates of the G-7 countries over the period 1988:1-2009:4. In order to study the global dimensions of credit shocks, we construct a global factor for each variable. We then employ a set of VAR models to analyze the importance of credit and productivity shocks. Our approach to the identification of these shocks is an agnostic one based on intuitively appealing sign restrictions. 
In Section 1.4, we estimate a VAR model of the global factors in credit, GDP, inflation, interest rates, productivity together with U.S. credit spreads and U.S. default rates. Using this model, we then analyze how global credit shocks affect world business cycles using impulse responses and variance decompositions. We also study how these shocks affect world GDP during global recessions through counterfactual simulations. In Section 1.5, we focus on the role of credit shocks originating in the U.S. using a FAVAR model that includes U.S. variables along with the global GDP factor. We conclude in Section 1.6 with a brief summary of our main results and directions for future research.

\subsection{Credit Markets and the Business Cycle: A Brief Survey}

A short review of the literature on credit markets and business cycles highlights the importance of the question we are studying. The role of credit markets in driving business cycles varies substantially across different classes of models. Some models imply that these markets are only peripherally important for the dynamics of business cycles while others assign a significant role to shocks originating in the financial sector. ${ }^{2}$

Basic economic theory suggests that, in a frictionless world under complete markets, macroeconomic and financial variables can interact closely through wealth and substitution effects. Developments in credit markets, which are simply reflected by movements in asset prices, can influence consumption through their impact on household wealth, and can affect investment by altering a firm's net worth and the market value of the capital stock relative to its replacement value (see Campbell (2003); Cochrane (2005)). However, in models with complete markets, the financial sector is a "veil" in the sense that there is no role for financial intermediaries or credit market disturbances, since these models do not account

\footnotetext{
${ }^{2}$ While the early literature did recognize that financial markets play an important role in the real economy, this emphasis later faded. For example, Fisher (1933) and Keynes were among the first to emphasize the importance of financial markets in shaping macroeconomic outcomes during the Great Depression. Subsequent research, however, focused largely on the role of money as the most relevant financial variable. The famous Modigliani and Miller (1958) "capital structure irrelevance" hypothesis and the general focus on efficient financial markets, however, inadvertently drew attention away from the relevance of financial structure for macroeconomic performance.
} 
for financial imperfections/frictions. The models, hence, imply that shocks originating in credit markets play only a minor role, if any, in explaining business cycles.

In theory, however, interactions between financial variables and the real economy can be amplified when financial imperfections are present. ${ }^{3}$ This amplification largely occurs through the financial accelerator and related mechanisms operating through firms, households and countries' balance sheets. According to these mechanisms, an increase (decrease) in asset prices improves an entity's net worth, enhancing (reducing) its capacities to borrow, invest, and spend. This process, in turn, can lead to further increases (decreases) in asset prices and produce general equilibrium effects (e.g., Bernanke and Gertler (1989); Bernanke et al. (1999); Kiyotaki and Moore (1997); and numerous other studies on the role of financial imperfections). In other words, disturbances in credit markets can translate into much larger cyclical fluctuations in the real economy in these models. ${ }^{4}$

Other studies apply models of frictions in credit markets to open economies and consider how the dynamics of exchange rates relate to business cycles (see Cespedes et al. (2004)). This line of research also studies how fluctuations in asset prices can affect the value of collateral required for international funding (see Mendoza (2010)). Caballero and Krishnamurthy (1998) and Schneider and Tornell (2004) model how, because of balance sheet constraints, fluctuations in credit and asset markets translate into boom-bust cycles in emerging market economies. ${ }^{5}$

Many empirical studies provide evidence regarding the linkages between the dynamics of business cycles and disturbances in credit markets (e.g., Bernanke and Gertler (1989); Borio and Lowe (2001)). These examine the procyclical nature of credit cycles and busi-

\footnotetext{
${ }^{3}$ Surveys of this literature can be found in Gertler (1988), and Gilchrist and Zakrajsek (2012a).

${ }^{4}$ Some recent studies have focused on the role of asset prices in transmitting financial cycles (Adrian and Shin (2009); and Geanakoplos (2009)). Recent studies also consider how the state of the financial system can affect business cycles (Gertler and Kiyotaki (2010); Brunnermeier and Sannikov (2014)).

${ }^{5}$ There is also a rich set of theoretical studies analyzing the implications of various types of financial crises for the real economy (see Gorton (2009) as regard to the recent financial crisis).
} 
ness fluctuations, albeit mostly for single country cases. For example, Bordo and Haubrich (2010) analyze cycles in money, credit and output between 1875 and 2007 in the United States. They show that episodes of financial stress exacerbate cyclical downturns. While most studies use aggregate data, some credit-related studies utilize micro data (see Kashyap and Stein (2000); and Kannan (2012)).

Our paper is closely related to some recent studies analyzing the importance of credit shocks using VAR models. Meeks (2012) examines the importance of credit shocks in explaining U.S. business cycles. He documents that credit shocks do play an important role during financial crises, but they have a lesser role during "normal" business cycles. Gilchrist et al. (2009) and Gilchrist and Zakrajsek (2012a) report that credit market spreads have a significant impact on business cycles in the U.S. during the period 1990-2008. Using a DSGE model, Perri and Quadrini (2011) find that the latest recession and its global reach can be explained by credit market shocks.

\subsection{Database and Methodology}

\subsubsection{Database}

Our dataset includes quarterly series of credit, credit spread, default rate, GDP, labor productivity, inflation, and the interest rates of the G-7 countries for the period 1988:1-2009:4. We concentrate on this period for the following reasons. First, it is a common denominator for the cross-country data we need to analyze the interaction between credit shocks and business cycle dynamics in the G-7 countries. Second, this period covers a substantial

portion of the "Great Moderation" era as well as the latest global financial crisis (see Blanchard and Simon (2001) and Stock and Stock and Watson (2005)). Third, this period also coincides with a rapid increase in trade and financial linkages among the G-7 countries and a broader converge of their business cycles (see Kose et al. (2008)).

Our measure of credit is aggregate claims on the private sector by deposit money banks. 
This measure is also used in earlier cross-country studies on credit dynamics (see Mendoza and Terrones (2008); and Claessens et al. (2012)). The use of credit volume differentiates our study from most others on the impact of credit shocks and allows us to construct a global credit factor since this variable is available for all of the G-7 countries at the quarterly frequency. We deflate the nominal credit series using the CPI to obtain real credit. ${ }^{6}$ Inflation corresponds to the changes in each country's CPI.

Unlike the other variables, credit spread and default rates series are available for only the U.S. In order to measure credit spreads, we use corporate bond spreads. In particular, these spreads are the yield differences between Moody's Seasoned Aaa and Baa corporate bonds for the U.S. The Aaa bonds are "judged to be the highest quality with minimal credit" risk while the Baa bonds are "subject to moderate credit risk and possess certain speculative characteristics".

There is no single accepted measure of credit spreads as the recent literature on the importance of credit shocks employs various alternative ones. For instance, Meeks (2012) uses a measure of credit spreads defined in terms of a risky bond portfolio that belongs to Moody's B1/B2 category. Such a portfolio is described by Moody's as being subject to "high credit risk". Gilchrist et al. (2009) take a panel of credit spreads and estimate a common factor of these spreads as their measure.

The default rate series corresponds to the monthly default rates for Moody's rated U.S. speculative-grade corporate bonds from the Moody's Investor Service. As in the case of credit spreads, we take the observation of the last month of each quarter as our quarterly default rates. Meeks (2012) uses a similar default rate series to identify credit shocks.

We track aggregate business cycles with real GDP. Our GDP data are chained volume

\footnotetext{
${ }^{6}$ Only a few others include credit volume to study the impacts of credit market shocks on the real economy (see Balke (2000)). It will be useful to employ a variable that accounts for a broader measure of credit than the one used we use here, but such series are not available on a consistent basis across countries.
} 
series from the OECD. The interest rates correspond to nominal short term government bill rates, generally Treasury Bill Rates, and are from the IFS. Labor productivity is defined as real GDP per hours worked and is obtained from the OECD. ${ }^{7}$ Before constructing our factors and estimating the VAR models, we make appropriate transformations in each data series. In particular, we take four-quarter growth rates of GDP, labor productivity, and credit. Interest rates are first differenced. Credit spreads and default rates are in levels. All variables are seasonally adjusted and expressed in percentages.

\subsubsection{Methodology}

Since our objective is to analyze the global dimensions of credit shocks, we undertake our exercise in two steps. First, we estimate the common component in each variable to obtain a global factor. Although our data sample includes only G-7 countries, this country group accounts for slightly more than half of global GDP over the 1988-2009 period (in PPP exchange rates). Second, we use VAR models to analyze the importance of credit and productivity shocks in explaining business cycles. We also consider how shocks originating in the U.S. transmit to the global economy using a FAVAR (Factor Augmented VAR) model. We now briefly explain each step in turn.

Estimation of Global Factors: To estimate the global factors, we extract the first principal component of each variable using the series of the G-7 countries. There are, of course, alternative approaches to construct global equivalents of these variables. For example, we could employ a full-fledged dynamic factor model, as in Kose et al. (2003). Their method is especially useful to estimate different common factors simultaneously, such as global, regional, and country-specific factors. However, the global factor obtained with a dynamic factor model is quite similar to the first principal component. ${ }^{8}$ We use the simpler approach since we are only interested in the global component of each variable.

\footnotetext{
${ }^{7}$ We provide a detailed list of the data series and their sources in a Supplemental Appendix which is available at http://people.virginia.edu/ cmo3h/.

${ }^{8}$ In fact, we did estimate the dynamic factor models for some of the variables and arrived at almost identical factors to those from the principal component models.
} 
Figure 1.1 presents the estimated global factors. The estimated factors are broadly consistent with a number of well-known cyclical episodes in the global economy. For instance, the downturns in the estimated global GDP factor coincide with the recessions of the early 1990s, early 2000s, and the latest episode of 2007-2009. The downturn during the latest episode is particularly striking because of its highly synchronous nature and its unprecedented depth. The estimated factors of the other variables also reveal interesting patterns. For example, the global credit factor indicates that the episodes we discuss above were associated with declines in credit. The global inflation factor shows a steady decline beginning in the early 1990s until the recent global recession, consistent with the literature on the "conquest of inflation" in advanced economies. The global interest rate factor also follows familiar patterns: it rises rapidly in the late 1980s and early 1990s and then declines thereafter.

Figure 1.1 also presents the evolution of the U.S. credit spread and default rates. Although there are small elevations in both variables during the early 1990s and 2000s, the increases recorded during the global financial crisis clearly are in a different league. For instance, the spread climbs to 3 percent in 2008-2009, which is more than twice its previous highest value over the 1988-2007 period. The default rates also follow a similar pattern and reach a new high during the recent crisis.

We are able to estimate global factors for all variables except the credit spread and default rates, since these series are available for only the U.S. We assume that credit spread and default rates for the U.S. are good representations for their global counterparts since the U.S. economy has been the dominant force in world markets. For example, over the period of 1988-2009, the U.S. economy constitutes roughly half of the G-7 output while it accounts for almost one-fourth of global output. Moreover, the U.S. financial markets are the largest, reflecting not only the size of the economy but also their depth. For example, capitalization of the U.S. equity markets accounts for around 40 percent of total capitaliza- 
tion of world equity markets. Changes in U.S. credit markets and asset prices have strong signaling effects worldwide, and spillovers from U.S. financial markets have been important, especially during periods of market stress.

VAR Models: We estimate two VAR models. The first one includes the estimated global factor of each variable, the U.S. credit spread and default rates. The second model is a FAVAR as it uses the U.S. specific variables along with the global GDP factor. ${ }^{9}$ The models we have can be represented by:

$$
y_{t}=a_{(0)}+A_{(1)} y_{t-1}+A_{(2)} y_{t-2}+\ldots+A_{(l)} y_{t-l}+u_{t} ; \quad t=1, \ldots, T
$$

where $y_{t}$ is an $m \times 1$ vector of variables at date $t, A_{(i)}$ is an $m \times m$ coefficient matrix for each lag of the variable vector with $a_{(0)}$ being the constant term. $u_{t}$ is the vector of one-step ahead prediction error. The two models differ only in terms of the set of variables in the $y_{t}$ vector. For the first VAR, $y_{t}$ includes the estimated global factors, and U.S. credit (i.e., corporate bond) spread and default rates. ${ }^{10}$ In the case of the U.S. FAVAR, the vector consists of the set of U.S. variables and the global GDP factor. In our estimation, the lag length, l, is kept at four.

We use these models to examine the roles of credit and productivity shocks in explaining the global and U.S. business cycles. Since there is already a large literature about the importance of productivity shocks as a source of business cycle fluctuations, it constitutes a natural benchmark against which we evaluate the role of credit shocks. We use global and the U.S. specific versions of these shocks in our respective models for the global economy and the U.S.

\footnotetext{
${ }^{9}$ Our second model follows the work of Bernanke et al. (2005) who developed the factor-augmented VAR (FAVAR) to study the effects of monetary policy in a closed economy framework.

${ }^{10}$ Bernanke et al. (2005) compare FAVARs that treat estimated factors as data as is done here, with more sophisticated Bayesian estimates that account for uncertainty in the estimated factors. They find that there is no real gain from the more computationally intensive Bayesian methods for this type of problem.
} 
We identify the shocks using a set of sign restrictions imposed on impulse responses following Uhlig (2005). ${ }^{11}$ Instead of relying on restrictions on the variance-covariance matrix of the structural residuals' orderings based on the presumed exogeneity or predetermination of variables, this identification approach allows us to produce impulse responses that are qualitatively consistent with standard theoretical predictions. The sign restrictions algorithm we use, however, differs from Uhlig (2005) in that we simultaneously identify two orthogonal shocks. ${ }^{12}$ An alternative approach would be to identify each shock, credit and productivity, one at a time. However, this does not guarantee the orthogonality of the two shocks, making it difficult to argue that the identified shocks are truly "structural".

The sign restrictions we impose are intuitively appealing. For example, we identify adverse credit market shocks by assuming that they simultaneously lead to a decrease in credit, an increase in the price of credit, i.e., the credit spreads. In addition, we assume that productivity does not fall and default rates do not rise. ${ }^{13}$ The sign restrictions on the responses of the four variables are imposed for four quarters following the initial shock. The restrictions on credit and credit spreads describe the natural responses of volume and price of credit to such disturbances. Given the forward looking nature of credit markets, the restrictions on productivity and default rates ensure that we identify a credit supply shock rather than an endogenous credit response to expected fluctuations in future activity. It is important to note we do not require that a contractionary credit shock brings "good times" with higher productivity or lower default rates. We merely require that the decline in credit not to be associated with expected declines in productivity or increases in default rates. In other words, our adverse credit shock reflects a credit supply contraction as opposed to an

\footnotetext{
${ }^{11}$ Uhlig (2005) considers the importance of monetary policy shocks by imposing sign restrictions on the impulse responses of prices, nonborrowed reserves and the federal funds rate.

${ }^{12}$ Our simultaneous identification scheme implies that the second shock is identified by drawing an impulse vector that is orthogonal to the first impulse vector and at the same time obeys the sign restrictions we impose. This is a more restrictive requirement than a sequential identification scheme where the orthogonality condition is relaxed. We restrict ourselves to identifying only two shocks (credit and productivity) at a time, since identifying multiple shocks is computationally burdensome. We also consider credit-policy and credit-demand pairs. However, we did not get sufficient number of correct draws of the impulse vectors for these pairs from a total of 100,000 draws.

${ }^{13}$ Meeks (2012) shows that such restrictions on default rates are required to identify credit shocks originating in the financial sector.
} 
endogenous decline in credit due to lenders reducing credit in response to expectations of an increase in future default rates and/or a decline in future productivity. Our identification scheme does not impose any restriction on the response of GDP.

We identify the positive productivity shocks by assuming that they are associated with a simultaneous increase in labor productivity and in GDP, and a fall in inflation for four quarters following the shock. The latter restriction on inflation can be formally derived from a New Keynesian DSGE model, where inflation is driven by marginal cost and positive productivity shocks lower marginal cost.

We keep the horizon for sign restrictions for both productivity and credit shocks at four quarters to maintain symmetry across the two shocks. The horizon of four quarters also captures the idea that the impact of each shock lasts for at least a year. ${ }^{14}$ We have conducted sensitivity exercises to check the robustness of our results to alternative identification restrictions and duration assumptions. All of our main results are robust to these variations.

\subsection{Credit Shocks and Global Business Cycles}

In this section, we place the global factors in credit, GDP, inflation, interest rates, and labor productivity in our VAR model, together with U.S. credit spreads and default rates. With this model, we estimate the autoregressive dynamics among the variables we are interested in, and identify global credit and productivity shocks. We analyze the role of worldwide credit shocks in explaining global business cycles in three steps. First, we consider the impulse responses of the variables in our VARs to these shocks. Next, we study the variance of global GDP attributed to credit and productivity shocks. Third, we conduct a series of

\footnotetext{
${ }^{14}$ The selection of horizon length closely follows Baumeister and Peersman (2013) who also use the same length to identify technological shocks for the Euro area. There are some studies that keep the sign restriction horizon shorter than the one we use. For instance, Uhlig (2005) identifies monetary shocks by keeping the sign restrictions horizon at 2 quarters. In the specific context of credit market shocks for the U.S., Meeks (2012) identifies this shock by imposing sign restrictions on spreads for 2 quarters and those on defaults for 12 quarters.
} 
counterfactual simulations to evaluate the role of credit shocks during global recessions.

\subsubsection{Impulse Responses}

Figure 1.2 shows the median impulse response functions to an adverse global credit shock, together with the 14 and 86 percentile responses (based on 500 draws). The shapes of these impulse response functions are broadly consistent with our expectations. A temporary adverse credit shock, by assumption, raises corporate bond spreads and reduces total credit at impact. Global productivity increases at impact, consistent with our identification scheme, but declines gradually over time. Although global activity rises in tandem with the temporary increase in productivity, it starts contracting after the third quarter possibly because of the adverse impact of the limited availability and higher price of credit on aggregate demand. In particular, the global GDP factor declines steadily over the 12-quarter horizon suggesting that credit shocks can have long lasting effects on economic activity. However, the response of global GDP factor to credit market shocks is not statistically significant.

Short-term interest rates increase on impact but fall subsequently, presumably reflecting monetary easing in response to the eventual decline in economic activity following the unexpected tightening in credit markets. Since real GDP and inflation increase on impact, we are not capturing monetary policy-induced credit supply shocks with our identification assumption. While we expect the contraction and higher price of credit to put downward pressure on prices, the impulse response of inflation to our credit "supply" shock suggests otherwise, probably because of the initial increase in productivity and global activity. A credit shock that is identified without restrictions on productivity implies a decline in global GDP and inflation, but, such a credit shock likely combines both demand and supply elements. ${ }^{15}$

As in the case of credit shocks, the impulses to productivity shocks that have not been

\footnotetext{
${ }^{15}$ We present these findings in Figure B1 in the Supplementary Appendix.
} 
restricted for identification purposes generally have the expected patterns. ${ }^{16}$ However, they are not statistically significant except for the initial four quarters imposed for identification. The credit channel appears to play the expected role in the transmission of productivity shocks. Specifically, credit volume increases while the costs of credit (spreads) and defaults decrease, as one would expect given that firms net worth and investment rise with productivity improvements. We also analyze the robustness of our results with respect to different identification schemes. Specifically, we identify credit shocks by selecting only impulse responses with either a positive credit spread response or a negative credit growth response. In addition, we consider versions where we eliminate the joint restrictions on default rates, productivity, and orthogonality. The results are qualitatively similar to those obtained with our baseline identification scheme.

\subsubsection{Variance Decompositions}

The insignificance of responses of global real variables to credit shocks does not necessarily imply that these shocks are not important. In fact, our variance decompositions suggest that measured by their contribution to fluctuations to the global GDP factor, credit shocks are as important as productivity shocks. We report our findings in Table 1.1. Although the reported variance decompositions are based on a set of orthogonal shocks, they will not necessarily add up to 100 percent since there are other potential unidentified shocks that will make up the rest of the variance.

The credit shock, for example, accounts for roughly 11 percent of the 12-quarter ahead forecast error variance of the global GDP factor. Productivity shocks, on the other hand, account for approximately 12 percent of the total forecast error variance of the global GDP factor. Thus, our decompositions suggest that credit shocks account for about as large a share of fluctuations on their own as the standard productivity shocks. ${ }^{17}$

\footnotetext{
${ }^{16}$ We present the responses to the global productivity shocks in Figure B2 in the Supplementary Appendix. The results of additional sensitivity exercises are available from the authors upon request.

${ }^{17}$ In Figure B5 of the Supplementary Appendix, we provide the posterior coverage intervals for the variance decompositions. The estimates we report here are fairly precise and support our headline conclusions about the importance of productivity and credit market shocks.
} 
In addition to global GDP, credit shocks play an important role in explaining the variance of other variables. For example, they explain almost 10 percent of the variance of global productivity and around 11 percent of the variations in inflation and interest rates. These shares are close to those obtained for the productivity shocks. We have so far focused on the importance of credit shocks over the period 1988-2009. We now turn to a different question and consider the role of these shocks in explaining the path of global GDP during global recessions.

\subsubsection{Credit Shocks during Global Recessions}

How important are global credit shocks during episodes of global recessions? This is an obvious question to ask given that the latest episode is a global event associated with disruptions in international credit markets. We also consider the roles played by credit shocks during the global recession of 1990-1991. These two episodes of global recessions correspond to declines in world real GDP per capita. In particular, they identify four troughs in global economic activity over the past 50 years - 1975, 1982, 1991, and 2009. While the Great Recession of 2007-2009 is associated mainly with financial sector problems, the previous global recession reflects a host of issues in various corners of the world: difficulties in the U.S. saving and loan industry, banking crises in several Scandinavian economies, adverse effects of an exchange rate crisis on a large number of European countries, and challenges faced by the east European transition economies.

To gauge the role of credit shocks during these episodes, we perform a number of counterfactual exercises. Each of these exercises represents simulations where the structural shock of interest is set to zero over the relevant period. In the case of the latest episode, for example, the counterfactual credit shock simulation shows how the global GDP factor would have evolved without the adverse "credit supply event" that has been the hallmark of the Great Recession. It is important to recognize that while the credit supply shock is set to zero in this exercise, the volume of credit can still contract in response to other shocks. 
So, the credit channel is still in operation, but credit supply shocks, per se, are not the source of the downturn in the counterfactual simulation.

The left graph of the top panel in Figure 1.3 compares the results of counterfactual simulation for the global GDP factor during the Great Recession episode. Specifically, it shows the differences between the actual cumulative change in the demeaned global GDP factor and the cumulative changes in the simulated values in the absence of the global credit shock during 2007:3-2009:4. The impact of the global credit shock has obviously intensified as the recession turned into a global event, spreading from the U.S. to other advanced countries. For example, without the credit shock, the global recession would have been about 10 percent milder, given the difference between actual and simulated cumulative growth in 2009:3.

The left graph of the lower panel in Figure 1.3 compares the contributions of credit and productivity shocks to the cumulative global GDP growth based on the counterfactual simulations. Credit shocks on their own accounted for a larger share of the cumulative decline in the global GDP factor than productivity shocks. We interpret this result as evidence for the important role of global credit shocks in the latest episode. ${ }^{18}$

Counterfactual simulations for the 1990-1991 global recession suggests, however, that credit shocks played a less important role than they did in the 2007-2009 period (right graphs in Figure 1.3). This finding is intuitively appealing. Unlike the 2007-2009 episode, where difficulties in international credit markets were a critical driving force, the 1990-91 global recession had a number of different sources. As we show in the next section, the impact of a U.S. credit shock on U.S. activity is quite sizeable during the 1990-91 recession, which is not surprising given that U.S. credit markets went through a prolonged period of contraction. Moreover, the extent of real sector synchronization is also much greater in the

\footnotetext{
${ }^{18}$ The results of counterfactual exercises above are qualitatively robust to alternative definitions of credit shocks. In particular, when we drop the joint restrictions on default rates, productivity and orthogonality in various combinations, the importance of credit shocks during the Great Recession holds in general and sometimes becomes a bit stronger. These results are available from the authors upon request.
} 
most recent episode. ${ }^{19}$

The conclusions we draw from the analysis in this section is that credit shocks matter for the global economy, albeit to varying degrees. Their effects may not generally be large, but global credit shocks have played an important role in some episodes, notably in the latest global recession. Such ambiguities in the effects of credit shocks are not new. Other studies analyzing the relationship between financial conditions and future economic activity and inflation at the country level also often report weak and unstable predictive power. ${ }^{20}$ One notable exception is that of Gilchrist et al. (2009) who argue that the predictive power of credit spreads for economic activity increases substantially, especially at longer horizons, when the measure of credit spreads is derived from securities issued by intermediate-risk rather than high-risk firms.

\subsection{The Global Transmission of U.S. Credit Shocks}

We have so far considered the role played by global credit shocks in explaining global GDP. There is much to be said about rapidly increasing international financial linkages, which have led to the speedy transmission of domestic credit shocks to other economies. National and global credit shocks may thus have partly become indistinguishable. Nevertheless, in view of the key role of the U.S. financial system in global financial markets and the large size of the U.S. economy, a key question is whether credit shocks that originate in the U.S. have international repercussions. In this section, we examine this question by analyzing a set of FAVAR models with U.S. variables along with the global GDP factor estimated earlier. As in the previous section, we consider the role of U.S. credit shocks by first studying impulse responses, then variance decompositions, and finally global recession episodes.

\footnotetext{
${ }^{19}$ Imbs (2010), using monthly data on industrial production, concludes that the degree of cross-country business cycle correlations during the latest crisis was the highest in three decades.

${ }^{20}$ There is a large literature analyzing the predictive power of financial variables for future activity. However, the predictive value of these financial variables, including asset prices, generally is limited (see Stock and W.Watson (2003)). A number of studies have documented the predictive value of interest rates for output fluctuations and the timing of recessions and recoveries. (see Wheelock and Wohar (2009)).
} 
The impulse response functions to a U.S. credit shock are shown in Figure 1.4. The shapes of the median responses are broadly similar to those from the VAR in the previous section. However, the impact effects of a 1 standard deviation credit shock on several of the variables are more modest in the US FAVAR model. A major feature of the effects of a U.S. credit shock is that it has noticeable international repercussions. In fact, while the impact response on U.S. GDP is positive, not surprising given our identifying restrictions on productivity, the global GDP factor declines on impact. That said, these transmission effects generally are not statistically significant. ${ }^{21}$

Table 1.2 presents the variance decompositions. U.S. credit shocks play an important role in explaining the variance of domestic macroeconomic aggregates. For example, they account for 9 percent of fluctuations in the U.S. GDP (based on the 12-quarter ahead forecast error variance). Our estimate of the fraction of variance of the U.S. GDP due to a credit shock is consistent with the findings by Meeks (2012). ${ }^{22}$ More interestingly, the U.S. credit shocks account for 11 percent of the variance of global GDP, confirming the important role played by disturbances in the U.S. credit markets in explaining global business cycles. Productivity shocks account for roughly 12 percent of the variation in both the U.S. GDP and the global GDP factor. This corroborates our earlier finding that credit shocks are as important as standard productivity shocks in driving business cycles.

How important are U.S. credit shocks during global recessions? To answer this question, we conduct a set of counterfactual exercises as in the previous section. The results are summarize in the top panels of Figs. 1.5 and 1.6, which show the differences between the actual cumulative change in the demeaned U.S. GDP (global GDP factor) and the cumulative changes in the simulated values of the same variables in the absence of the U.S.

\footnotetext{
${ }^{21}$ As in the case of the earlier VAR, we also identify U.S. productivity shocks using the schemes described in Section 1.2. The impulse responses to these shocks are presented in Figure B4 in the Supplementary Appendix. The findings are broadly consistent with the ones from the global VARs.

${ }^{22}$ The variance decompositions based on shocks, which are identified with sign restrictions, are generally different from those based on the standard recursive decompositions. We, thus, restrict comparison of our results against those studies utilizing sign restrictions only (see Meeks (2012) for a similar point).
} 
credit shock during the two global recession episodes. The lower panel in Figures 1.5 and 1.6 display the differences between the actual and counterfactual simulations for the two shocks.

Two major findings stand out. First, credit shocks originating in the U.S. account for a larger difference in the cumulative GDP change in the cumulative change for the global GDP factor under the counterfactual simulations than U.S. productivity shocks. In the case of the U.S. GDP, domestic credit shocks are about as important as productivity shocks in the early stages of the latest global recession. Nevertheless, U.S. credit shocks appear to play a sizeable role in the 1990-91 recession. ${ }^{23}$

Second, the 1991 downturn in the U.S. clearly is associated with adverse disturbances in the U.S. credit markets and to a lesser extent abroad. ${ }^{24}$. Our results suggest that the U.S. specific credit disturbances transmit to global activity as evidenced by the largest difference accounted by the U.S. credit market shocks in driving global GDP especially in the later stages of the 1991 global recession. In contrast, our earlier counterfactual simulations with the VAR suggest that global credit shocks generally do not account for the largest differences between actual and counterfactual global GDP in the 1991 episode. Together, these findings suggest that the main credit shock during this episode was a disturbance in the U.S. credit markets and that the strong global repercussions do not necessarily arise primarily because of transmission through financial channels.

The important role played by credit market disturbances in explaining the severity of recessions during certain episodes is also consistent with some recent studies. For example, Perri and Quadrini (2011) argue that credit shocks are more relevant than productivity shocks in explaining the Great Recession, especially its global dimension. Using a DSGE model, they show that in a financially integrated world, credit shocks originating in one

\footnotetext{
${ }^{23}$ As in the case of the counterfactual exercise for global credit shocks, these results are stronger especially when restrictions on default rates are relaxed.

${ }^{24}$ For a discussion about disruptions in the U.S. credit markets in the late 1980 s and early 1990 s, see Reinhart and Rogoff (2009).
} 
country (the US in our case) can result in highly synchronized global business cycles. Mian and Sufi (2010), using detailed microeconomic data, document that the dramatic expansion and collapse of mortgage lending that is at the heart of the Great Recession align well with a credit supply explanation rather than one based on productivity driven credit demand. In related research, Claessens et al. (2012) analyze the interactions between recessions and disruptions in credit and asset markets using a large cross-country sample of business and financial cycles. Their findings also suggest that when recessions coincide with substantial declines in credit, they tend to become deeper.

\subsection{Conclusion}

The latest financial crisis has been a bitter reminder of the important role played by credit markets in driving macroeconomic fluctuations. Although there has been a large research program analyzing how gyrations in credit markets translate into fluctuations in the real sector at the country level, the global dimensions of credit shocks have not yet been studied. Our paper aims to provide a perspective about the linkages between credit markets and global business cycles using a simple framework. In particular, we analyze the importance of credit market shocks for the G-7 countries using a series of VAR models.

We start with a set of impulse responses to get a grasp of the dynamic reactions to disturbances in credit markets. We find that these disturbances do have an impact on output, but their effects on other variables are not always significant. We then conduct variance decompositions to analyze the importance of credit market shocks in driving business fluctuations. The results of this exercise suggest that these shocks are as important as productivity shocks.

We then assess the role of credit shocks during global recessions. In particular, we undertake a series of counterfactual simulations to examine the evolution of global GDP during the 1991 and 2009 global recessions. We find that credit shocks have played an important 
role during the latest global recession. Our simulations indicate that the impact of credit shocks during the 1991 global recession is smaller, but this is mostly due to the U.S. specific nature of the credit shock and the confluence of other factors during this episode.

We also study the global implications of credit shocks that originate in the U.S. by employing a set of FAVAR models. Our results with respect to the impulse responses and variance decompositions of these models are mostly consistent with the ones from the global VAR models. During the latest episode, U.S. credit shocks have been influential in driving global growth dynamics. Moreover, they have played an important role in shaping the evolution of U.S. business cycles during the 1991 recession.

We plan to study the potential importance of cross-country spillovers through various financial market linkages in our future research. In addition to credit markets, it would be interesting to analyze how asset (equity and real estate) market linkages can transmit business cycles across countries. It would also be useful to study the importance of credit market shocks originating in advanced countries for emerging market economies. 


\subsection{Figures and Tables}

Figure 1.1: G-7 Common Factors and U.S. Specific Variables
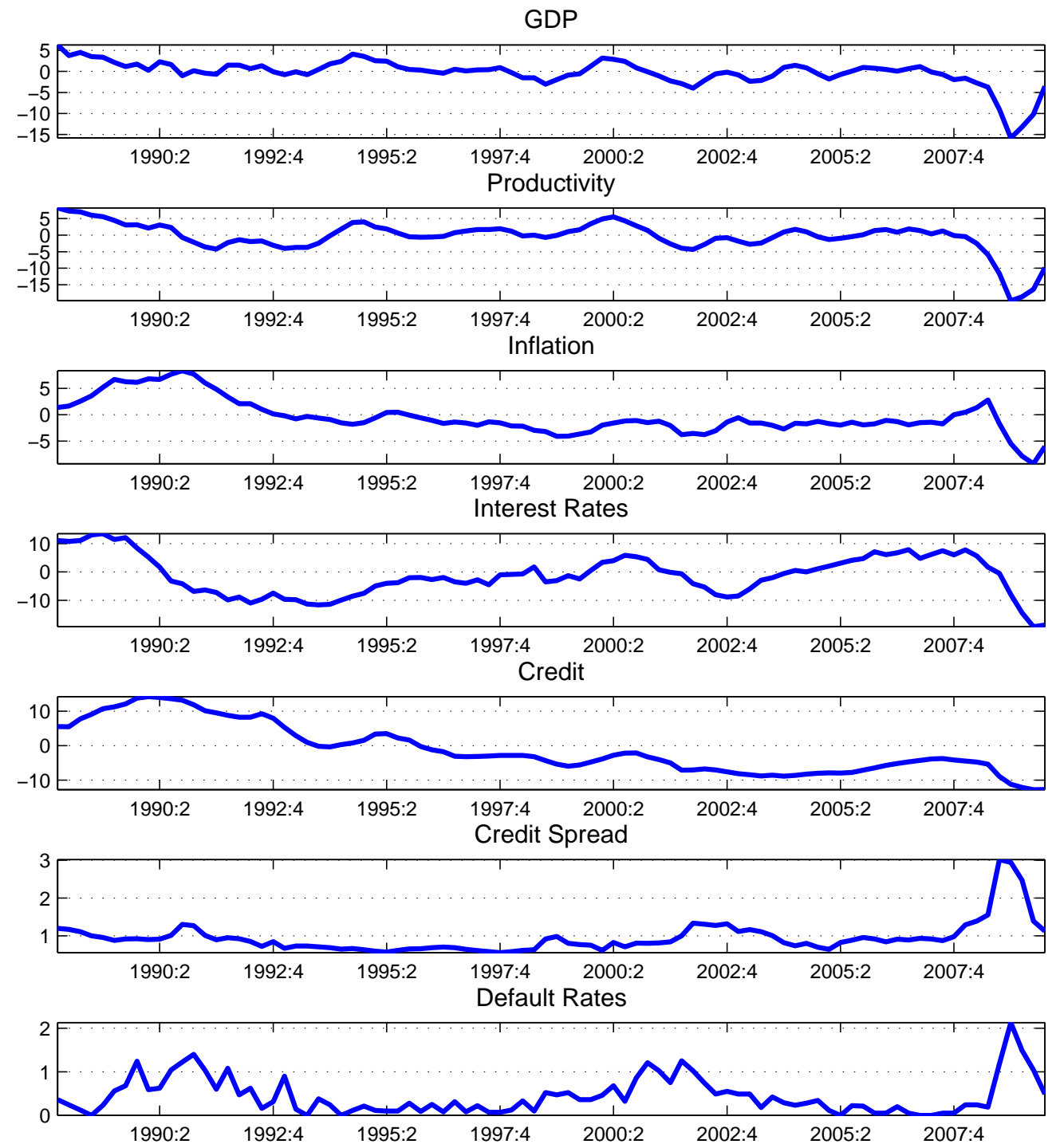

Note: The graph shows the common factors of productivity, GDP, inflation, credit, and interest rates for the G-7 countries estimated using the principle component method. It also shows the U.S. corporate bond spread and the U.S. default rates. 
Figure 1.2: Impulse Responses due to a Credit Shock: G-7 VAR
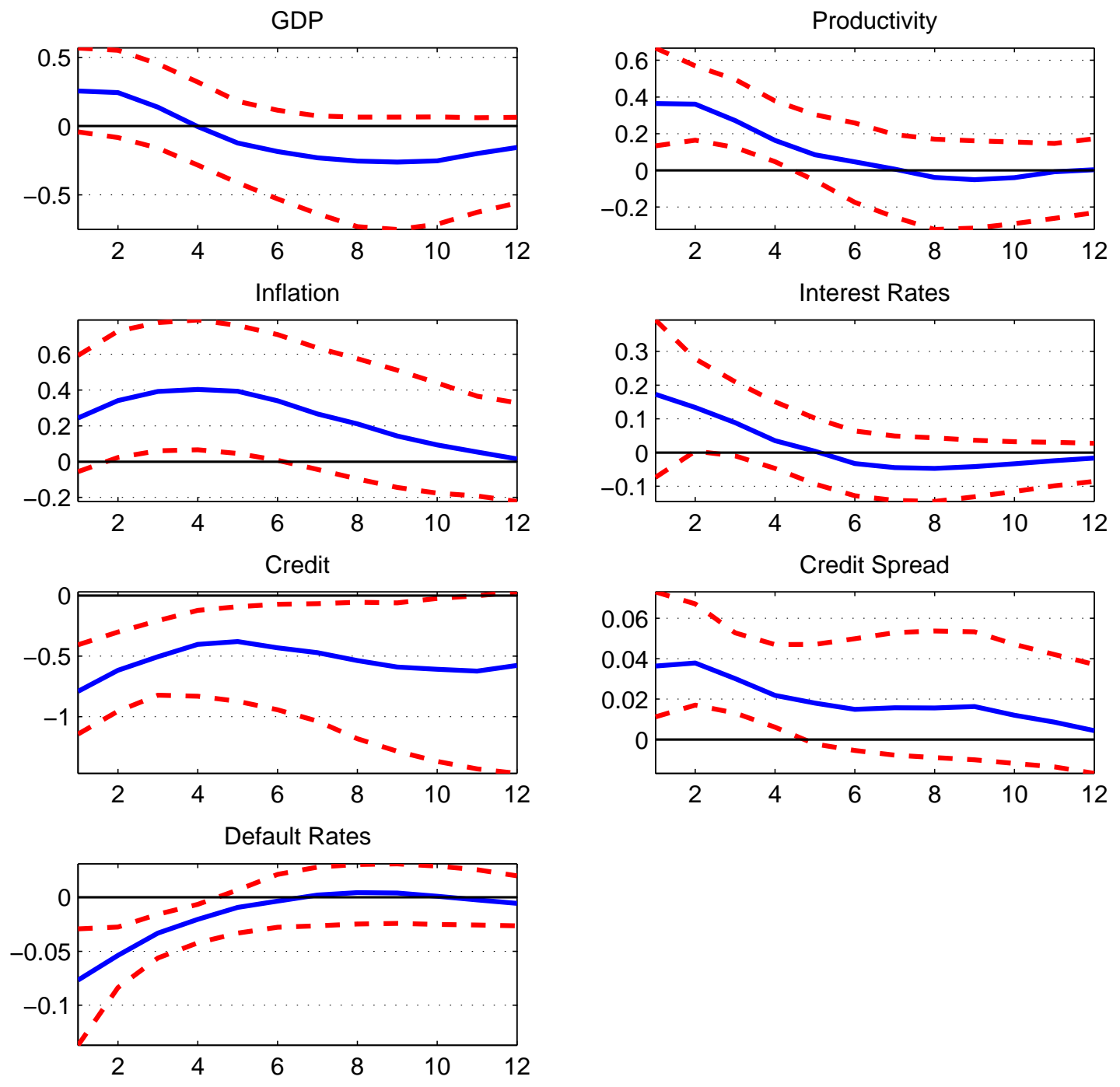

Note: The graph shows the impulse responses of the G-7 factors, the U.S. credit spread and the U.S. default rates due to a 1 s.d. global credit shock in the G-7 VAR model. The solid line represents the median and the dotted lines represent the 16-84 percentile bands based on 500 draws. 
Table 1.1: Variance Decomposition: G-7 VAR

\begin{tabular}{|l|c|c|c|c|c|c|c|c|}
\hline Shocks & Horizon & GDP & Productivity & Inflation & Int. Rates & Credit & Spread & Default Rates \\
\hline Credit & 1 & 8.9 & 6.5 & 6.8 & 9.9 & 14.6 & 9.2 & 15.7 \\
& 4 & 9.7 & 8.8 & 9.2 & 10.1 & 13.9 & 9.5 & 14.9 \\
& 8 & 10.6 & 10.3 & 10.6 & 10.5 & 12.5 & 10.9 & 14.2 \\
& 12 & 10.8 & 10.4 & 10.9 & 10.8 & 12.1 & 11.1 & 13.9 \\
\hline Productivity & 1 & 9.3 & 7.1 & 23.5 & 9.1 & 9.1 & 8.5 & 1.9 \\
& 4 & 10.5 & 9.4 & 19.6 & 10.3 & 11.4 & 9.9 & 12.2 \\
& 8 & 12.1 & 11.0 & 16.6 & 11.8 & 13.3 & 11.4 & 12.5 \\
& 12 & 12.3 & 11.4 & 16.3 & 12.3 & 14.5 & 11.8 & 12.5 \\
\hline
\end{tabular}

Table 1.2: Variance Decomposition: U.S. FAVAR

\begin{tabular}{|c|c|c|c|c|c|c|c|c|c|}
\hline Shocks & Horizon & Global GDP & GDP & Productivity & Inflation & Int. Rates & Credit & Spread & Default Rates \\
\hline \multirow[t]{4}{*}{ Credit } & 1 & 9.2 & 8.3 & 4.7 & 4.3 & 7.3 & 10.1 & 4.9 & 18.9 \\
\hline & 4 & 10.7 & 8.0 & 6.0 & 6.9 & 9.4 & 10.9 & 8.0 & 14.4 \\
\hline & 8 & 11.1 & 8.4 & 7.3 & 8.9 & 10.5 & 10.8 & 9.1 & 13.2 \\
\hline & 12 & 11.0 & 9.3 & 7.8 & 9.5 & 10.9 & 10.7 & 9.5 & 13.0 \\
\hline \multirow[t]{4}{*}{ Productivity } & 1 & 7.8 & 11.3 & 11.9 & 14.2 & 8.0 & 14.4 & 8.2 & 8.9 \\
\hline & 4 & 10.8 & 12.2 & 13.1 & 13.7 & 10.1 & 13.5 & 10.7 & 10.1 \\
\hline & 8 & 12.1 & 13.2 & 13.6 & 13.6 & 11.1 & 13.6 & 11.8 & 11.5 \\
\hline & 12 & 12.3 & 12.9 & 13.6 & 13.6 & 11.7 & 13.6 & 12.3 & 11.7 \\
\hline
\end{tabular}

Note: Table 1.1 shows the proportion of forecast error variance of the global factors and the U.S. credit spread and default rates explained by the global credit and productivity shocks for different forecast horizons in the G-7 VAR. Table 1.2 shows the variance decompositions of the U.S. variables and and the global GDP factor due to U.S. credit shock and productivity shocks in the U.S. FAVAR. Figures are the median variance decompositions in percentages. 
Figure 1.3: Counterfactual from G-7 VAR: Global GDP
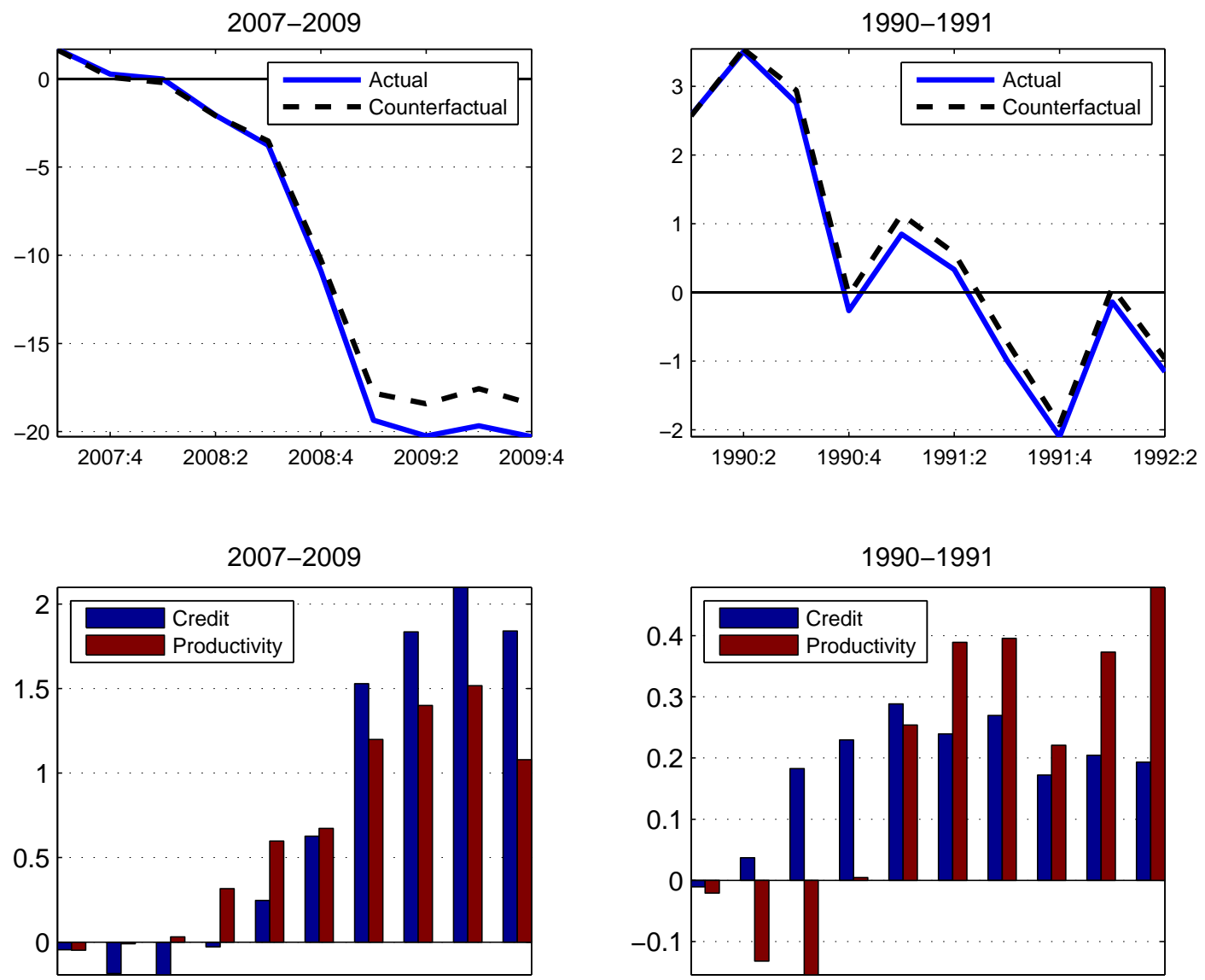

Note: The top panel shows the dynamics of cumulative four quarterly growth rates of the global GDP factor during the recessions of 2007-2009 and 1990-1991 respectively. The solid line represents the actual GDP factor and the dotted line represents the counterfactual when the global credit shock is set to zero during the sample period considered. We perform a similar exercise for the global productivity shock. The lower panel, then, shows the difference between the counterfactual and the actual global GDP factor when the respective shock is shut down during the two recessions. The bars shown are the median differences. A positive (negative) bar at each period then captures how the decrease in the global GDP factor would have been lesser (greater) in the absence of the respective shock. 
Figure 1.4: Impulse Responses due to a Credit Shock: U.S. FAVAR
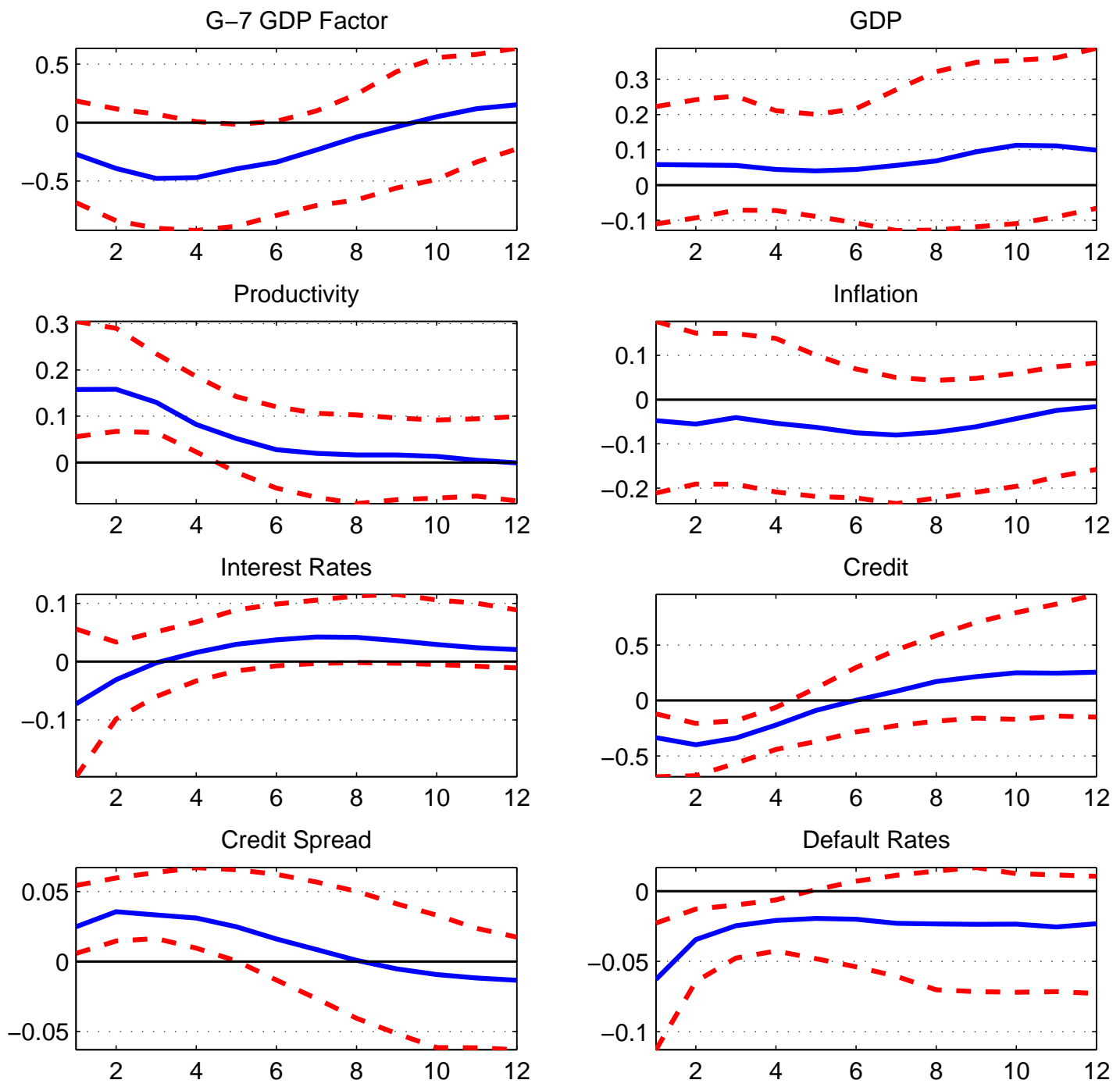

Note: The graph shows the impulse responses of the G-7 factors, the U.S. credit spread and the U.S. default rates due to a 1 s.d. global credit shock in the G-7 VAR model. The solid line represents the median and the dotted lines represent the 16-84 percentile bands based on 500 draws. 
Figure 1.5: Counterfactual from U.S. FAVAR: US GDP
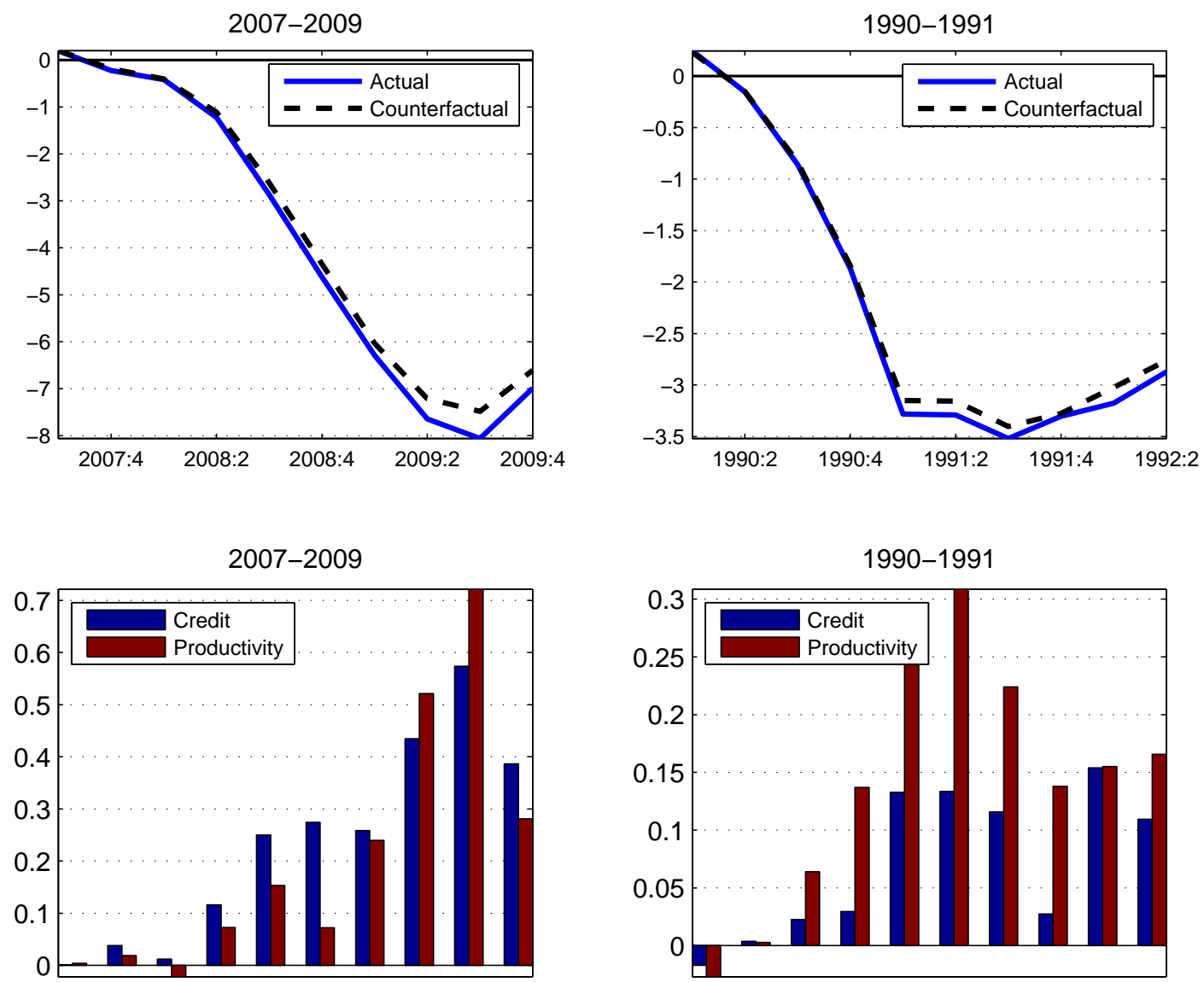

Note: The top panel shows the dynamics of cumulative four quarterly growth rates of U.S. GDP during the recessions of 2007-2009 and 1990-1991 respectively. The solid line represents the actual U.S. GDP and the dotted line represents the counterfactual when the U.S. credit shock is set to zero during the sample period considered. We perform a similar exercise for the U.S. productivity shock. The lower panel, then, shows the difference between the counterfactual and the actual U.S. GDP when the respective shock is shut down during the two recessions. The bars shown are the median differences. A positive (negative) bar at each period then captures how the decrease in the U.S. GDP would have been lesser (greater) in the absence of the respective shock. 
Figure 1.6: Counterfactual from U.S. FAVAR: Global GDP
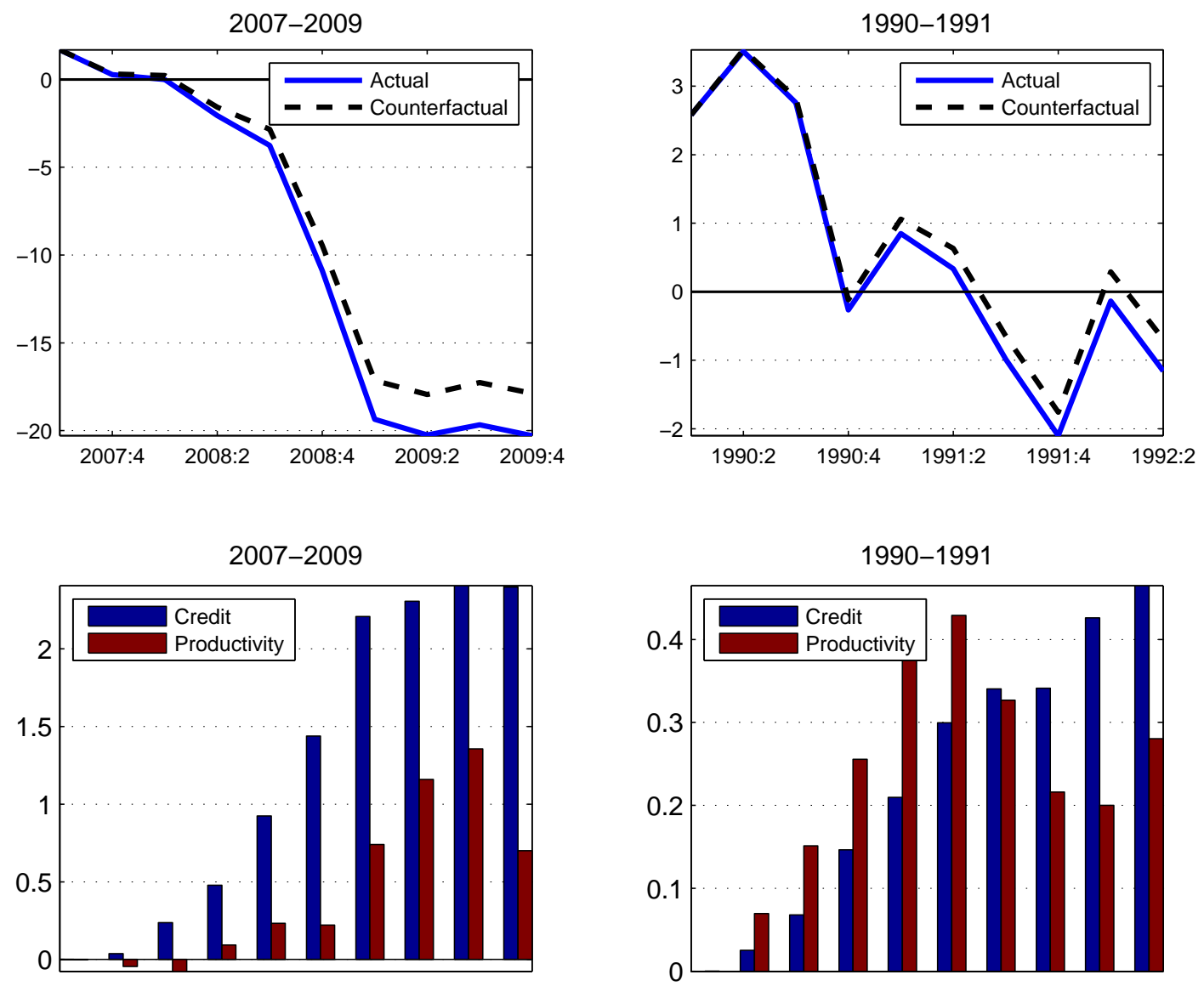

Note: The top panel shows the dynamics of cumulative four quarterly growth rates of the global GDP factor during the recessions of 2007-2009 and 1990-1991 respectively. The solid line represents the actual global GDP factor and the dotted line represents the counterfactual when the U.S. credit shock is set to zero during the sample period considered. We perform a similar exercise for the U.S. productivity shock. The lower panel, then, shows the difference between the counterfactual and the actual global GDP factor when the respective shock is shut down during the two recessions. The bars shown are the median differences. A positive (negative) bar at each period then captures how the decrease in the U.S. GDP would have been lesser (greater) in the absence of the respective shock. 


\section{Chapter 2}

\section{Credit Shocks and the U.S. Business Cycle: Is This Time Different?}

"No matter how different the latest financial frenzy or crisis always appears, there are usually remarkable similarities with past experience from other countries and from history."

Carmen Reinhart and Kenneth Rogoff in "This Time Is Different"

\section{$2.1 \quad$ Introduction}

Following the subprime crisis in 2007 that triggered a major recession in the U.S., a number of studies have examined the role of credit shocks as an independent source of business cycle fluctuations. ${ }^{1}$ Credit shocks, as defined in these studies, are exogenous shocks to credit supply conditions unrelated to the credit worthiness of borrowers (i.e. demand side of credit). A common approach adopted in existing empirical work is to infer those shocks from movements in credit spreads using a structural VAR model. The VAR model used in these studies is time invariant which, by construction, implies that the effects of credit

\footnotetext{
${ }^{1}$ Empirical papers that use a structural VAR to examine the importance of credit shocks are Helbling et al. (2011), Gilchrist and Zakrajsek (2012a) and Meeks (2012). In a DSGE context, see Gilchrist and Zakrajsek (2012b).
} 
shocks on the macro economy are the same irrespective of the phase of business and financial cycles. The objective of this paper is to go beyond such an "average" relationship and evaluate whether credit shocks matter more during recessions than during booms and during periods of financial stress than periods of financial tranquility. More broadly, I ask: are the effects of credit shocks on the U.S. economy time varying? I examine this question during the Great Moderation period, with a specific focus on the Great Recession of 2007-2009.

One motivation for time variation comes from the empirical nature of credit spreads. To illustrate, Fig. 2.1 plots a measure of credit spreads called the Excess Bond Premium (EBP) used in Gilchrist and Zakrajsek (2012a). I start with their key result that the series reflects credit supply conditions and discuss in greater detail how their EBP series is constructed in Section 2.2. As the graph shows, a striking feature of the EBP series is that it exhibits big jumps during certain episodes while it generally remains low for most of the times during the sample period. The timing of such big jumps generally coincides with periods of financial stress such as the 2001 dot-com bust, 9/11 attacks, and the 2007 subprime crisis. ${ }^{2}$ This empirical feature suggests that during these episodes, the volatility of shocks driving credit supply conditions jumps and/or the transmission of those shocks is much more significant. To see how this is related to real economic activity, Fig. 2.1 also plots the annual GDP growth rates. ${ }^{3}$ If one takes the causal view that movements in credit supply conditions affect real economic activity, those effects seem more pronounced during these episodes whereas for most of the times outside these episodes those effects are quite small. This observation suggests that the effects of credit shocks on real economic activity can be time varying.

In general equilibrium, the effects of credit shocks on the macro economy depend on monetary policy response. Another motivation for time variation is drawn from how mon-

\footnotetext{
${ }^{2}$ There is also a jump in EBP during the stock market crash of 1987, but that is relatively minor compared to these episodes.

${ }^{3}$ In this figure, I show annual GDP growth rates to bring out the "trend" better. While estimating the model, I use annualized quarter-to-quarter growth rates of GDP.
} 
etary policy response to those shocks could be different across the monetary "regimes" of Alan Greenspan and Ben Bernanke. Like previous papers that focus on evolving U.S. monetary policy across Fed chairmanships during the pre-Moderation eras, an obvious aspect of time variation considered here is the changing relative weights on output and inflation stabilization. A more relevant aspect, however, is whether U.S. monetary policy has evolved since the days of Greenspan to directly respond to credit supply conditions over and above their indirect effects on output and inflation. ${ }^{4}$ These are open empirical questions I investigate in this paper.

A final motivation for time variation comes from the theoretical insights of recent DSGE models that incorporate financial frictions associated with intermediaries. ${ }^{5}$ In these models, the amplification mechanism associated with such frictions depends on the state of the economy such as shock size, intermediary leverage and capital position. For instance, in Brunnermeier and Sannikov (2010), financial intermediaries can get constrained when hit by big shocks resulting in much stronger feedback effects through asset prices. Adrian and Boyarchenko (2013) show that strong amplifications can arise depending on intermediary leverage and capital position. In He and Krishnamurthy (2013), the dynamics of risk premia themselves depends on intermediary equity capital. Since the state of the economy (shock size, leverage, capital position) vary over time, the results from these theoretical models suggest that the effects of credit shocks on the economy, as they pick up the state-dependent amplification mechanism, can be time varying as well. ${ }^{6}$ In this regard, Clark (2009) provides evidence that macro and financial variables are characterized by stochastic volatility during the sample period considered in this paper. Kalemli-Ozcan et al. (2012) document that the leverage of investment banks increased in the run-up to the subprime crisis following the

\footnotetext{
${ }^{4}$ For the pre-Moderation eras, Primiceri (2005) and Cogley and Sargent (2005) consider monetary regimes as a source of time variation by focusing on the evolution of the weights on inflation and unemployment rates in the Fed's monetary reaction function. In this paper, the focus is on whether the reaction function has evolved to additionally include financial variables like credit spreads.

${ }^{5}$ Thus, these frictions pertain to the supply side of credit. This is contrary to financial frictions arising from the demand side of credit as emphasized in the financial accelerator literature, for instance Kiyotaki and Moore (1997) and Bernanke et al. (1999).

${ }^{6}$ Even though the shocks that these models consider are not credit shocks per se, the idea is that the amplification mechanism in these models apply to them as well.
} 
Security and Exchange Commission deregulation on minimum capital requirements in 2004.

It follows from the above discussions that: (a) shocks to credit supply conditions can have time varying effects on the economy, especially more pronounced during periods of financial stress vis-a-vis tranquility; (b) an "average" relationship inferred from the entire sample period will not point out the significant effects during certain episodes; (c) such effects can be attributed to either stochastic volatility, time varying transmission mechanism or both. To investigate these empirically, I estimate a time-varying VAR model with stochastic volatility on the lines of Primiceri (2005). ${ }^{7}$ Included in the VAR are output, inflation, EBP, and the nominal interest rate.

The model differs from a conventional time-invariant VAR in two respects. First, the conditional volatility of shocks driving the VAR system is allowed to vary over time: stochastic volatility. Second, the rest of the VAR parameters (coefficients and identifying matrix) are also allowed to drift which is meant to capture time variation in the transmission mechanism. ${ }^{8}$ Using this model, I let the data decide whether the effects of credit shocks on the U.S. economy show time variation during the sample period and if so, whether stochastic volatility or time varying transmission mechanism (or both) explains it. By discriminating between the two sources of time variation, this paper attempts to shed light on an important policy question: is it luck (volatility) or structural change (transmission mechanism) that has greater relevance for understanding the effects of credit shocks on the U.S. economy?

The main findings are as follows: credit shocks exhibit stochastic volatility during the Great Moderation period. The conditional volatility of these shocks systematically rises

\footnotetext{
${ }^{7}$ An alternative econometric model is a Markov-Switching VAR on lines of Sims and Zha (2006) where the VAR parameters are allowed to evolve across discrete regimes according to an underlying Markov process. One advantage of the time-varying VAR over Markov-Switching VAR is that the former is a more general framework that allows drifts across a set of parameters to occur at different points in time, whereas the latter only allows those drifts to occur at the same point in time. In the context of this paper, it turns out that those parameter drifts do occur at different points in time. See Fig. 2.2 for instance.

${ }^{8}$ The point here is that these parameter drifts approximate the state-dependent amplification mechanisms highlighted by the theoretical DSGE models. See Harrison and West (1997).
} 
during periods of stress to the U.S. financial sector. Adjusted for shock size, however, I do not find any evidence that the transmission mechanism of credit shocks is time varying during the sample period. In the specific context of the Great Recession of 2007-2009, I find that credit shocks have a non-trivial role. In the absence of credit shocks, the decline in output growth would have been better off by as much as $4 \%$ at the height of the recession. However, credit shocks do not entirely explain the depth and duration of the Great Recession.

The rest of the paper is organized as follows. In Section 2.2, I discuss the theory that underpins how credit shocks can be inferred from credit spreads data. Section 2.3 presents a review of related empirical papers. In Section 2.4, I present the econometric model and discuss the identification strategy. I discuss the Bayesian estimation procedure and priors in Section 2.5. Section 2.6 presents the results and Section 2.7 concludes.

\subsection{Theoretical Background}

To discuss the theory that underpins how credit shocks can be inferred from credit spreads data and how those shocks affect the economy, I begin with a review of the external finance premium that is widely discussed in the financial accelerator literature. For the purpose of exposition, I refer to Bernanke et al. (1999) which incorporate financial frictions in a DSGE model. Asymmetric information between borrowers and lenders is modeled using a costly state verification framework. Because lenders incur a monitoring cost, they take into account expected defaults by borrowers and demand a premium on loans they provide to the latter. This premium is the external finance premium and plays a crucial role in amplifying and propagating business cycle shocks. The model-based external finance premium is shown to closely match credit spreads data in Graeve (2008).

While the above puts credit spreads in a macro model by linking it to the external finance premium, another set of literature in finance shows that expected defaults explain 
only a small component of actual credit spreads data (e.g. Elton et al. (2001), Driessen (2005)). Among other things, these papers show that the residual can be attributed to a default risk factor that captures compensation demanded by intermediaries for bearing exposure to corporate credit risks over and above expected losses. Using micro-level data on corporate bonds, Gilchrist and Zakrajsek (2012a) purge this residual from the component that reflects expected defaults. ${ }^{9}$ The residual, which they call the Excess Bond Premium (EBP), captures the risk-bearing capacity of the financial sector over and above expected defaults. Exogenous shocks to this risk bearing capacity then get reflected in movements of EBP. ${ }^{10}$ Thus, they interpret an unanticipated positive innovation to EBP as a reduction of the risk bearing capacity of the financial sector which then results in a reduction of the supply of credit (and consequently, equilibrium credit) in the economy: adverse credit shock. ${ }^{11}$

In a DSGE framework, such movements in EBP can be proxied by exogenous innovations to the external finance premium as in Gilchrist and Zakrajsek (2012b). The primary effect of an adverse shock is to reduce the amount of loans in equilibrium. Although the details vary depending on how borrowing needs are specified, the end result is a reduced level of economic activity as a consequence of being dependent on those intermediated loans for production and consumption purposes. ${ }^{12}$ Such a slack in economic activity generally reduces marginal costs by reducing wages and rental rates which then works to decrease inflation. The decline in economic activity and inflation should generally mean that the nominal interest rate also declines in response to the adverse credit shock. As discussed in Gilchrist

\footnotetext{
${ }^{9}$ Their decomposition is based on the "distance-to-default" framework of Merton (1974).

${ }^{10}$ Exogenous shocks to the risk bearing capacity can be tied to more fundamental supply shocks like shocks to intermediary capital which then result in a reduced risk bearing capacity and a rise in risk premia as shown in He and Krishnamurthy (2011). Meeks (2012) considers an adverse credit shock in terms of a positive innovation to the monitoring cost parameter in the financial contract of Bernanke et al. (1999) that results in a rise in the external finance premium. While not providing an explicit link to credit spreads, other papers also model credit shocks in terms of shocks to intermediary balance sheet, for instance Meh and Moran (2010).

${ }^{11}$ Such a shock pertains to the supply side of credit because it is a shock orthogonal to expected defaults. In other words, it is a shock unrelated to the credit worthiness of borrowers (corporate firms) or the demand side of credit.

${ }^{12}$ In Gilchrist and Zakrajsek (2012b), the borrowing is done by entrepreneurs for the production of capital goods. Hence, an adverse credit shock results in reduced amount of capital and which then, through the production function, results in reduced output.
} 
and Zakrajsek (2012b), when a Taylor-type monetary reaction function is augmented to include credit spreads, the nominal interest rate can also directly respond to credit shocks beyond their indirect effects on output and inflation.

\subsection{Related Empirical Work}

The key identification challenge in inferring credit shocks from credit spreads data using a structural VAR framework lies in disentangling movements of credit spreads due to such exogenous shocks from endogenous responses to future expected defaults as a result of other fundamental shocks (say, productivity shocks). Gilchrist and Zakrajsek (2012a) achieve this disentanglement in two steps. First, with their careful decomposition of credit spreads data, they construct the EBP series which reflects only credit supply condition. The EBP series is still an endogenous variable and they use a recursive identification scheme in a VAR to pin down exogenous innovations to EBP: credit shocks. Meeks (2012) deploys an alternative identification strategy using sign restrictions. In particular, the restrictions imposed are that credit spreads increase and default rates do not rise following an adverse credit shock. The latter restriction distinguishes supply effects from those arising from the demand side of credit. These two papers study credit shocks specifically in the context of the U.S. economy. Helbling et al. (2011) explore the global dimension of these shocks using a similar sign restrictions approach.

While the above papers infer credit shocks from credit spreads ("price" of credit), others do it from credit volume ("quantity" of credit). As Bernanke and Gertler (1995) note, establishing an independent causal factor from credit volume is even more problematic compared with credit spreads and these papers rely on confidential or micro-level data for the same. ${ }^{13}$ I provide two illustrative examples. Peek et al. (2003) use confidential bank supervisory information on CAMEL ratings to isolate the effects of supply shocks and show that loan supply shocks have had a significant impact on real macroeconomic variables during 1978-

\footnotetext{
${ }^{13}$ To quote Bernanke and Gertler (1995), "...credit is not a primitive driving force; rather credit conditions are best measured by the external finance premium and not aggregate quantity of credit".
} 
1998. Focusing primarily on house prices, Milcheva (2013) identifies innovations in credit supply using a mortgage mix variable. ${ }^{14}$ Despite differences in identification strategy, objective and coverage, a common feature of all these papers is that they use a time-invariant model and hence, they are not able to address the questions set out in this paper. The point of departure and the main contribution of the paper is that the econometric model considered here features time varying parameters.

Finally, this paper is also closely related to those that use a time-varying VAR model with stochastic volatility. Primiceri (2005) and Cogley and Sargent (2005) use the model to study the causes behind the Great Moderation by distinguishing between good luck (stochastic volatility) and good policy (better monetary policy). Baumeister and Peersman (2013) estimates a similar model to study time variation in the effects of oil supply shocks on the U.S. economy. Clark (2009) documents that real and financial variables exhibit stochastic volatility during the Great Moderation period but does not analyze time variation in the transmission mechanism.

\subsection{Methodology}

\subsubsection{Econometric Model}

Following Primiceri (2005), the VAR model is written as:

$$
y_{t}=c_{t}+B_{1, t} y_{t-1}+\ldots+B_{p, t} y_{t-p}+u_{t} ; \quad t=1,2, \ldots . T
$$

where $y_{t}$ is an $(n \times 1)$ vector of observed endogenous variables; $c_{t}$ an $(n \times 1)$ vector of time varying intercept terms; $B_{i, t}, i=1, \ldots, p$ are $(n \times n)$ matrices of time varying coefficients; $u_{t}$ are heteroskedastic unobservable reduced form shocks with time varying variance covariance matrix $\Omega_{t}$. The matrix $\Omega_{t}$ is decomposed as follows:

$$
\Omega_{t}=A_{t}^{-1} H_{t}\left(A_{t}^{-1}\right)^{\prime}
$$

\footnotetext{
${ }^{14} \mathrm{~A}$ third approach often used in other studies deploys Senior Loan Officers Survey data.
} 
where $A_{t}$ is lower triangular and is given by:

$$
A_{t}=\left[\begin{array}{cccc}
1 & 0 & \cdots & 0 \\
\alpha_{21, t} & 1 & \ddots & \vdots \\
\vdots & \ddots & \ddots & 0 \\
\alpha_{n 1, t} & a_{n 2} & \alpha_{n n-1, t} & 1
\end{array}\right]
$$

and $H_{t}$ is the diagonal matrix:

$$
H_{t}=\left[\begin{array}{cccc}
h_{1, t} & 0 & \cdots & 0 \\
0 & h_{2, t} & \ddots & \vdots \\
\vdots & \ddots & \ddots & 0 \\
0 & \cdots & \cdots & h_{n, t}
\end{array}\right]
$$

The decomposition is related to the recursive identification strategy used to identify credit shocks in this paper (discussed in more detail in Section 2.4.2). The matrix $A_{t}$ captures the contemporaneous effects of structural shocks on variables included in the VAR. The diagonal entries in the matrix $H_{t}$ denote variances of the structural shocks. ${ }^{15}$ Note that both matrices are time varying.

Stacking up all the coefficients of the VAR in (2.1) in a vector $B_{t}$ and using the above decomposition of $\Omega_{t}$, the model can be compactly written in its structural form as:

$$
y_{t}=X_{t}^{\prime} B_{t}+A_{t}^{-1} H_{t}^{\frac{1}{2}} \epsilon_{t}
$$

where $X_{t}^{\prime}=I_{n} \otimes\left[1, y_{t-1}^{\prime}, \ldots, y_{t-p}^{\prime}\right]$ and $V\left(\epsilon_{t}\right)=I_{n}$.

Stack up the off-diagonal elements of $A_{t}$ in a vector $\alpha_{t}$ (henceforth, covariance states). Then, time variation of the VAR parameters is described by the following laws of motion ${ }^{16}$ :

\footnotetext{
${ }^{15}$ Unlike Primiceri (2005), the diagonal elements of $H_{t}$ are variances and not standard deviations. The evolution of stochastic volatilities is also modeled in terms of variances.

${ }^{16}$ Note that the evolution of reduced form VAR coefficients $B_{t}$ includes the intercept terms that pick up
} 


$$
\begin{aligned}
B_{t} & =B_{t-1}+\nu_{t} ; & & \nu_{t} \sim N(0, Q) \\
\alpha_{t} & =\alpha_{t-1}+\zeta_{t} ; & & \zeta_{t} \sim N(0, S) \\
\log \left(h_{i, t}\right) & =\log \left(h_{i, t-1}\right)+\sigma_{i} \eta_{i, t} ; & & \eta_{i, t} \sim N(0,1), \quad i=1, . ., n .
\end{aligned}
$$

In Equation (2.5), the size adjusted orthogonalized residual terms or "structural" shocks are represented by $H_{t}^{\frac{1}{2}} \epsilon_{t}$. Note that the matrix $H_{t}$ is diagonal. It is clear from (2.5) that the transmission of structural shocks for the model's endogenous variables $y_{t}$ is governed by the parameters $B_{t}$ and $A_{t}$ both of which are time varying. Thus, Equations (2.6) and (2.7), which determine drifts of these parameters, jointly capture time variation in the transmission mechanism of structural shocks. On the other hand, stochastic volatility of structural shocks is captured by Equation (2.8).

The evolution of the parameters $B_{t}$ and $\alpha_{t}$ follows a random walk process while that of $h_{i, t}$ follows a geometric random walk. Such a specification, which assumes that changes in the transmission mechanism and volatility of structural shocks are permanent, is consistent with the literature. From a computation stand point, the random walk specification also reduces the number of parameters to be estimated for a model that is already heavily parametrized. ${ }^{17}$ In the context of the paper, such parameter drifts are designed to account for small and infrequently occurring sub-samples with apriori unknown structural breaks that stress to the U.S. financial sector is associated with. The specification is also flexible enough to uncover a gradual evolution in either the volatility or the transmission mechanism of the underlying shocks.

The matrix $S$ is assumed to be block diagonal where $S_{1}, S_{2}$ and $S_{3}$ are the three blocks corresponding to the covariance states that appear in the $2 \mathrm{nd}$, the $3 \mathrm{rd}$ and the 4 th equations any time varying trends in the data.

${ }^{17}$ Primiceri (2005) considers an alternative version where the random walk specification is replaced by an $\mathrm{AR}(1)$ process. He finds the estimated $\mathrm{AR}(1)$ coefficient to be close to a random walk. 
of the VAR in (2.5). With this assumption, the parameters in $\alpha_{t}$ can be estimated equation by equation. This significantly reduces computation costs. The innovations to volatility are independent across equations. Finally, innovations to the VAR coefficients $\left(\nu_{t}\right)$, covariance states $\left(\zeta_{t}\right)$ and stochastic volatilities $\left(\eta_{i, t}\right)$ are assumed to be independent of each other.

\subsubsection{Identification}

The identification strategy in this paper closely follows Gilchrist and Zakrajsek (2012a) in that I use their EBP series and a recursive ordering scheme similar to theirs. The ordering and the variables included in the VAR are: GDP, Inflation, EBP, and the nominal interest rate. This is a more parsimonious specification than the one in Gilchrist and Zakrajsek (2012a). Introducing time variation in the VAR parameters greatly increases the number of parameters to be estimated. In particular, the size of the VAR coefficients $\left(B_{t}\right)$ and the variance-covariance matrix of the innovations to these coefficients $(Q)$ grows exponentially with the number of variables and their lags included in the VAR. ${ }^{18}$ While preserving model parsimony, these four variables are chosen such that GDP reflects real economic activity; inflation, the nominal side of the economy; and nominal interest rate, monetary policy response to credit shocks. ${ }^{19}$

The ordering of output and inflation is quite standard in the monetary literature. For EBP and the nominal interest rate, I follow Gilchrist and Zakrajsek (2012a) and place the nominal interest rate last. The ordering scheme implies that credit shocks affect output and inflation with a lag while allowing for contemporaneous effects on the nominal interest rate. Put another way, the ordering means that the nominal interest rate can contemporaneously respond to credit shocks even though those shocks have no contemporaneous effects on output and inflation. Thus, implicit in this formulation is a Taylor-type monetary reaction

\footnotetext{
${ }^{18}$ To get an idea, each dot in Fig. 2.20 represents a parameter estimated in the time-varying VAR.

${ }^{19}$ The imperative for a parsimonious specification is also the main reason why I adopt the recursive identification strategy of Gilchrist and Zakrajsek (2012a) rather than the sign restrictions approach of Meeks (2012). While the latter is appealing in that it is more consistent with economic theory compared to the recursive identification scheme that relies on presumed exogeneity or predetermination of variables, it adds one more variable to the VAR, i.e. default rates.
} 
function augmented to include current credit supply conditions in addition to the usual output and inflation. The ordering scheme allows me to distinguish between a direct monetary response to credit shocks and an indirect response because those shocks affect output and inflation with a lag. ${ }^{20}$ I check for robustness of results with an alternative ordering scheme that places EBP last.

\subsubsection{Database}

The EBP series is from Gilchrist and Zakrajsek (2012a). ${ }^{21}$ The rest of the variables are from FRED, St. Louis. The real GDP series is in chained 2005 dollars. Inflation is defined in terms of the GDP Deflator with the base year 2005. Both series are seasonally adjusted. Nominal interest rate is taken to be the Effective Federal Funds Rate and is seasonally unadjusted. All series are in quarterly frequency. Since the EBP and Effective Federal Funds Rate are specified in annual percentages, I take quarter-to-quarter growth rates of GDP and GDP Deflator and convert them into annual rates.

An important technical consideration in this paper is how to handle the downward trend in the nominal interest rate during the sample period. Since the time-varying VAR features intercept terms that can evolve over time, I do not detrend the nominal interest rate in the baseline specification. Fig. 2.19 shows that the intercept term in the equation of the nominal interest rate estimated from the baseline specification indeed picks up the downward trend in the data. ${ }^{22}$ In an alternative specification, I estimate the model with detrended interest rate.

The sample runs from 1973:1 to 2010:3 which is the period for which the EBP series is available. The first 14 years are used as a training sample to calibrate the priors. The model is estimated for the period 1986:4 - 2010:3. The start date of the estimation period

\footnotetext{
${ }^{20}$ See Neely (2004) for a similar point. The monetary response mentioned here is the systematic part as implied by the monetary reaction function and not monetary shocks.

${ }^{21}$ The series is available online at the American Economic Review website.

${ }^{22}$ The model also picks up very minor trends in output and inflation. Those are not reported in the paper but available upon request.
} 
roughly marks the beginning of Greenspan's tenure as Fed Chairman. By confining the estimation period to the Great Moderation period, I also abstract away from discussing the pre-Moderation eras for which there is already a rich literature.

\subsection{Bayesian Inference}

\subsubsection{Estimation}

Here, I provide a summary of the Bayesian procedure used to estimate the time-varying VAR model. The reader is referred to Primiceri (2005) and Cogley and Sargent (2005) for details. The estimation procedure deploys Gibbs sampling that breaks up the parameter space into the following blocks: $B_{t}^{T}, \alpha_{t}^{T}, \log \left(h_{i, t}^{T}\right), Q, S$ and $\sigma_{i}$. The uppercase $T$ denotes the entire history of the time varying parameter in question. ${ }^{23}$

To begin with, conditioned on all other parameter blocks, the VAR in (2.5) and Equation (2.6) describe a state space system where $B_{t}^{T}$ is the unobservable state. This system is linear and Gaussian. Thus, $B_{t}^{T}$ can be sampled via forward iteration using the Kalman Filter and backward iteration using the algorithm described in Carter and Kohn (1994). While drawing $B_{t}^{T}$, I impose a stationarity condition and drop explosive draws. ${ }^{24}$

The parameters of $\alpha_{t}^{T}$ are drawn equation by equation making use of the triangular decomposition. From $\alpha_{t}^{T}$, denote the set of parameters that enters the $j^{\text {th }}$ equation of the VAR by $\alpha_{i, t}^{T}$, where $j=i+1$. Conditioned on the rest of the parameters, the relevant state space representation is given by the $j^{\text {th }}$ equation of (2.5) and the law of motion of $\alpha_{i, t}^{T}$ from Equation (2.7). This system, again, is linear and Gaussian. Then, $\alpha_{i, t}^{T}$ is sampled, for each

\footnotetext{
${ }^{23}$ The Gibbs sampling is based on codes used in Baumeister and Peersman (2013). I thank Gert Peersman for providing the link to these codes.

${ }^{24}$ As Cogley and Sargent (2005) point out, the stability condition embodies the prior belief that the Fed conducts monetary policy in a manner that rules out explosive behavior of macroeconomic variables, especially inflation. Imposing the stability condition follows their rejection sampling approach which is to discard the entire vector $B_{t}^{T}$ if that draw is explosive. The algorithm, then, attempts to draw a non-explosive vector $B_{t}^{T}$ for some time. If it fails repeatedly, the Gibbs draw for the entire parameter space is back dated and the process repeats.
} 
$j^{\text {th }}$ equation, using a similar strategy as in the case of $B_{t}^{T}$.

Drawing the stochastic volatilities, $\log \left(h_{i, t}^{T}\right)$, involves a different algorithm. As shown in Primiceri (2005), each equation of (2.5) can be manipulated to yield a measurement equation where the unobservable state is $\log \left(h_{i, t}^{T}\right)$. The corresponding state transition equation is given by Equation (2.8). Even though this state space system is linear, the measurement equation is no longer Gaussian. Primiceri (2005) uses a mixture of normals approximation to draw $\log \left(h_{i, t}^{T}\right)$. This paper follows Cogley and Sargent (2005) and uses the algorithm of Jacquier et al. (1994).

The hyper-parameters $Q$ and $S$ are drawn from their respective $I W$ posterior distributions. The standard deviation of the innovations to stochastic volatilities, $\sigma_{i}$, are drawn from the $I G$ posterior distribution.

For Gibbs sampling, I use a burn-in of 50,000 draws and 50,000 more draws thereafter, storing every 10th draw. This results in a final set of 5000 posterior draws for making inferences. As in Primiceri (2005), I use a lag length of 2.

To check for convergence, I look at all trace plots which show good mixing. These are not presented here for space considerations. Instead, Fig. 2.20 plots the inefficiency factors one statistic that shows the extent of autocorrelation in the MCMC draws. The inefficiency factor for each estimated parameter of the VAR model represented by each dot is well below 20 , the cut-off value that is generally indicative of convergence. I also experiment with lesser number of draws and different starting points by changing the estimation period. These do not significantly change any of the results.

\subsubsection{Priors}

For specifying the priors, I use the first 14 years of the data as a training sample and estimate a time-invariant version of the VAR. Priors for the initial states $B_{0}, \alpha_{0}$ and $\log \left(h_{i, 0}\right)$ 
are then calibrated using information from these point estimates. The priors for these initial states are assumed to be normally distributed, independent of each other, and independent of the hyper-parameters.

To calibrate the prior for $B_{0}$, I proceed as follows: Let $\hat{B}_{O L S}$ denote the point estimate from the training sample. I retain the intercept terms and coefficients on first lags from $\hat{B}_{O L S}$ and set the rest to zeros. Denote the resulting vector by $\hat{B}$. Also, from the point estimate of the variance-covariance matrix $V\left(\hat{B}_{O L S}\right)$, retain only the diagonal entries. Denote the resulting diagonal matrix by $V(\hat{B})$. Then, the prior for $B_{0}$ is set as:

$$
B_{0} \sim N(\hat{B}, 2 \times V(\hat{B}))
$$

This specification follows the shrinkage approach of Del Negro (2003) which considerably reduces drawing explosive draws. The vector $\hat{B}$ satisfies stationary conditions.

To calibrate $\alpha_{0}$ and $\log \left(h_{i, 0}\right)$, I perform a triangular decomposition of the (time invariant) variance-covariance matrix of the reduced form error terms along the lines of Equations (2.3) and (2.4). Let $\hat{\alpha}$ stack up the off-diagonal terms of the matrix of covariance states and let $\hat{h}$ stack up the diagonal terms of the "variance" matrix. The prior for $\alpha_{0}$ is set as:

$$
\alpha_{0} \sim N(\hat{\alpha}, V(\hat{\alpha}))
$$

where $V(\hat{\alpha})$ is assumed to be diagonal and each diagonal element is set to ten times the absolute value of the corresponding element in $\hat{\alpha}$. This strategy follows Baumeister and Peersman (2013) and takes into account the relative magnitude of each element in $\hat{\alpha}$.

The prior for the log volatilities is set as:

$$
\log \left(h_{0}\right) \sim N\left(\log (\hat{h}), 10 \times I_{4}\right)
$$


The variance covariance is set as 10 times the identity matrix. This makes the prior weakly informative. ${ }^{25}$

Coming to the hyper-parameters, the prior for $Q$ is an Inverse-Wishart with the following specification:

$$
Q \sim I W\left(k_{Q}^{2} \times T_{0} \times V(\hat{B}), T_{0}\right)
$$

where $T_{0}$ is the prior degrees of freedom which is set equal to the length of the training sample. ${ }^{26}$ The scale matrix is set to be a constant fraction of $V(\hat{B})$ times the prior degrees of freedom. That constant fraction is given by $k_{Q}^{2}$. In the baseline specification, I set $k_{Q}=0.01$ which is also the value used in Primiceri (2005). A bigger value of $k_{Q}$ embodies the prior belief that time variation in the VAR coefficients (and hence, transmission mechanism) is larger. As I discuss in Section 2.6.2 later, it turns out that time variation in the transmission mechanism from the baseline specification is weak. Therefore, I use a bigger value of $k_{Q}=0.05$ in an alternative specification to check the robustness of this result. A value bigger than this results in too many explosive draws and the MCMC routines would not converge. Note that the choice of $k_{Q}$ in the robustness exercise is considerably stronger than the one used in Cogley and Sargent (2005), which is 0.0187 (or $k_{Q}^{2}=0.00035$ as referred to in the paper).

The three blocks of the hyper-parameter $S$ are assumed to follow Inverse-Wishart distributions with the prior degrees of freedom set equal to the minimum value required for the prior to be proper. That is,

$$
S_{i} \sim I W\left(\hat{S}_{i}, i+1\right) ; \quad i=1,2,3 .
$$

\footnotetext{
${ }^{25}$ Calibrating the prior in this manner using the training sample that belongs to the pre-Moderation period may not be very appealing. I have, however, done robustness checks with alternative priors and the results do not change significantly.

${ }^{26}$ With 36 parameters in $B_{t}$, this choice of $T_{0}=56$ makes the prior proper. The minimum degrees of freedom required for the prior to be proper is 37 .
} 
where $\hat{S}_{i}$ is a diagonal matrix with the relevant elements of $\hat{\alpha}$ multiplied by $10^{-3}$ as in Baumeister and Peersman (2013).

The prior for the variances of the innovations to the univariate stochastic volatilities is an Inverse-Gamma distribution as follows:

$$
\sigma_{i}^{2} \sim I G\left(10,0.5^{2}\right)
$$

Compared to Cogley and Sargent (2005), this prior is tighter and less diffused. With a very diffused specification, the Gibbs sampling takes a long time to converge.

\subsection{Results}

I begin the results section with time variation in the conditional volatility of credit shocks. Next, I analyze the evolution of the transmission mechanism of these shocks using impulse responses. Then, I present variance decompositions and examine whether the relative importance of credit shocks for business cycle fluctuations is also time varying. Finally, I evaluate the role of credit shocks in explaining the magnitude of the 2007-2009 recession and compare this episode with the 2001 recession.

\subsubsection{Stochastic Volatility}

Fig. 2.2 shows the evolution of the standard deviation of orthogonalized residuals in each equation of the VAR during the sample period, along with the 16th and the 84th percentiles. The one pertaining to the equation of EBP is the conditional volatility of credit shocks and is the main focus in this paper. ${ }^{27}$

From the graph, one can clearly see that credit shocks exhibit stochastic volatility during the sample period. Furthermore, the evolution of the conditional volatility of credit

\footnotetext{
${ }^{27}$ Except for the fact that these are orthogonalized residuals, a "structural" interpretation of the rest of the shocks in terms of what they represent is not discussed in this paper.
} 
shocks reveals an interesting temporal pattern that mirrors periods of stress and tranquility of the U.S. financial sector. To elaborate, the conditional volatility of credit shocks is higher during the stock market crash of 1987, the dot-com bubble bust of 2001, the $9 / 11$ attacks, and the 2007 subprime crisis compared with the tranquil periods. ${ }^{28}$ This pattern, therefore, suggests that periods of stress of the U.S. financial sector are systematically associated with larger volatility of credit shocks. ${ }^{29} 30$

While the above discussion ties periods of big shocks size with periods of financial stress, it does not say anything about the shock sign: whether those shocks are adverse (positive) or favorable (negative). To shed light on this, Fig. 2.3 plots the time series of the orthogonalized residuals in each equation of the VAR. The orthogonalized residuals in the equation of EBP are the ones referred to as credit shocks. All shocks shown are adjusted for size by the respective conditional volatilities estimated at each period. Looking at the time series of credit shocks, one can see that the three episodes of financial stress discussed above are associated with big and adverse credit shocks. However, during the tranquil periods, those shocks are either favorable or small. This implies that for shocks to credit conditions to be associated with financial stress, those shocks must be both big and adverse whereas other combinations of shock size and sign are immaterial. From a statistical standpoint, this result is consistent with the narrative that financial crises occur infrequently: a feature of the data which time-invariant VAR models overlook.

In terms of magnitude, the Great Recession of 2007-2009 is much more severe than the recession of 2001. Also, the level of EBP is much higher during the former than the latter (Fig. 2.1). Despite these, the conditional volatility of credit shocks during the Great Reces-

\footnotetext{
${ }^{28}$ This finding is also robust to alternative specifications of the VAR model. See Fig. 2.13.

${ }^{29}$ It is worthwhile to note here that the increase in the volatility of credit shocks is absent during the East Asian Crisis of 1997 and the Russian Default of 1998 so that higher volatility primarily reflects stress to the U.S. financial sector.

${ }^{30} \mathrm{An}$ alternative scheme of putting in perspective is by the phase of the business cycle. However, as Fig. 2.2 shows, this scheme is less convincing. Although the rise in the volatility of credit shocks coincide with periods around the 2001 and 2007-2009 recessions, not all recessions (e.g. the 1991 recession) are associated with such an increase in volatility and and not all increases in volatility are associated with recessions (e.g. the stock market crash of 1987).
} 
sion is not bigger than the 2001 recession (Fig. 2.2). This result suggests that the dynamics of EBP and also the rest of the macro variables, through their endogenous relationship with EBP in the VAR, are not driven by larger exogenous shocks to credit supply condition (credit shocks) during the Great Recession vis-a-vis the 2001 recession. The time series of realized credit shocks (Fig. 2.3) around the recessions of 2001 and 2007-2009 further supports this point. As the figure shows, the realized credit shocks during the Great Recession are not bigger than those during the 2001 recession. ${ }^{31}$ This suggests the deterioration of credit supply conditions during the Great Recession is not entirely exogenous and is partly an endogenous response to developments in other sectors of the economy beyond financial markets. There is another subtle difference across the two recessions. In the case of the 2001 recession, the U.S. economy is hit by an adverse credit shock one time right before the recession. During the Great Recession, however, adverse credit shocks continue to buffet the economy as the recession progresses. This finding is consistent with the narrative that credit supply conditions worsen as the Great Recession unfolds, prolonging the recession in turn.

Though this paper focuses on the stochastic volatility of the orthogonalized residuals in the equation of EBP, or credit shocks, the evolution of conditional volatility in the rest of the equations of the VAR reveals important insights (Fig. 2.2). Starting with the equation of output, the conditional volatility is significantly higher around the 2007-2009 recession compared with the preceding periods. Because the residuals capture that part of output not endogenously explained by the VAR model, this result suggests that there is a significant component of output dynamics not explained by credit shocks during the Great Recession. This is a result that I reiterate later that credit shocks on their own do not explain all of the depth and duration of this recession. A similar conclusion is reached by looking at the evolution of the conditional volatility of shocks pertaining to the equation of inflation. With regard to the equation of the nominal interest rate, the conditional volatility steadily

\footnotetext{
${ }^{31}$ The figure also shows that credit shocks are leading in nature around these two recessions. This highlights the predictive content of credit shocks and corroborates the point that these shocks are an independent causal factor for business cycle fluctuations.
} 
declines from the beginning of the sample reaching a low point around the mid 1990's. It stays at this level for much of the sample period thereafter before increasing around the 2007-2009 recession. This trend reflects that a Taylor-type monetary rule, as implicitly captured by endogenous VAR relationships, is less descriptive of the actual conduct of U.S. monetary policy during the beginning and the end of the sample period. ${ }^{32}$

In the context of the paper, the most important result that this section establishes is that credit shocks exhibit stochastic volatility during the Great Moderation period. This is clearly at odds with models that assume a constant volatility of such shocks. The assumption of constant volatility when the data generating process is characterized by stochastic volatility can result in less precise estimates of the VAR parameters. Thus, the VAR model in this paper that incorporates stochastic volatility is more appropriate for an accurate inference regarding the effects of credit shocks on U.S. macroeconomic variables during this sample period.

\subsubsection{Time Varying Transmission Mechanism}

This section discusses the transmission mechanism of credit shocks - the effects of these shocks on macroeconomic variables. In particular, I investigate whether the transmission mechanism shows time variation during the sample period. Recall that the transmission mechanism depends on the VAR coefficients $\left(B_{t}\right)$ and the covariance states $\left(\alpha_{t}\right)$. Hence, time variation in the transmission mechanism is captured by drifts of these VAR parameters. Instead of individually analyzing the evolution of each parameter in these vectors, I investigate time variation in the transmission mechanism using impulse responses which capture the joint effects of all parameters in these vectors.

\footnotetext{
${ }^{32}$ Taylor-type monetary rules have been shown to be less relevant before the 1990's. The poor fit of the monetary reaction function during the later period is presumably because the nominal interest rate is near the zero lower bound. The conjecture is that a Taylor-type rule prescribes a path of negative interest rates during this period and to fit the data near the zero lower bound, the VAR returns huge positive innovations to the interest rate equation. The residuals in the interest rate equation during this period as shown in Fig. 2.3 support such a conjecture.
} 
The impulse responses are computed in this manner: for each period during the sample, I fix the parameters in $B_{t}$ and $\alpha_{t}$ prevailing at that point in time and compute impulse responses assuming no uncertainty about the evolution of these parameters in the future. ${ }^{33}$ To infer time variation in the transmission mechanism from these impulse responses, I fix the shock size and sign. In particular, the credit shock, that hits the economy at the beginning of each period the impulses are calculated, raises EBP by $0.27 \%$ or 27 basis points on impact. ${ }^{34}$ I call these normalized impulse responses. ${ }^{35}$

Fig. 2.4 shows the median normalized impulse responses calculated at the beginning of each period during the sample. These are based on the baseline specification of the VAR (Baseline Model). The surf plot shows a snapshot picture of the evolution of the transmission mechanism of credit shocks. From the entire sample period shown there, I then pick specific periods of U.S. recessions and booms for a more detailed evaluation that takes into account the degree of statistical uncertainty. In these graphs, I show the median impulses along with the 16-84 percentile bands. Given the general leading nature of credit shocks as discussed before, the impulse dates for recessions are picked as one quarter prior to the NBER recession start dates. For booms, the choice is somewhat arbitrary. I pick 1995:2 which represents a boom during Greenspan's tenure as Fed Chairman; and 2006:4 which represents Bernanke's. The conclusions drawn, however, are not sensitive to the precise choice of these periods.

In addition to the results from Baseline Model, I perform a battery of robustness checks

\footnotetext{
${ }^{33}$ More precisely, the impulse response of the variable $Y$ due to a shock $u$ at horizon $k$ is defined as the difference between the conditional expectations: $E\left[Y_{t+k} \mid \Omega_{t-1} ; u_{t}\right]-E\left[Y_{t+k} \mid \Omega_{t-1}\right]$, where $\Omega_{t-1}$ denotes all information available as of time $t-1$, ignoring uncertainty about the evolution of the VAR parameters. In Potter (2000), future uncertainty in the evolution of VAR parameters is explicitly taken into account. The conditional expectations, in that case, are simulated using Monte Carlo integration techniques.

${ }^{34}$ This is the standard deviation of credit shocks estimated at 2007:3. I chose this scale so that the magnitude of the responses of the VAR variables can be easily related to the 2007-2009 recession. Other than that, the choice of this particular value is not crucial for the analysis in this section.

${ }^{35}$ In the context of the time-varying VAR model, it is important to note that the forecasts of the conditional means can exhibit time varying trends. Thus, the impulse responses are to be interpreted as deviations of the variables upon realization of the shock from this trend. This qualification is especially important for the nominal interest rate which shows a clear downward trend during the sample period.
} 
with alternative specifications of priors, trends, ordering, and variables. The impulse responses from these exercises are given in Figs. 2.14 - 2.16. Admittedly, some of the impulse responses show variations across these specifications. I discuss these specifications in greater detail in Section 2.6.5. Here, I only refer to them to draw conclusions that are robust to these specifications. I now discuss the effects of credit shocks on output, inflation, and the nominal interest rate one by one. ${ }^{36}$

Output: From the point estimates in Fig. 2.4, the effects of credit shocks on output show little time variation during the sample period. The normalized impulse responses of output appear to be the same irrespective of the impulse dates. The median responses only show minor time variation, the adverse effects on output being slightly more pronounced during the 2001 and 2007-2009 recessions compared to other periods. Fig. 2.5 evaluates the statistical significance of such a time variation. Panel (a) shows the results from Baseline Model. From the overlapping percentile bands of the impulse responses calculated at different dates (reading across rows), I conclude that there is no evidence of time variation in the effects of credit shocks on output once shock size is adjusted for.

To corroborate the above evidence against time variation, I re-estimate the model with a stronger prior on the extent of time variation in the transmission mechanism, by increasing the parameter $k_{Q}$ to 0.05 from 0.01 as is in Baseline Model. I call this version Model A. Panel (b) of Fig 2.5. shows the results from this version. As expected, with the stronger prior the median impulse responses show more time variation with respect to Baseline Model. The adverse output effects are now much more pronounced around the 2001 and 2007-2009 recessions; and also, they are much weaker during the beginning of the sample period. Even then, the difference in output responses across different impulse dates, judging from the overlapping percentile bands, is not statistically significant.

\footnotetext{
${ }^{36}$ The impulse responses of EBP themselves do not reveal any interesting time variation and hence, they are not discussed in detail here. See Fig. 2.4 for the median impulses.
} 
Despite the evidence against time variation, it is, nonetheless, interesting to see how the results from the time-varying model compare with those from a time-invariant model. This is shown in Fig. 2.6. ${ }^{37}$ Because the time-invariant model must be estimated using a stationary interest rate series, the results from the time-varying model shown in Fig. 2.6 are the ones from the specification that uses detrended interest rate (Model B). Panel (a) presents the normalized impulse responses by fixing the size of the credit shock in the time-invariant model as the same as the time-varying model. ${ }^{38}$ This exercise allows me to compare inferences regarding the transmission of credit shocks across the two class of models. The graph points out that for a given shock size, one can be more certain about the adverse effects of credit shocks on economic activity using the time-varying model than the time-invariant model. The percentile bands are wider in the case of the time-invariant model compared with the time-varying model. ${ }^{39}$ This is a result that underscores the earlier point that the assumption of constant volatility in the time-invariant model when the data generating process exhibits stochastic volatility can result in less precise inferences. Panel (b) adjusts the impulse responses from the time-invariant model by the shock size estimated from that model. Because the time-invariant model fails to pick up the larger shock size estimated around the Great Recession, it under-estimates the destabilizing effects of adverse credit shocks on real economic activity around this recession, especially during the first few quarters after the impact of the shock.

In summary, the time-varying VAR model deployed in this paper do not provide conclusive evidence that the effects of credit shocks, after adjusted for shock size, on real economic activity are time varying during the Great Moderation period. ${ }^{40}$ In particular, one cannot

\footnotetext{
${ }^{37}$ To conserve space, I only present the results for output. Results for the rest of the variables are available upon request.

${ }^{38}$ More precisely, the shock size used is the standard deviation of credit shocks estimated as of 2007:3 from the time-varying model.

${ }^{39}$ For a more guarded comparison of the percentile bands, the time-invariant model is estimated with the Minnesota priors for greater precision. The percentiles bands shown for the time-invariant model are also based on the same number of 5000 draws.

${ }^{40} \mathrm{~A}$ relevant aspect considered in other nonlinear models (e.g. the threshold VAR model in Balke (2000)) is whether the shock sign matters. That is, are the effects the same for adverse and favorable shocks? Conditioned on VAR parameters at the time the impulse responses are calculated, the time-varying VAR model in this paper is linear. Hence, the question whether adverse shocks during recessions result in different
} 
conclusively say that the transmission mechanism of credit shocks for real economic activity is different across recessions and booms (i.e. by the phase of the business cycle); periods of financial stress and tranquility (i.e. by the phase of the financial cycle); and the chairmanships of Greenspan and Bernanke (i.e. by monetary regimes).

Inflation: The point estimates from Fig. 2.4 show some time variation in the impulse responses of inflation during the sample period. When hit by the shock, the decline in inflation is much weaker during the earlier period of the sample compared with the later period. Fig. 2.7 examines this difference in greater detail, taking into account statistical uncertainty. Panel (a) shows the results from Baseline Model. As in the case of output, I compare the percentile bands of the impulse responses calculated at different dates. Those percentile bands are overlapping which point out that there is no significant time variation in the effects on inflation. Panel (b) shows the results from the version with the stronger prior on time variation with similar outcome.

It seems that the only takeaway from Fig. 2.7 is that the deflationary effects of adverse credit shocks are more certain during the later part of the sample compared with the earlier period. However, as the results from the robustness exercises show (Fig. 2.15, Model D in particular), such a conclusion is not robust. In addition, these results do not provide conclusive evidence that the effects of credit shocks on inflation vary across time during the sample period.

All in all, the only robust conclusion one can draw regarding the effects of credit shocks on inflation is that those effects are weak. To put this in perspective, I refer to the median impulse responses calculated at 2007:3 from Baseline Model as shown in Fig. 2.7(a) where the deflationary response is relatively strong. When hit by adverse shocks, the level of prices bottoms out only at around $-0.2 \%$ with respect to the trend whereas the correspond-

output responses compared with favorable shocks during booms is something that the time-varying VAR considered in this paper is not able to address. 
ing number for output is $-0.6 \%$. These results highlight that despite the slack in economic activity that adverse credit shocks entail, such a slack does not result in significant deflation.

Interest Rate: The impulse response of the nominal interest rate captures the "systematic" component of monetary policy response as opposed to monetary shocks. ${ }^{41}$ Generally speaking, as the point estimates from Fig. 2.4 show, the Fed systematically responds to the destabilizing effects of adverse credit shocks by easing monetary policy. Having said that, the graph indicates two subtle aspects of time variation in monetary easing across the earlier and the later parts of the sample period with the time around the end of the 2001 recession as the break point. The first aspect is the response of the nominal interest rate on impact: during the earlier period the nominal rate either remains unchanged or increases; whereas, in the later period it declines on impact. The second aspect is the extent of rate cut after impact: the drop in the nominal rate is larger during the earlier part of the sample period.

To discuss the above two aspects of time variation in greater detail, I plot the impulse responses of the nominal interest rate for all impulse dates during the sample period and including the percentile bands. To conserve space, the impulses are plotted only for select horizons. The horizons chosen are: 0 (on impact), 6, 9 and 12 quarter(s) after the impact of the shock. Fig. 2.8 presents the results from Baseline Model.

The top-left graph in Fig. 2.8 shows that the initial response of the nominal interest rate to adverse credit shocks is insignificant during the sample period, except for a brief period around 2001 during which the response is positive (monetary contraction). As mentioned earlier, the identification strategy in this paper ensures that output and inflation do not contemporaneously respond to credit shocks. Hence, the initial reaction of the nominal interest rate can be thought of as systematic "preemptive" easing: a direct response to

\footnotetext{
${ }^{41}$ Of course, in practice the Fed's monetary response is the sum of the systematic component and monetary shocks. I do not discuss the identification of monetary shocks in this paper. Hence, the analysis here is restricted to the systematic component of monetary policy.
} 
credit shocks as opposed to an indirect response because those shocks also adversely affect output and inflation with a lag. Thus, the insignificant or positive response of the nominal interest rate to adverse credit shocks provides no evidence of systematic preemptive easing in response to adverse credit shocks throughout the sample period. This result then suggests that the 50 basis points rate cut by the Fed in September 2007 around the start of the subprime crisis but well before the start of the Great Recession in December 2007, even though preemptive, is likely a monetary surprise and not a systematic response to the disruptions in financial markets. ${ }^{42}$

The rest of the graphs in Fig. 2.8 show the responses of the nominal interest rate after the impact of the adverse credit shock. The responses of the nominal interest rate at these horizons are all negative (monetary easing). Note that at these horizons, credit shocks also affect output and inflation and the Fed is systematically responding to the destabilizing effects of adverse credit shocks on output and inflation. The (negative) point estimates generally show an upward trend which implies that the extent of rate cuts has gradually decreased over time. Given the overlapping percentile bands, this aspect of time variation in the monetary response is, however, not statistically significant. ${ }^{43}$

\subsubsection{Relative Importance of Credit Shocks for Business Cycle Fluctua- tions}

The impulse responses from the time-varying model illustrate how output, inflation and the nominal interest rate respond to one of the four shocks that drive the VAR system - credit shock. This section examines the relative role of credit shocks in explaining the

\footnotetext{
${ }^{42}$ Irrespective of whether it represents a systematic response or a monetary surprise, the 50 basis points rate cut is preemptive in that the start of the subprime crisis, which gets reflected in the initial increase in EBP, happens before output begins to collapse during the Great Recession. There is not much movement in inflation during this period either. The preemptive nature of the rate cut is also consistent with the FOMC Meeting statement of September 2007 which justifies the rate cut on the ground that it will "help forestall some of the adverse effects on the broader economy that might otherwise arise from the disruptions in financial markets".

${ }^{43}$ This aspect of time variation is due to the downward trend of the nominal interest rate during the sample period. When the time-varying model is run on detrended interest rate (Model B), the upward trend disappears. See Fig. 2.9.
} 
fluctuations of these variables vis-a-vis the rest of the orthogonal shocks in the VAR. ${ }^{44}$ For this, I compute the share of the forecast error variance (FEV) of these macro variables explained by credit shocks. The FEV is calculated for each period during the sample by fixing the VAR parameters estimated at that period. Unlike the normalized impulse responses, the conditional volatility estimated at each period is also fixed while calculating the FEV so that the size of the shock that prevails at that period is factored in. Thus, the variance share computed at each date shows the relative importance of credit shocks as implied by the model parameters estimated at that particular date. And as the model parameters evolve over time, the implied relative importance of credit shocks evolves as well.

Fig. 2.10 plots the median variance shares along with the $16-84$ percentile bands. ${ }^{45}$ Focusing on output first, the graph shows that the variance explained by credit shocks is time varying. The variance share is fairly constant during the earlier part of the sample before rising around the start of the 2001 recession. After this, it falls but remains at a level higher than the one during the earlier part of the sample period. Given that normalized impulse responses of output do not show significant time variation, the larger variance share in the later part of the sample period starting around the 2001 recession can be pinned down to the increase in the conditional volatility of credit shocks during this period (Fig. 2.2). Note that the conditional volatility of credit shocks around the 2007-2009 recession is comparable with that of the 2001 episode. Despite that, the variance share is smaller during the 20072009 recession because the size of exogenous innovations to output itself is also big during the later period. ${ }^{46}$ This reiterates the earlier point that there is a large component of output fluctuations not explained by credit shocks during the Great Recession. The pattern of time variation in the variance share of inflation and the nominal interest rate is very similar with that of output, and so is the interpretation. Consistent with the weak impulse responses of inflation, the variance share is much smaller for inflation compared with output at any

\footnotetext{
${ }^{44}$ Other than the fact that these shocks are orthogonal to credit shocks so that variance decomposition exercises can be performed, a structural interpretation of these shocks is not discussed in this paper.

${ }^{45}$ For brevity, the FEV is shown only for the 20th forecast horizon.

${ }^{46}$ This is the conditional volatility of the orthogonalized residuals to the equation of output shown in Fig. 2.2 .
} 
given period.

The variance of EBP explained by its own innovatons, or credit shocks, is consistently very high, roughly $75 \%$ in the earlier part of the sample period until around $2004 .{ }^{47}$ This implies that the driving force for credit supply conditions is largely exogenous and unrelated to developments in other sectors of the economy during this period. Subsequently, the variance share dips to $53 \%$ at the start of the Great Recession and then further down to around $40 \%$ as the recession unfolds. Stated differently, this implies an increasing role for other shocks in the VAR system beyond credit shocks in explaining the dynamics of EBP during the Great Recession, thereby reiterating the earlier point on important feedback mechanisms between the real economy and the financial sector.

\subsubsection{Credit Shocks and the Great Recession}

The analysis so far shows that credit shocks exhibit stochastic volatility. In the specific context of the Great Recession of 2007-2009, the conditional volatility of credit shocks is higher than the preceding tranquil periods. By accounting for stochastic volatility, the timevarying model deployed in this paper also results in a more accurate inference regarding the effects of credit shocks on the macro economy. These two aspects must be taken into consideration for a precise understanding of the macro-financial linkages around the time of the Great Recession and, in turn, a precise evaluation of the extent to which credit shocks explain its depth and duration. It is in this sense that the time-varying model is better tasked than a time-invariant model.

To evaluate the role of credit shocks for the Great Recession, I compute counterfactuals that show how the recession would have unfolded in the absence of credit shocks. For this, I first fix all VAR parameters estimated as of the start of the recession and compute conditional forecasts by including all estimated shocks in the VAR system except the credit

\footnotetext{
${ }^{47}$ Note that EBP is an endogenous variable in the VAR and hence its dynamics is determined not only by credit shocks but also exogenous shocks to other variables in the VAR system.
} 
shocks. ${ }^{48}$ Fig. 2.11 presents the results. The left panel compares the actual data and the counterfactual and the right panel shows the median difference between the two, along with the $16-84$ percentile bands.

Starting with output, the graph shows that credit shocks indeed have a non-trivial role during the Great Recession. In the absence of credit shocks, the counterfactual shows that the annualized output growth rate would have been better off by as much as $4 \%$ at the height of the recession. The counterfactual also shows that the recovery horizon would have been shorter. Thus, deteriorations in credit supply conditions, even after controlling for reduced credit demand and increasing expected defaults, are an important causal factor for the output collapse during the Great Recession.

An alternative perspective is that credit shocks do not entirely explain the depth and duration of the Great Recession. When credit shocks are switched off, output would have still declined steeply. This is due to large exogenous innovations to the equation of output in the VAR during this period (Fig. 2.3) - quantities which are not endogenously explained by credit supply conditions. In addition, the difference in the recovery horizon between the actual and the counterfactual is very small (only about a quarter). ${ }^{49}$ Thus, despite the general consensus on the financial nature of the Great Recession and references of a credit crunch, these results point out that credit shocks do not entirely explain the magnitude of the Great Recession.

The muted behavior of inflation during the Great Recession despite the sharp contraction in output is quite remarkable. ${ }^{50}$ In the absence of credit shocks, inflation would have been even more muted. As far as the nominal interest rate is concerned, the counterfactual

\footnotetext{
${ }^{48}$ Since credit shocks are leading, the starting point of the counterfactual horizon is chosen as one quarter prior to the NBER recession start date. The shocks fed into the VAR equations while making these forecasts are the actual shocks, adjusted for size, estimated at each period during the counterfactual horizon.

${ }^{49}$ Incorporating asset price interaction effects, by including stock prices in the VAR, does not significantly change the result (Fig. 2.17). Including leverage (financial/nonfinancial) in the VAR also does not change any of these results.

${ }^{50}$ See Del Negro et al. (2013) for a detailed discussion.
} 
shows that monetary easing would have still continued consistent with the counterfactual path of output and inflation. Interestingly, the nominal interest rate would have been above the zero lower bound by only about $1 \%$.

As a reference point, Fig. 2.12 shows the results from a similar exercise for the 2001 recession. Compared with the Great Recession, this recession is much milder. Also, credit shocks explain most of the dynamics of output during this episode: output fluctuations almost disappear in the counterfactual. There are not much fluctuations in inflation during this period and the counterfactual shows that those would have continued even in the absence of credit shocks. ${ }^{51}$ Given the path of output and inflation in the counterfactual, it is surprising that the nominal interest rate still declines, reaching a level as low as about $2 \%$ from about $6 \%$ at the start of the recession. This suggests that the decline in the nominal interest rate during this period does not reflect a systematic monetary response to business cycle fluctuations but rather a downward trend brought about by monetary shocks. This is consistent with a narrative in the monetary literature that the nominal interest rate during 2003-2006 is too low for too long (see Taylor (2007)).

Finally, the counterfactuals for EBP during the recessions of 2007-2009 and 2001 show important differences. In the absence of credit shocks, the increase in EBP during the 2001 recession almost disappears thereby reiterating the earlier point that the driving force of credit supply conditions is largely exogenous and unrelated to developments in other sectors of the economy. However, during the Great Recession, EBP still rises even in the absence of credit shocks thereby implying that its dynamics is not entirely exogenous and endogenously depends on other sectors of the economy beyond financial markets. This is an important dimension how the Great Recession or this time is different from the 2001 recession.

\footnotetext{
${ }^{51}$ Average inflation during the sample period is about $2 \%$. So, inflation fluctuations in the counterfactual are very minor, within $+/-1 \%$ from the average.
} 


\subsubsection{Robustness}

In this section, I describe details of the alternative specifications of the VAR model mentioned at various places while discussing the main results. In Model A, I increase the prior on the extent of time variation in the transmission mechanism. I use detrended interest rate data in Model B. The detrending is based on an HP filter with a smoothing parameter of 10,000 . This choice of the smoothing parameter results in a slow moving trend while leaving most of the business cycle fluctuations intact. ${ }^{52}$ In Model C, I change the ordering of the variables by placing EBP last. By construction, this ordering means that the nominal interest rate does not respond to credit shocks on impact, otherwise this specification does not change any of the results.

To check if asset price interactions result in a greater amplification and propagation of credit shocks, I augment the VAR with stock prices following Gilchrist and Zakrajsek (2012a) and Meeks (2012). ${ }^{53}$ Stock prices are ordered $4^{\text {th }}$ in the VAR before the nominal interest rate. This specification is labeled Model D. An additional variable in the VAR significantly increases the computational costs and achieving convergence in the MCMC routines is difficult. Hence, I estimate this version by specifying a lag length of only 1.

As a final robustness check, I estimate the baseline model by including unemployment rates instead of output as a measure of real economic activity as done in Primiceri (2005) and Cogley and Sargent (2005). In the context of jobless recoveries, it is interesting to see whether the recovery horizon of unemployment rates in response to adverse credit shocks has increased during the Great Recession. Fig. 2.18 presents the results. It shows that there is no significant time variation in the response of unemployment rates to credit shocks.

\footnotetext{
${ }^{52}$ I also experiment with first differencing the interest rate which produces very similar results.

${ }^{53}$ I also experiment with house price as another proxy for asset prices. Also, another version includes credit volume in the VAR. These do not change any of the results. These are not shown, but available upon request. I considered including stock market volatility VIX data to check if there are important interactions with uncertainty. But the VIX series is highly correlated with the EBP series and hence I dropped this specification.
} 


\subsection{Conclusion}

This paper investigates whether the effects of credit shocks on the U.S. economy are time varying during the Great Moderation period. By estimating a time-varying VAR with stochastic volatility, I discriminate between two possible sources of time variation: stochastic volatility of shocks and changes in their transmission mechanism. I find that credit shocks exhibit stochastic volatility: the conditional volatility of these shocks is systematically higher during periods of stress to the U.S. financial sector like the dot-com bust of 2001 and the subprime crisis of 2007. Adjusted for shock size, however, the results from this paper do not provide evidence that the transmission mechanism of credit shocks is time varying during the period 1986-2010.

In the specific context of the Great Recession of 2007-2009, I find that credit shocks have a non-trivial role. In the absence of credit shocks, the decline in output growth would have been better off by as much as $4 \%$ at the height of the recession. However, despite the general consensus on the financial nature of the recession and references of a credit crunch, credit shocks do not entirely explain the magnitude of the Great Recession. One explanation is that by using corporate bonds data for the purpose of identifying credit shocks, the analysis in this paper is confined to the corporate sector or business loans. This leaves out the household sector or housing loans which some recent papers have shown are important in the context of the Great Recession. The results from this paper, nonetheless, are complementary to those studies in that they highlight part of the disruptions in economy-wide credit markets and consequently, part of the cause of the Great Recession originates in the corporate sector. In future work, I plan to extend the time-varying framework to include housing loans.

In the aftermath of the subprime crisis that led to the Great Recession, a renewed interest has emerged in incorporating financial shocks in DSGE models and solving those

models using techniques beyond perturbation methods. The empirical results from this 
paper suggest that incorporating stochastic volatility of those shocks is an additional feature worth considering in DSGE models. This is a research topic I plan to pursue in the future. 


\subsection{Figures and Tables}

Figure 2.1: Credit Supply Condition and Economic Activity
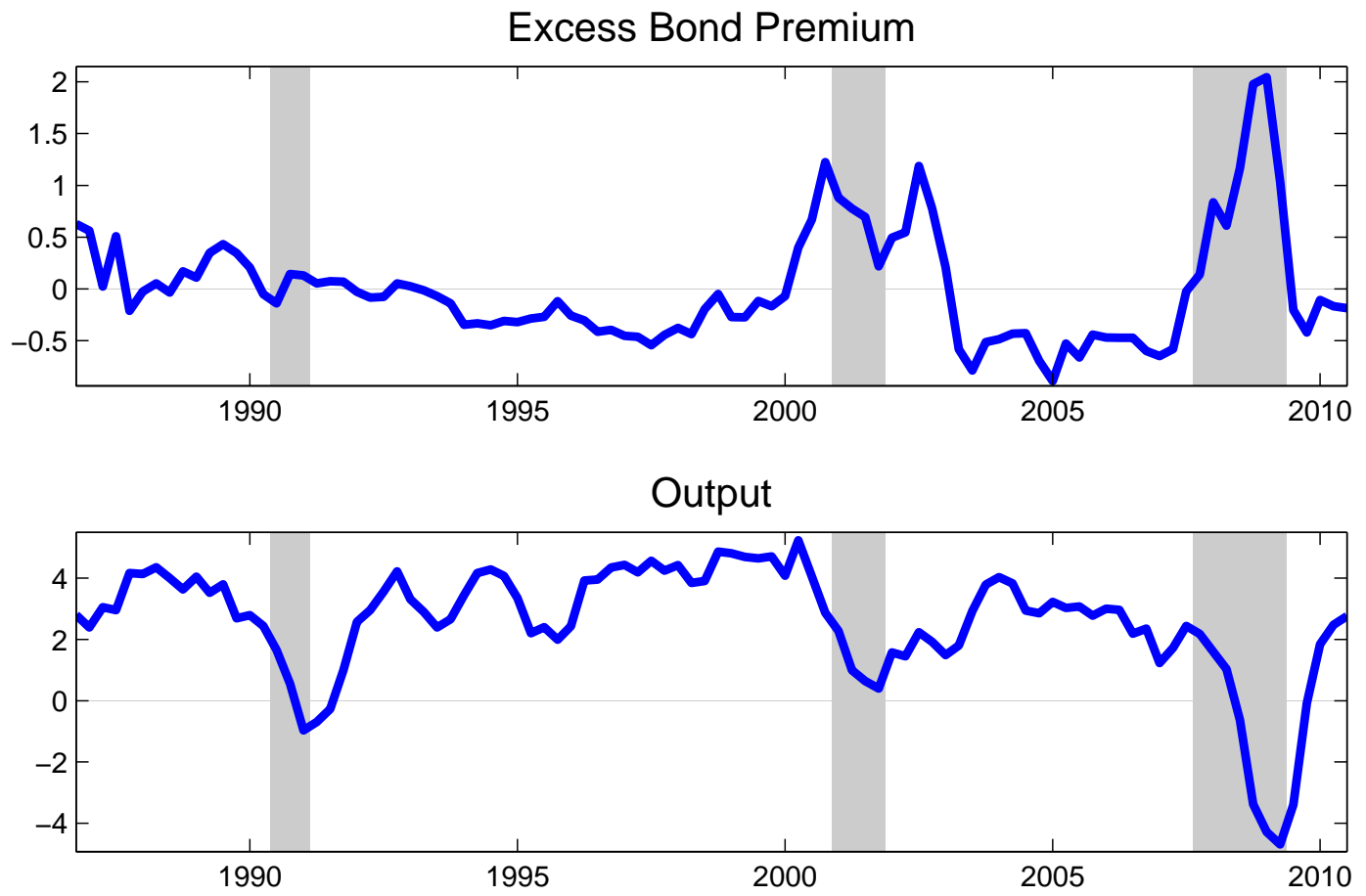

Note: The graph shows the annual GDP growth rate and the Excess Bond Premium (EBP) during the sample period. Numbers shown are in percentages. NBER recession dates are shaded. 
Figure 2.2: Conditional Volatility of Orthogonalized Residuals in Each Equation
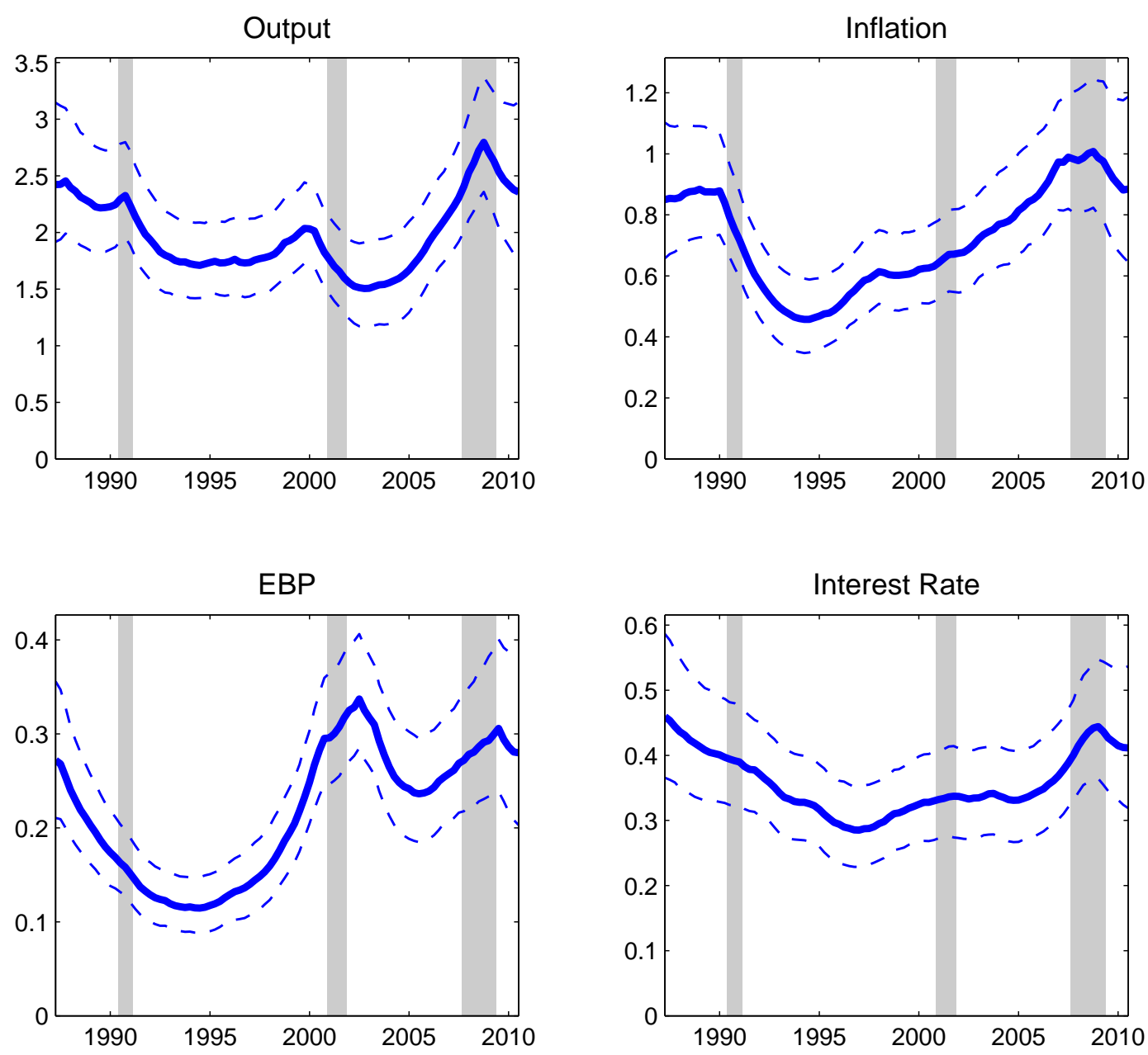

Note: The graph shows the standard deviation of the orthogonalized residuals in each equation of the variables in the time-varying model. The one that pertains to the equation of EBP is the conditional volatility of credit shocks. The solid line represents the median and the dotted lines represent the 16 th and 84th percentiles based on 5000 draws. NBER recession dates are shaded. 
Figure 2.3: Time Series of Orthogonalized Residuals in each Equation
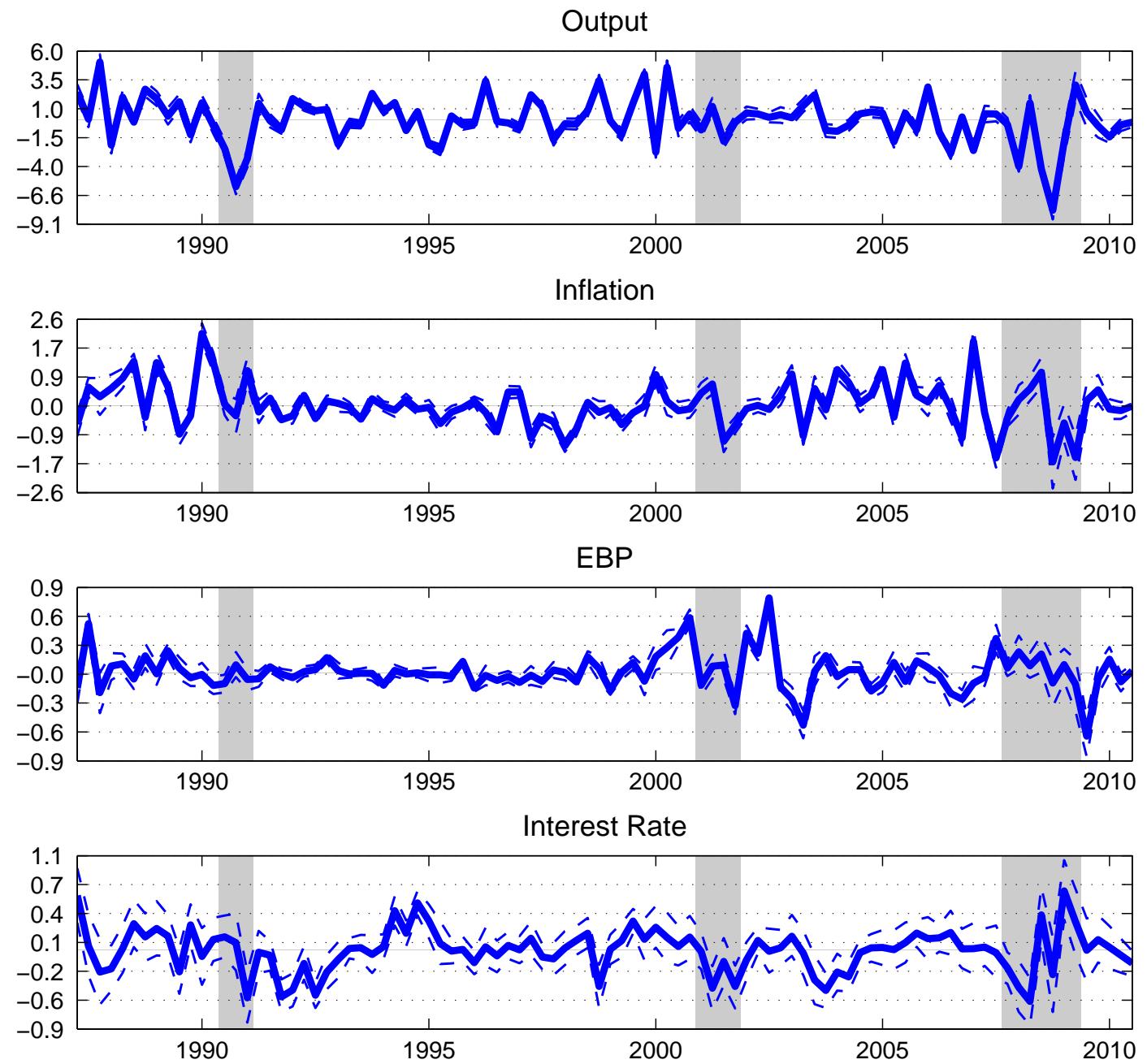

Note: The graph shows the time series of the orthogonalized residuals in each equation of the variables in the time-varying model. The shocks are adjusted for size by the conditional volatility estimated at each period. The orthogonalized residuals in the equation of EBP are the credit shocks. The solid line represents the median and the dotted lines represent the 16 th and 84 th percentiles based on 5000 draws. NBER recession dates are shaded. 
Figure 2.4: Impulse Responses: Summary
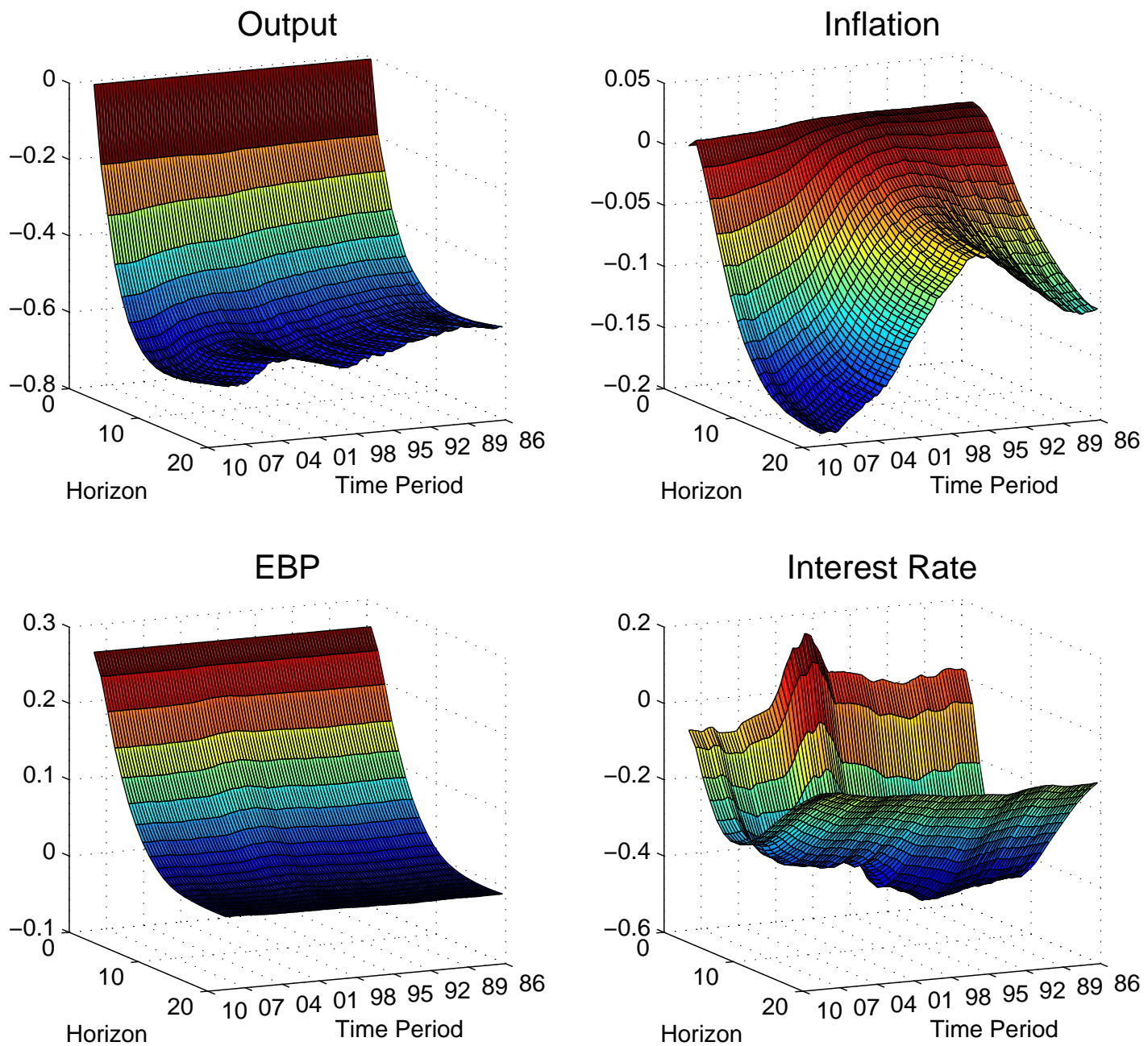

Note: The graph shows the median impulse responses due to adverse credit shocks for each period during the sample. The size of the credit shock for all impulses is such that EBP increases by 27 basis points on impact. The impulses for output and inflation are cumulated. Numbers shown are in percentages. 
Figure 2.5: Impulse Response of Output

(a) Baseline
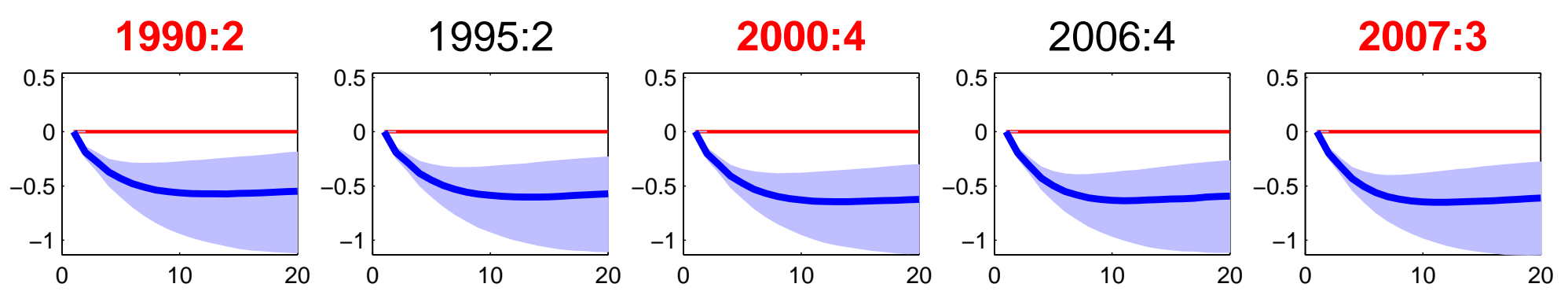

\section{(b) Bigger Prior}
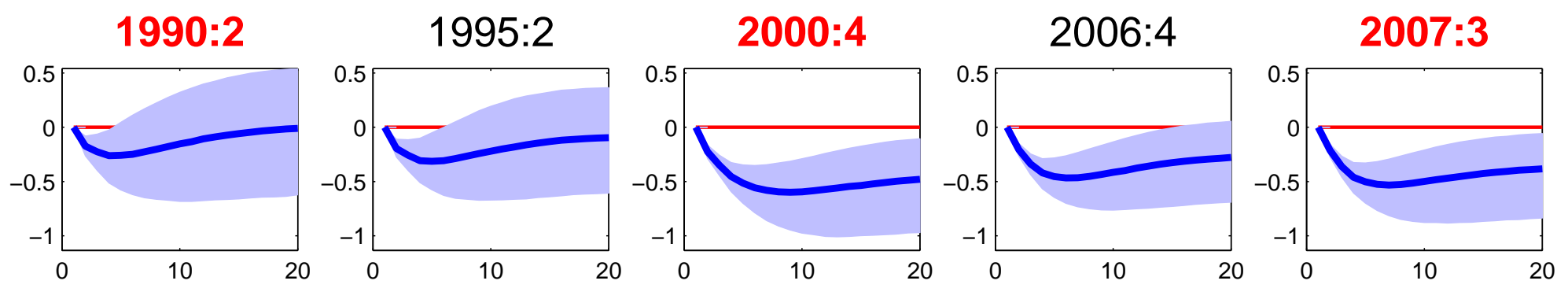

Note: The graphs show the cumulated impulse responses of output due to adverse credit shocks during select periods of U.S. recessions (dates bolded and red) and booms (dates thin and black). Panel (a) are estimated from the baseline specification of the VAR model (Baseline Model); and Panel (b) from a specification with a bigger prior on time variation in the transmission mechanism (Model A). The solid line represents the median and the shaded represents the 16-84 percentile bands based on 5000 draws. Numbers shown are in percentages. 
Figure 2.6: Time-varying vs. Time-invariant Model

(a) Normalized Impulse Responses

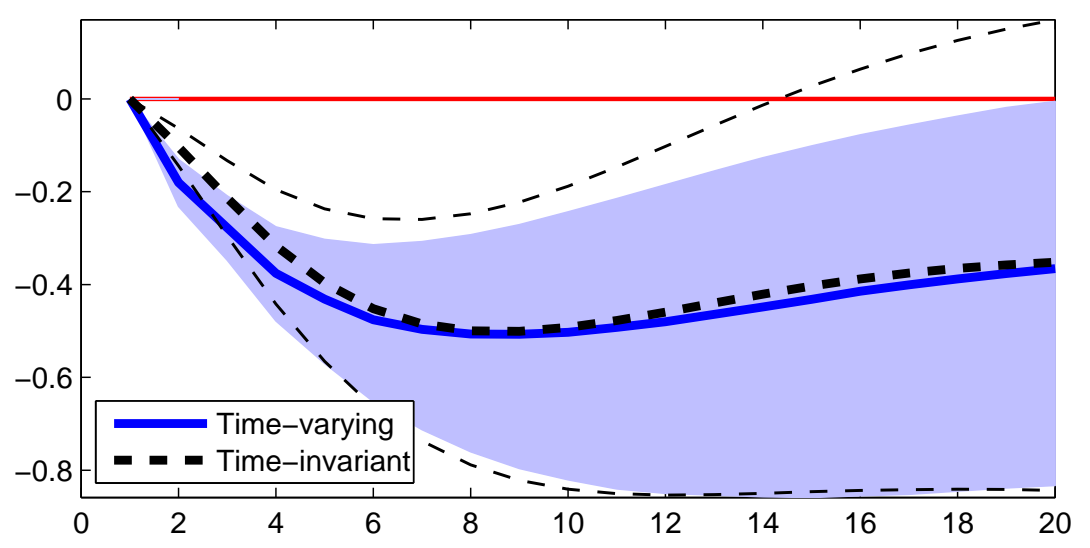

(b) Size Adjusted Impulse Responses

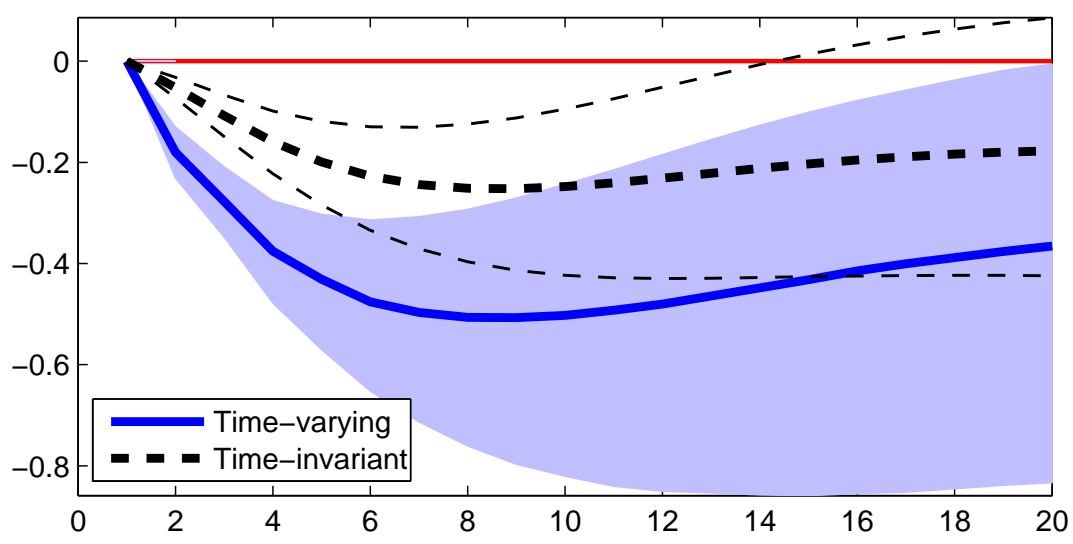

Note: The graph compares the impulse responses estimated from the time-varying and the time-invariant models. The impulse responses from the time-varying model are the ones calculated from the specification that uses detrended interest rate (Model B). Panel (a): Impulse responses are normalized such that the size of the credit shock is the same across the two models. The shock size used is the one estimated as of 2007:3 from the time-varying model. Panel (b): The impulse responses from the time-invariant model are constructed using the size of the credit shock estimated from this model. The impulse responses from the time-varying model are constructed using the size of the credit shock estimated as of 2007:3 which is the same as in Panel (a). Numbers shown are in percentages. 
Figure 2.7: Impulse Response of Inflation

(a) Baseline
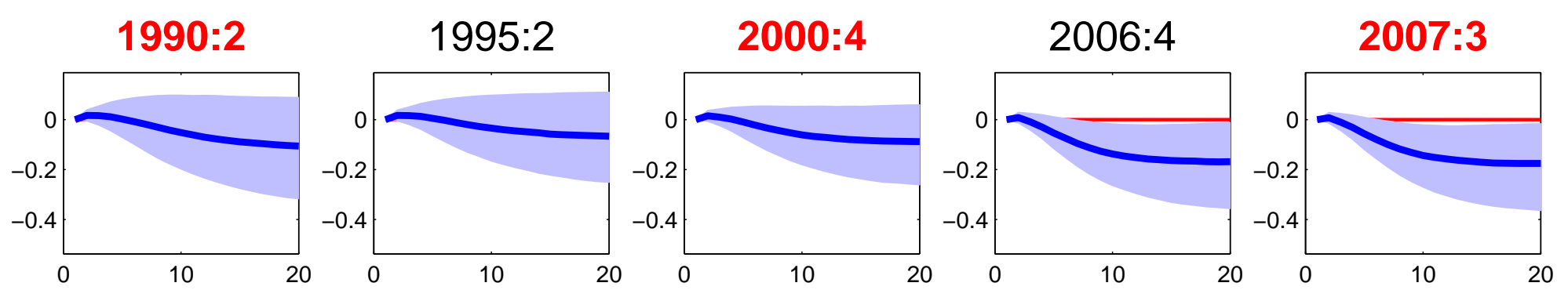

(b) Bigger Prior
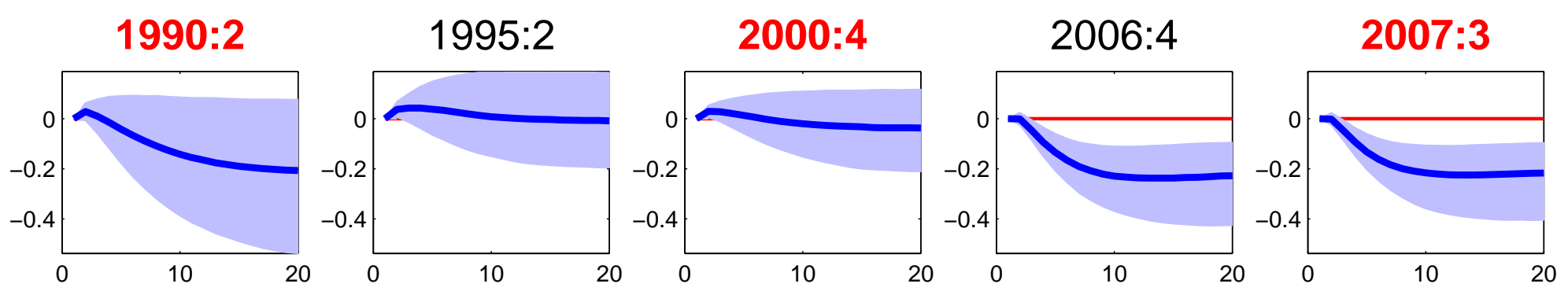

Note: The graphs show the cumulated impulse responses of inflation due to adverse credit shocks during select periods of U.S. recessions (dates bolded and red) and booms (dates thin and black). Panel (a) are estimated from the baseline specification of the VAR model (Baseline Model); and Panel (b) from a specification with a bigger prior on time variation in the transmission mechanism (Model A). The solid line represents the median and the shaded represents the 16-84 percentile bands based on 5000 draws. Numbers shown are in percentages. 
Figure 2.8: Impulse Response of Interest Rate At Different Horizons
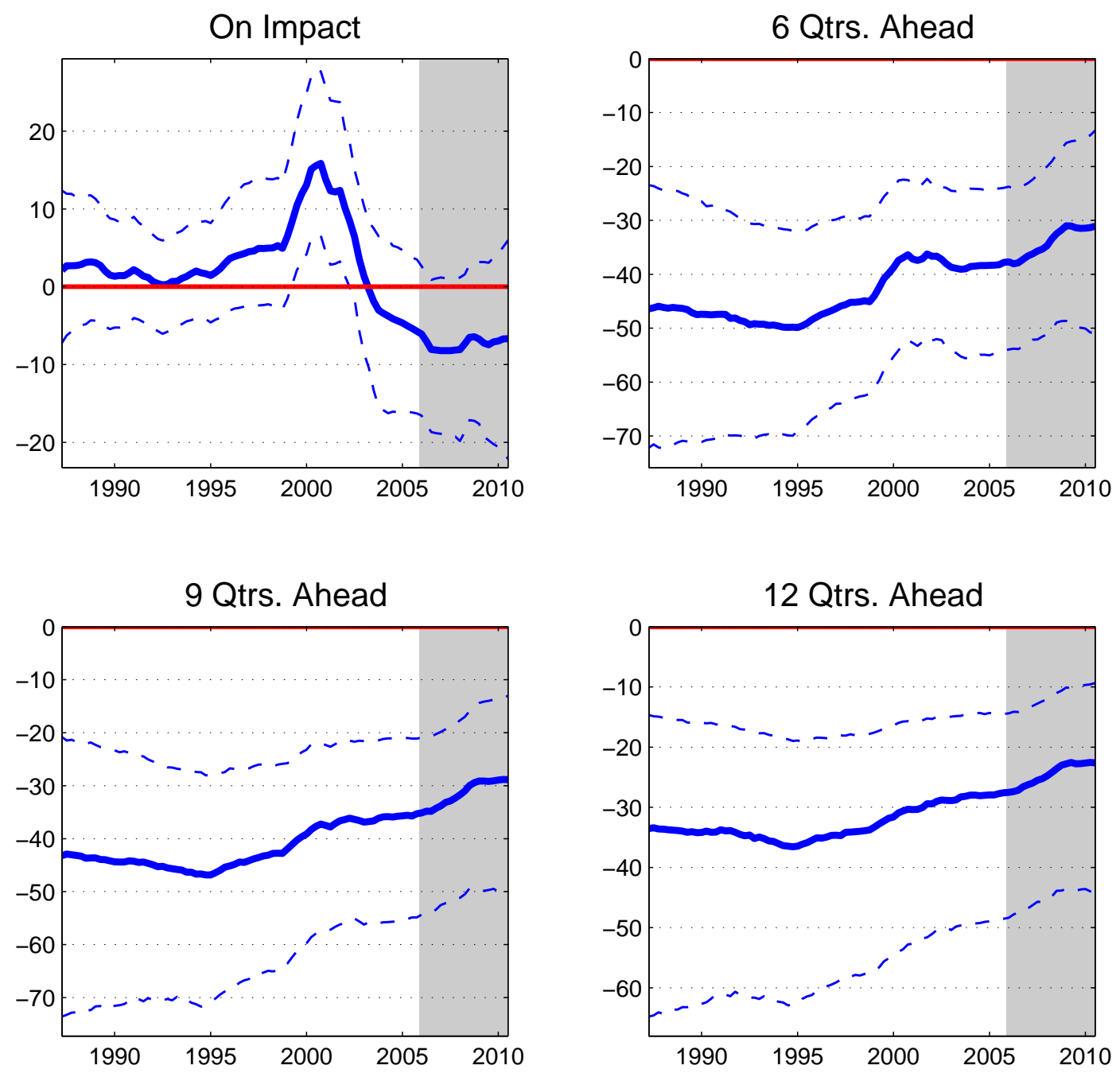

Note: The graph shows the evolution of the impulse responses of the nominal interest rate at different horizons when hit by adverse credit shocks. The solid blue line represents the median impulse and the dotted (thin) blue lines represent the 16 th and the 84 th percentiles based on 5000 draws. Numbers shown are in basis points. Bernanke's tenure as Fed Chairman is shaded. 
Figure 2.9: Impulse Response of Interest Rate At Different Horizons
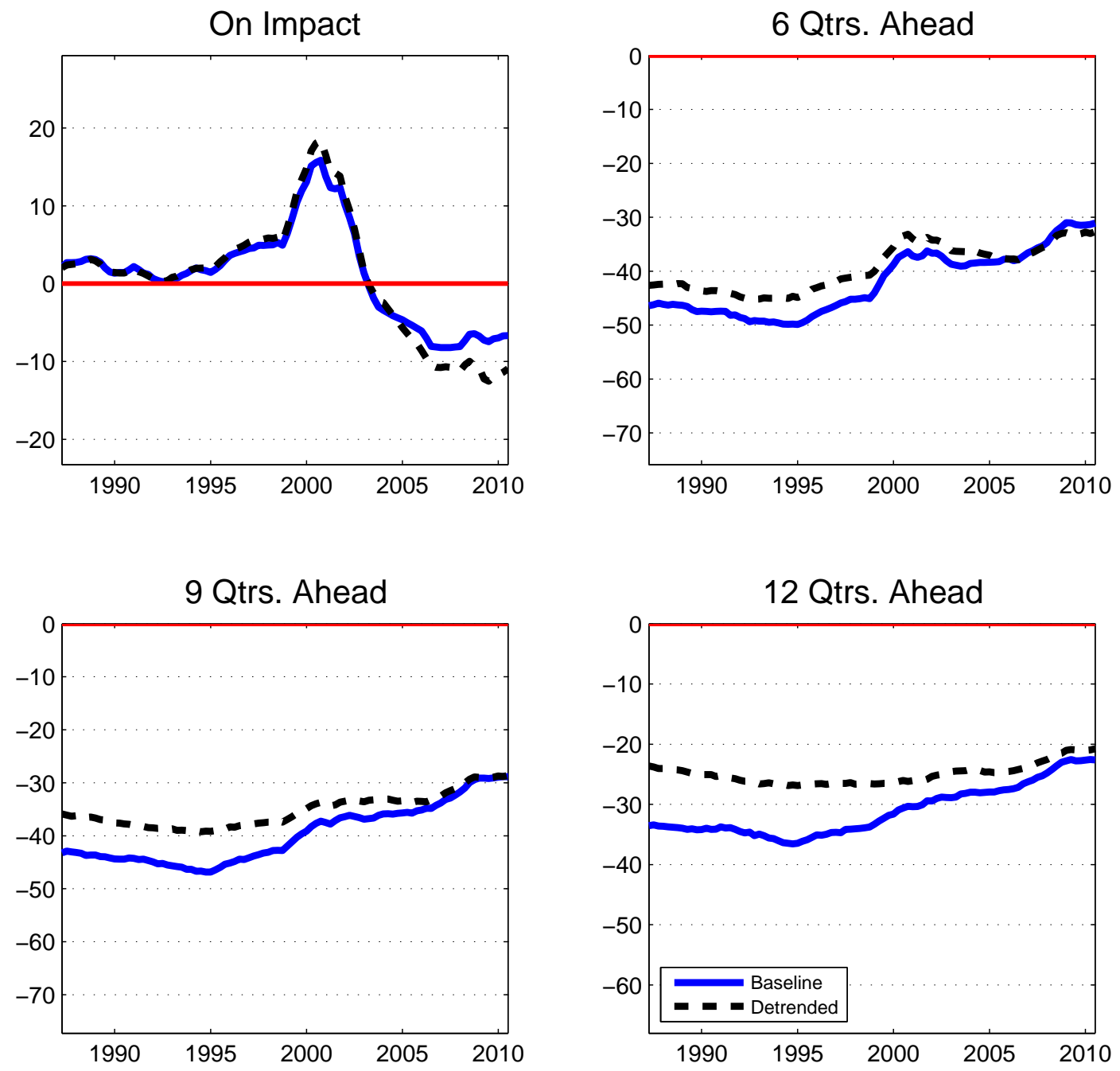

Note: The graph compares the evolution of the (median) impulse responses of the nominal interest rate at different horizons as estimated from the baseline specification of the time-varying model (Baseline Model) and those from an alternative specification which uses detrended interest rate (Model B). Numbers shown are in basis points. 
Figure 2.10: Variance Decomposition
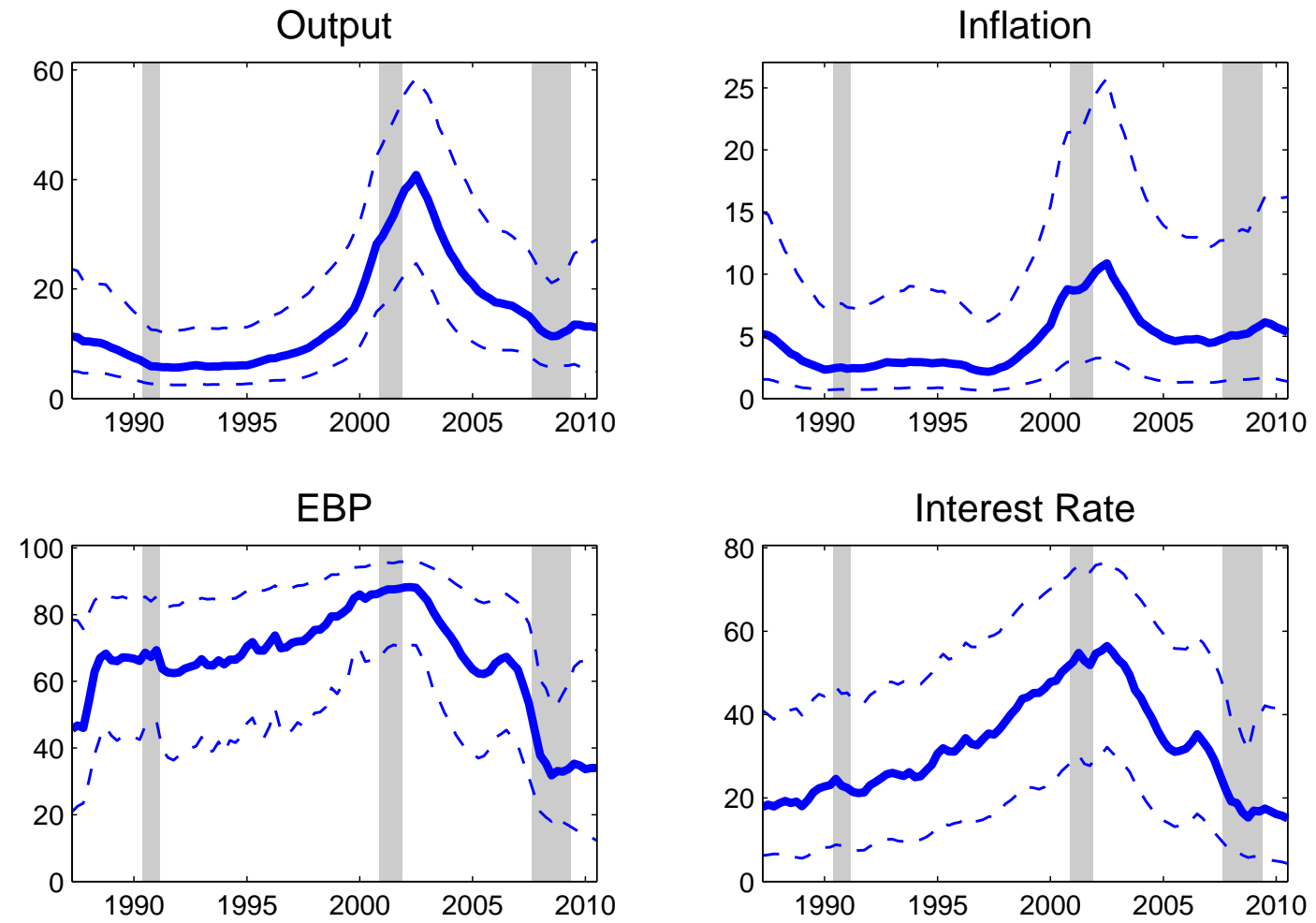

Note: The graph shows the percentage share of forecast error variance of each variable, at the 20th horizon, explained by credit shocks estimated at each period during the sample from the time-varying model. The solid line represents the median variance share and the dotted lines represent the 16 th and the 84 th percentiles based on 5000 draws. NBER recession dates are shaded.

Table 2.1: Variance Decomposition

\begin{tabular}{|c|c|c|c|c|c|c|}
\hline Variable & 1990:2 & 1995:2 & $2000: 4$ & $2006: 4$ & $2007: 3$ & Time-invariant \\
\hline Output & 7.1 & 6.3 & 28.2 & 16.9 & 15.0 & $11.2\left[\begin{array}{ll}5.1 & 19.9\end{array}\right]$ \\
\hline Inflation & 2.4 & 2.9 & 8.8 & 4.7 & 4.7 & $3.8\left[\begin{array}{ll}1.1 & 10.8\end{array}\right]$ \\
\hline EBP & 66.1 & 71.7 & 86.1 & 65.3 & 53.4 & $71.7\left[\begin{array}{lll}58.9 & 82.6\end{array}\right]$ \\
\hline Interest Rate & 23.1 & 32.0 & 51.4 & 33.5 & 25.6 & $20.7\left[\begin{array}{ll}8.2 & 37.0\end{array}\right]$ \\
\hline
\end{tabular}

Note: This tabulates the median variance decomposition shown in the graph above during select periods of U.S. recessions (dates bolded and red) and booms (dates thin and black) as estimated from the time-varying VAR model. Also shown are the median estimates and along with the 16th and 84th percentiles (italicized) from the time-invariant model. 
Figure 2.11: Counterfactual: 2007-2009 Recession
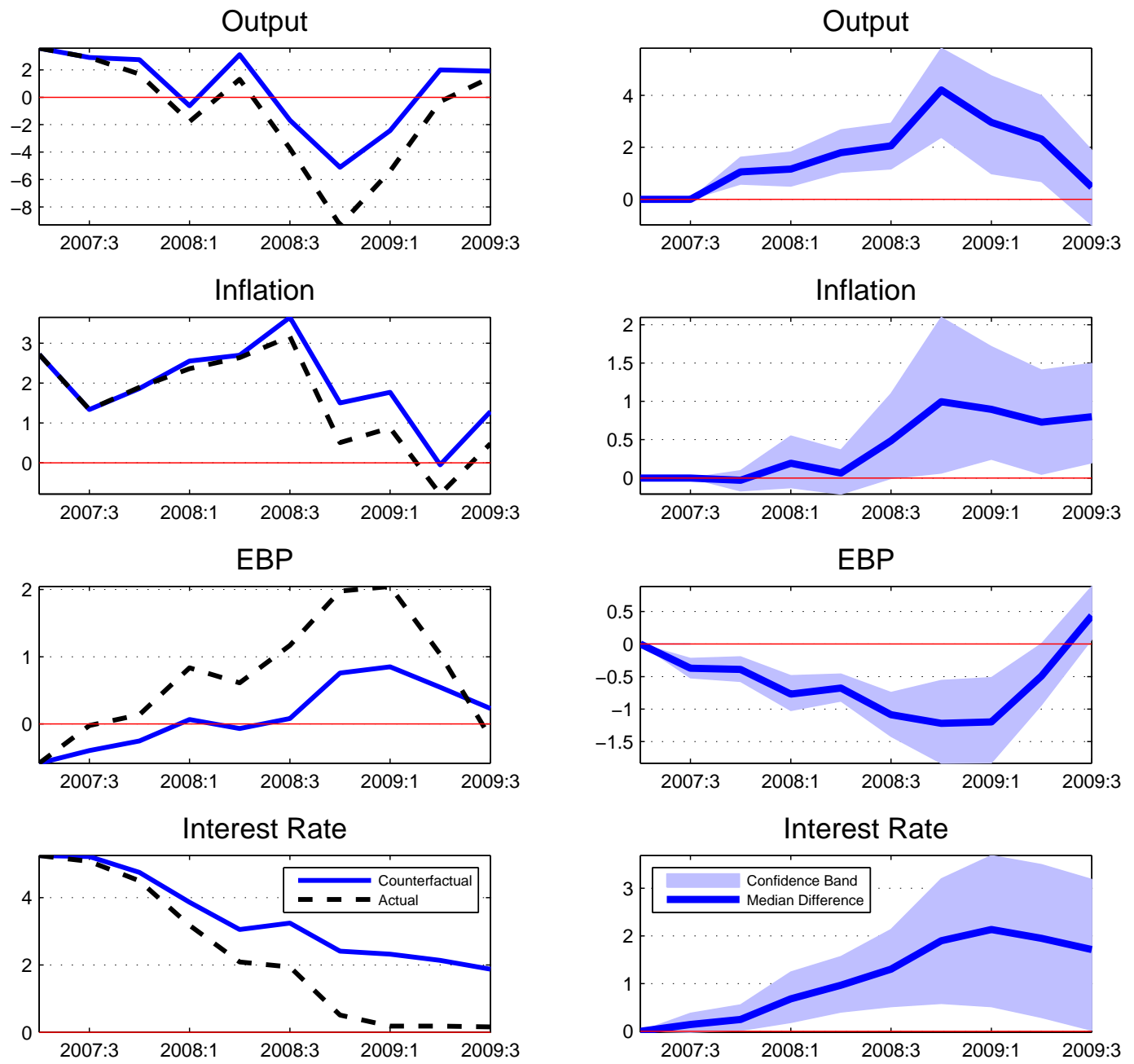

Note: The left panel of the graph compares the actual data and the counterfactuals during the recession of 2007-2009. The counterfactuals are obtained by setting the estimated credit shocks to zeros during this period. The dotted line represents the actual data and the solid line represents the median counterfactual. The right panel of the graph shows the difference between the actual and the counterfactual. The solid line is the median difference and the shaded represents the 16-84 percentile bands based on 5000 draws. A positive (negative) line indicates that the counterfactual would have been bigger (smaller) than the actual data in the absence of credit shocks. Numbers shown are in percentages. 
Figure 2.12: Counterfactual: 2001 Recession
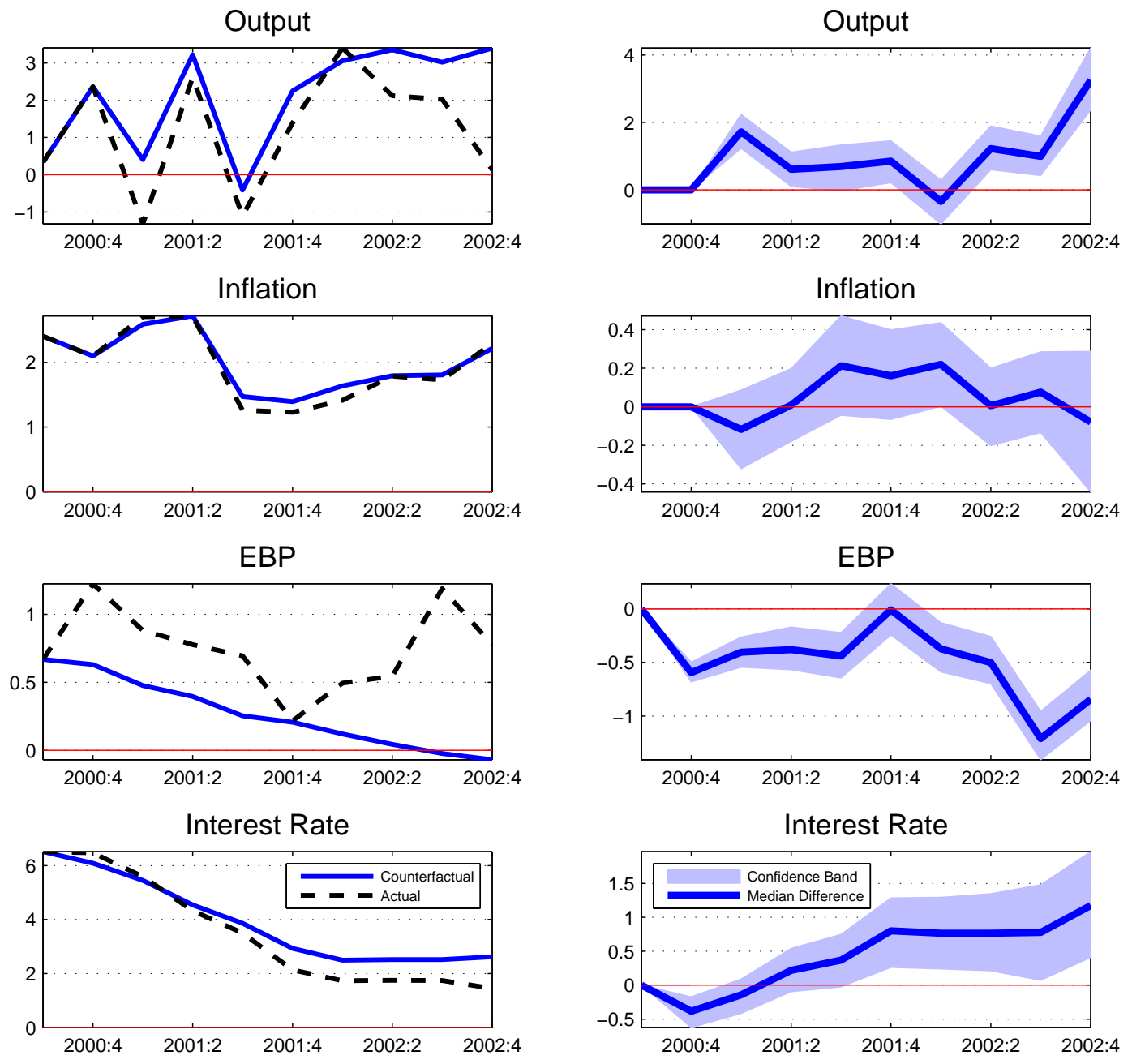

Note: The left panel of the graph compares the actual data and the counterfactuals during the recession of 2001. The counterfactuals are obtained by setting the estimated credit shocks to zeros during this period. The dotted line represents the actual data and the solid line represents the median counterfactual. The right panel of the graph shows the difference between the actual and the counterfactual. The solid line is the median difference and the shaded represents the 16-84 percentile bands based on 5000 draws. A positive (negative) line indicates that the counterfactual would have been bigger (smaller) than the actual data in the absence of credit shocks. Numbers shown are in percentages. 
Figure 2.13: Stochastic Volatility of credit shocks: Robustness

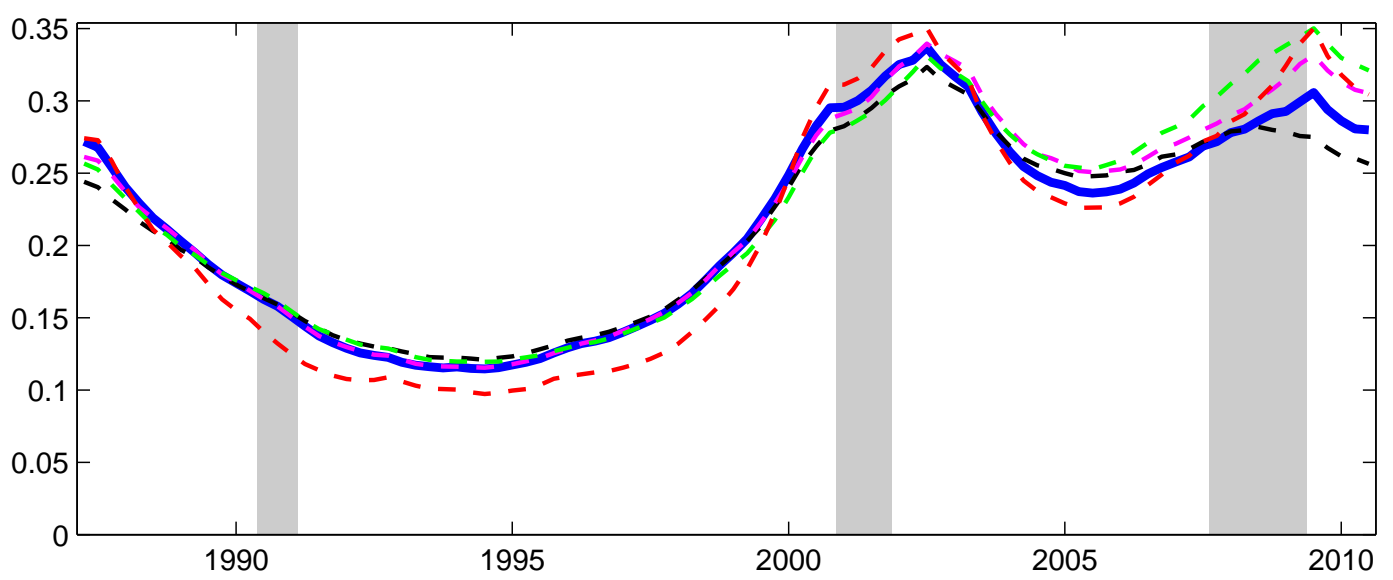

Note: The graph shows the standard deviation of credit shocks estimated at each period during the sample across different specifications of the model. The solid (blue) line represents the median estimate from Baseline Model. The dotted lines represent the corresponding estimates from alternative specifications of the time-varying VAR model, as discussed in Section 2.6.5. NBER recession dates are shaded. 
Figure 2.14: Impulse Response of Output: Alternative Specifications
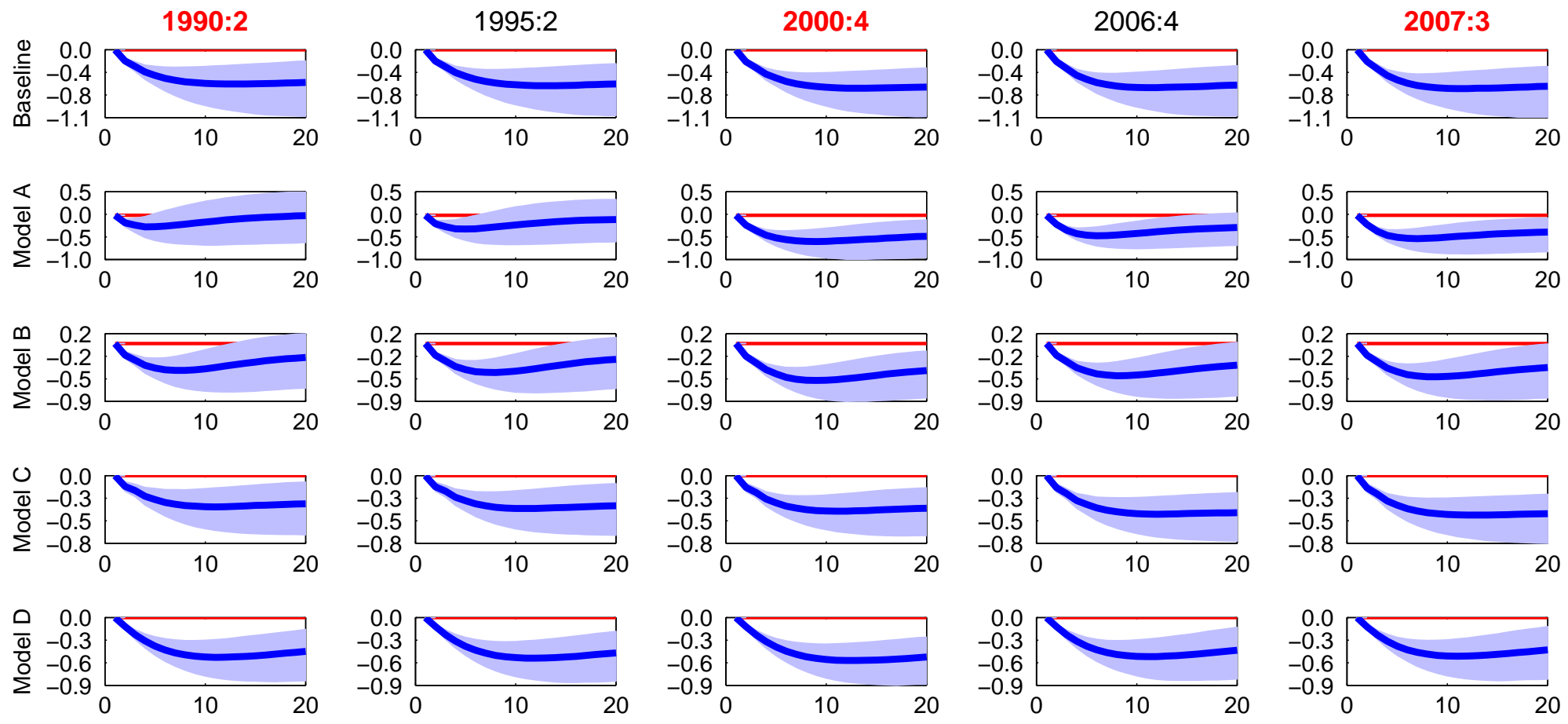

Note: The graph shows the cumulated impulse responses of output due to adverse credit shocks across alternative specifications of the time-varying VAR model. Baseline: benchmark specification; Model A: bigger prior on time variation of transmission mechanism; Model B: Baseline run on HP detrended interest rate; Model C: EBP ordered last in the VAR; Model D: VAR(5) that includes stock prices. The solid line represents the median and the shaded represents the 16-84 percentile bands based on 5000 draws. 
Figure 2.15: Impulse Response of Inflation: Alternative Specifications
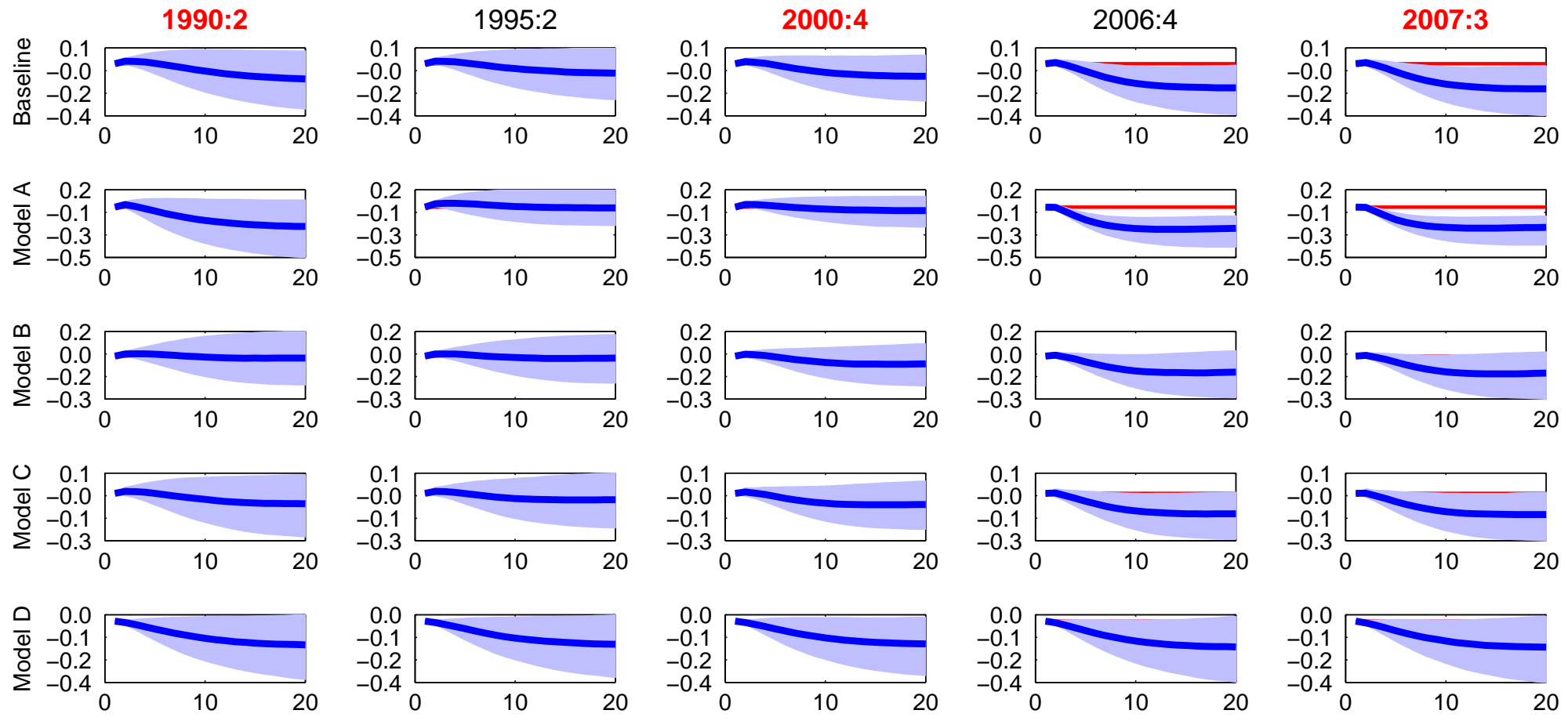

Note: The graph shows the cumulated impulse responses of inflation due to adverse credit shocks across alternative specifications of the time-varying VAR model. Baseline: benchmark specification; Model A: bigger prior on time variation of transmission mechanism; Model B: Baseline run on HP detrended interest rate; Model C: EBP ordered last in the VAR; Model D: VAR(5) that includes stock prices. The solid line represents the median and the shaded represents the $16-84$ percentile bands based on 5000 draws. 
Figure 2.16: Impulse Response of Interest Rate: Alternative Specifications
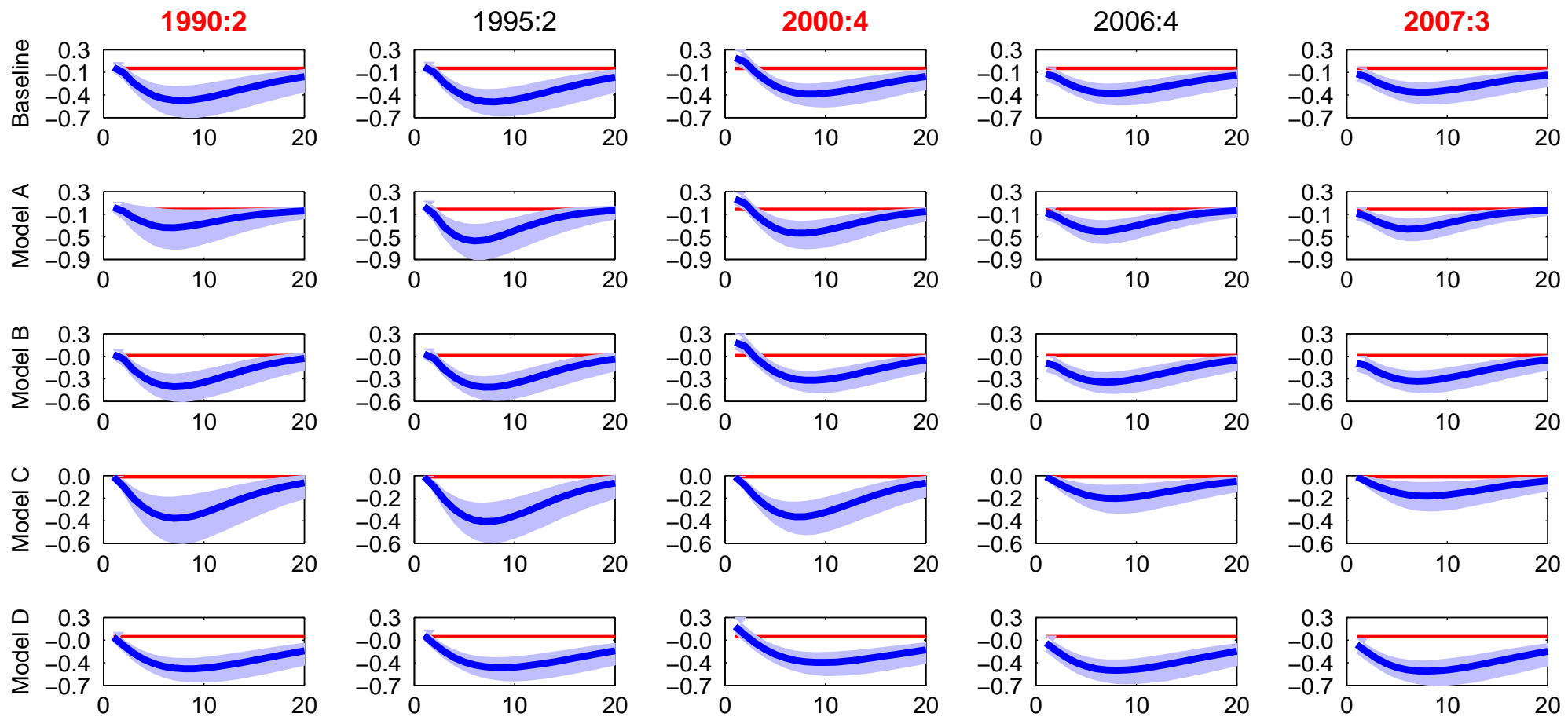

Note: The graph shows the impulse responses of the nominal interest rate due to adverse credit shocks across alternative specifications of the time-varying VAR model. Baseline: benchmark specification; Model A: bigger prior on time variation of transmission mechanism; Model B: Baseline run on HP detrended interest rate; Model C: EBP ordered last in the VAR; Model D: VAR(5) that includes stock prices. The solid line represents the median and the shaded represents the $16-84$ percentile bands based on 5000 draws. 
Figure 2.17: Output Counterfactual: 2007-2009 Recession

Baseline vs. Model D

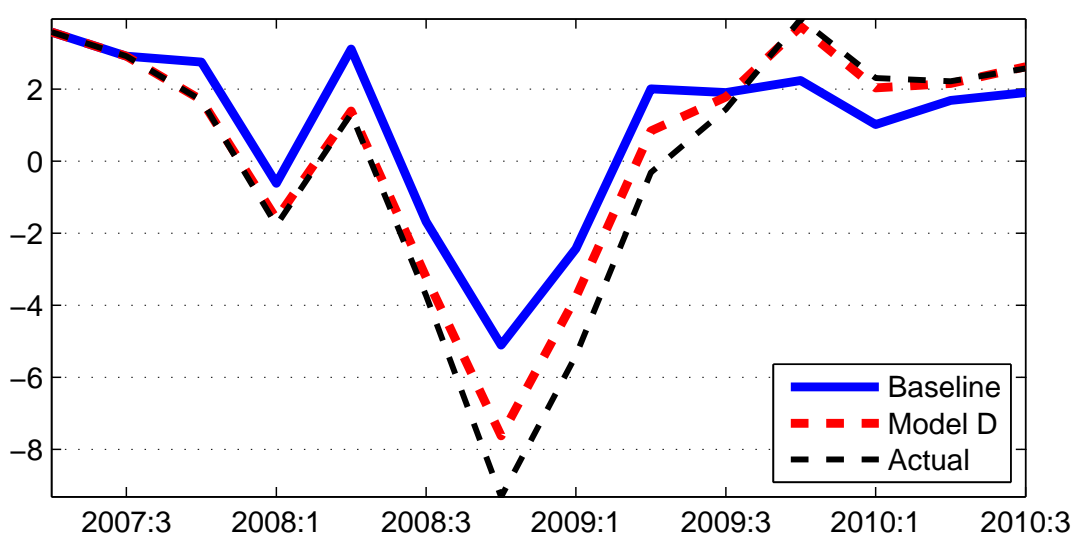

Note: The graph compares the (median) counterfactuals for output from the baseline specification of the time-varying VAR (Baseline Model) and those from the alternative specification that includes asset prices in the VAR (Model D). Numbers shown are in percentages. 
Figure 2.18: Impulse Response of Unemployment Rate
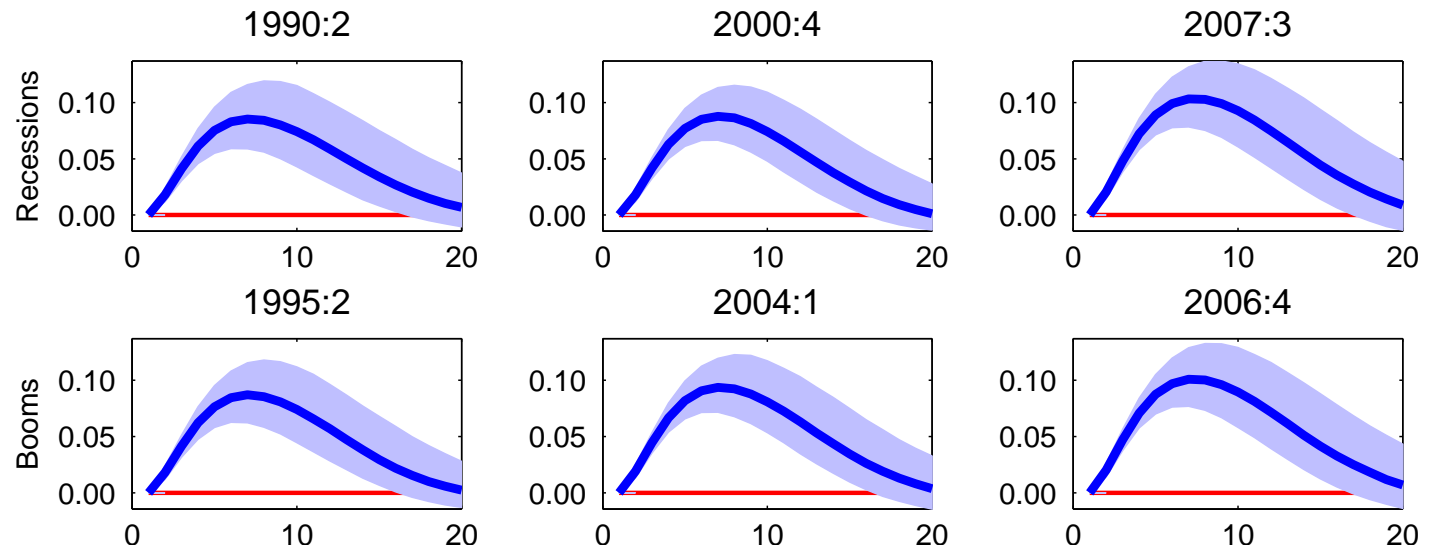

Note: The graph shows the impulse responses of the unemployment rate due to adverse credit shocks during select periods of U.S. recessions and booms. The impulses are estimated from a version of the baseline model by including unemployment rates instead of output. The solid line represents the median and the shaded represents the $16-84$ percentile bands based on 5000 draws.

Figure 2.19: Time Varying Intercept Term in Interest Rate Equation

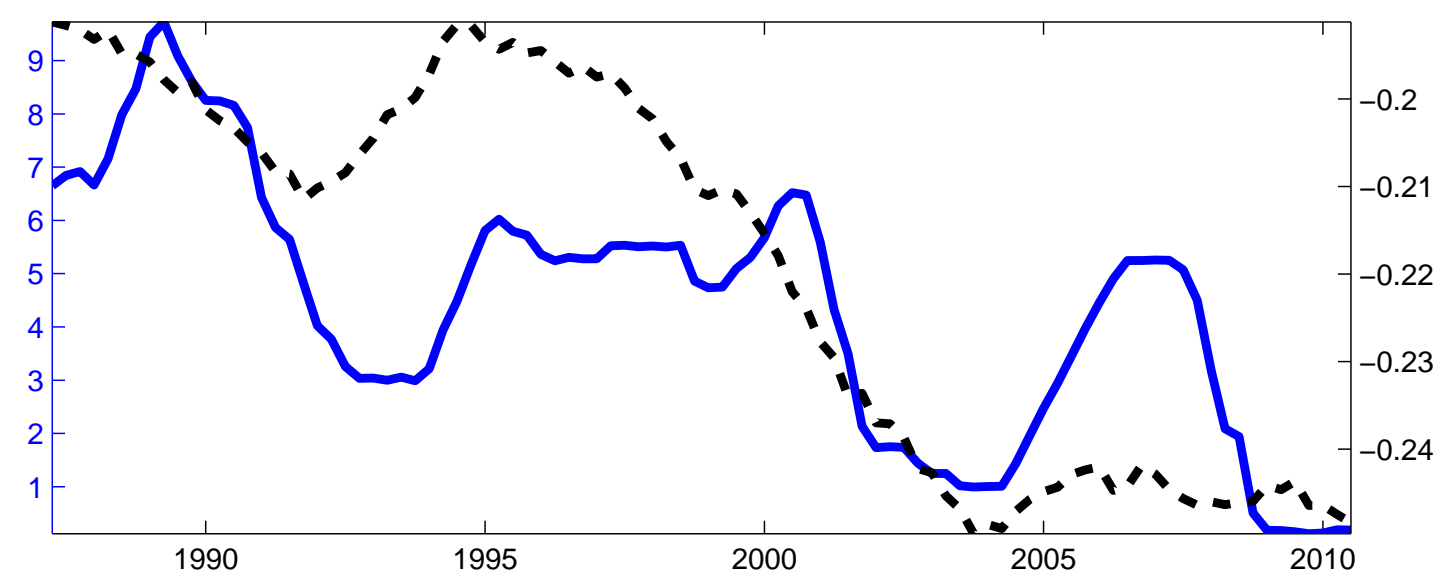

Note: The graph shows the evolution of the intercept term in the equation of the interest rate in Baseline Model against the actual data during the sample period. The solid (blue) line, shown on the primary axis, represents the actual data. The dotted (black) line, shown on the secondary axis, represents the intercept term. 
Figure 2.20: Inefficiency Factors of VAR Parameters
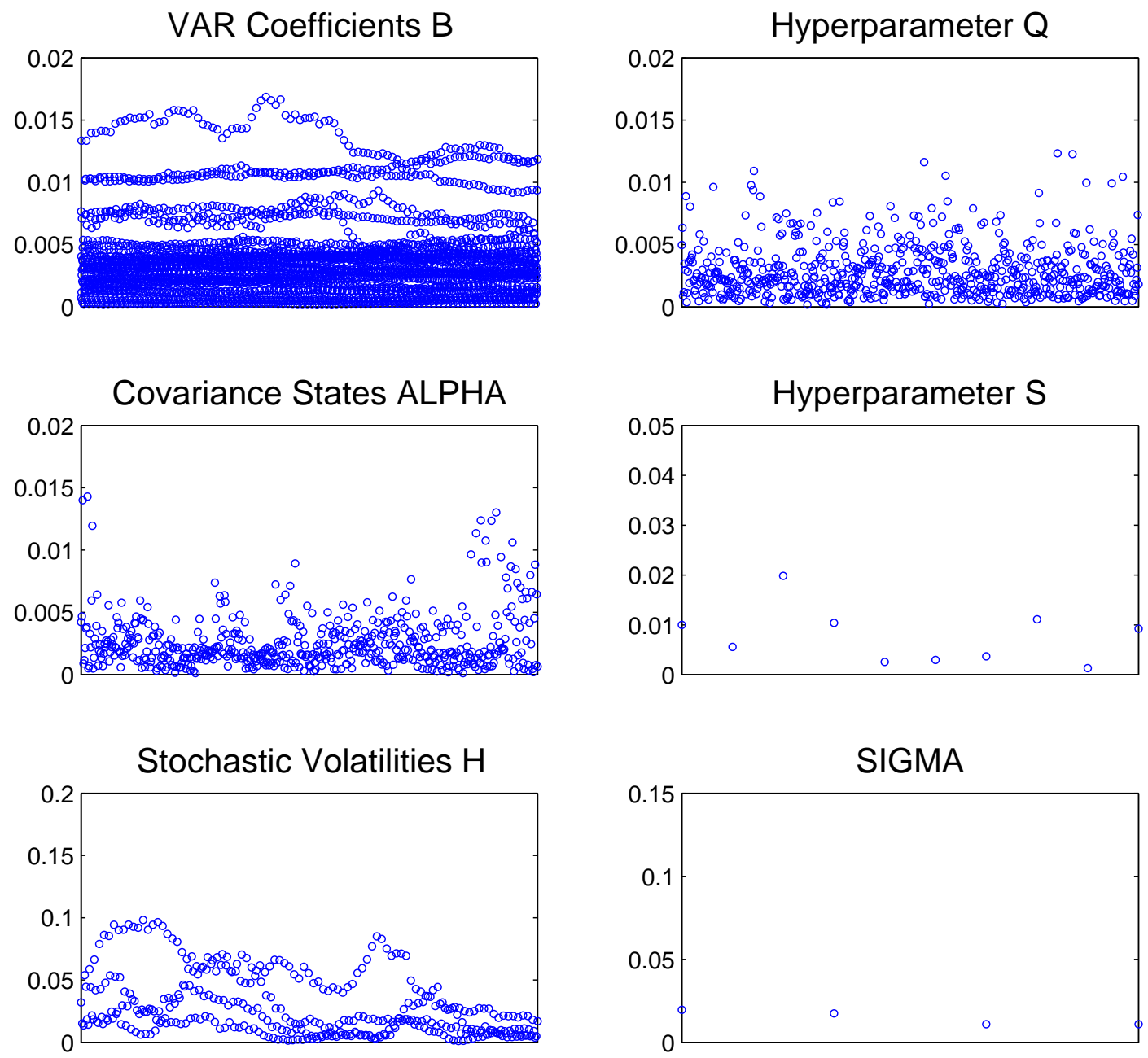

Note: Each dot in the graph shows the inefficiency factor calculated for each parameter in the time-varying VAR (Baseline Model). These are based on 5000 draws. For a set of parameters shown on the left panel, the graph on the right panel shows the inefficiency factors for the corresponding hyperparameters. An inefficiency factor less than 20 is generally indicative of convergence of MCMC draws. 


\section{Chapter 3}

\section{Raising the Inflation Target to}

\section{Manoeuvre the Zero Lower Bound: The Role of Fiscal Policy}

\subsection{Introduction}

Most advanced economies saw a deep and prolonged slump in economic activity during the Great Recession of 2007-2009. Central banks in these economies responded by easing monetary policy to the extent that the policy rates or short term nominal interest rates are now at or near zero. Figure 3.1 presents these stylized facts by taking a representative example of the U.K. Generally speaking, the nominal interest rate cannot be negative so that this scenario presents a constraint on further monetary easing, through the nominal rate, to stabilize the economy: the zero lower bound (ZLB henceforth) constraint. ${ }^{1}$ Given this experience, a view has emerged whether the the nominal rate should have been higher prior to the crisis that would have allowed central banks to cut rates more. To that end, one policy proposal is that central banks should pursue a higher inflation target which would

\footnotetext{
${ }^{1}$ On rare occasions, policy rates have taken negative numbers, the most recent example being in the Euro Area when the ECB cut rates below zero in the summer of 2014. However, these are exceptions rather than the norm so that the ZLB constraint is still discussed in the literature as a binding constraint on monetary policy.
} 
then raise the long run nominal rate through the Fisher relation (Blanchard et al. (2010)).

The ZLB is primarily a constraint on monetary policy and that too only when the monetary policy instrument is the short term nominal interest rate. Even when ZLB is a binding constraint, there are other macroeconomic stabilization tools available. For instance, the central bank can resort to unconventional monetary policy like quantitative easing and the fiscal authority can pursue countercyclical fiscal policy. Given this, it is therefore important to evaluate the efficacy of these alternative tools vis-a-vis raising the inflation target as a means to mitigate the effects of the ZLB constraint. This paper focuses on the role of countercylical fiscal policy. Given that government debt levels have shot up in recent years (Figure 3.1), another objective of this paper is to understand if and how high government debt limits the scope of countercyclical fiscal policy in stabilizing the economy especially during ZLB episodes.

I address these questions in the context of a New Keynesian DSGE model. The model features a monetary authority choosing the inflation target and setting the nominal rate using a Taylor rule truncated at ZLB and a fiscal authority that conducts fiscal policy according to a fiscal surplus rule. To have a better understanding of how the level of government debt matters, the model also features Ricardian and non-Ricardian households (rule-of-thumb consumers). This results in a framework where the Ricardian Equivalence does not hold. The model is solved using global methods in a fully stochastic set-up and where agents are aware of the occasionally binding constraint associated with ZLB. This solution method allows me to capture nonlinear global dynamics and expectational effects at or near the bound. Using this structural framework, I then perform policy counterfactuals with respect to monetary and fiscal policy to answer the questions set out in the paper.

Even though the context and the issues in this paper are quite general in nature and apply to most advanced economies, I focus on the U.K. economy for the purpose of calibrating the model. The main reason for this is that the U.K. is an inflation targeting 
economy (starting 1992), with a publicly announced annual target of $2 \%$. This allows me to conveniently abstract away from modeling how agents learn the inflation target. ${ }^{2}$ A second reason is that the U.K. has a formal national fiscal rule which takes the form of a cyclically adjusted budget balance rule or a debt rule (IMF's Fiscal Monitor, Oct 2012). While such rules have been deployed rather flexibly to respond to the slump in economic activity during the crisis years, the fiscal mandate now, as per the Fiscal Responsibility Act of 2010, is to meet specific statutory targets on fiscal deficits and government debt in the medium term. The fiscal surplus rule deployed in the model aligns well with such a fiscal institutional framework.

The main findings are as follows: a higher inflation target, by providing more "room to manoeuvre", indeed helps to stabilize business cycle fluctuations (second moments) in the presence of the ZLB constraint thereby corroborating the point in Blanchard et al. (2010). However, the results from the model in this paper also suggest that a carefully calibrated countercyclical fiscal policy presents an alternative policy choice to meet the same objective. From a welfare perspective, a countercyclical fiscal policy is even better. This is because a higher inflation target, by increasing long run price dispersion, reduces long run output and consumption which then reduces welfare, outweighing the gains from stabilizing business cycle fluctuations. Countercyclical fiscal policy, on the other hand, is neutral in the long run. In an equilibrium where the monetary authority stabilizes inflation and the fiscal authority stabilizes government debt (monetary-led equilibrium), a countercyclical fiscal policy also does not pose significant fiscal challenges for the government. The efficacy of countercyclical fiscal policy in mitigating the effects of the ZLB constraint, however, depends on the initial level of government debt - an initial high level of government debt reduces that efficacy.

The rest of the paper is organized as follows. In Section 3.2, I briefly review the related

\footnotetext{
${ }^{2}$ See Nunes (2009) for a model that features agents learning about the inflation target in the case of the U.S. The Federal Reserve made the inflation target explicit in 2012. However, insofar as inflation has been low and stable in most advanced economies since the beginning of the Great Moderation, the distinction between an explicit and an implicit target seems to be a minor point.
} 
literature. Section 3.3 describes the model. In Section 3.4, I discuss model calibration. Here, I also explain the nature of the equilibrium (i.e. monetary-led equilibrium) used in the paper and relate that to the choice of parameter values in the monetary and fiscal rules. I discuss the global solution method in Section 3.5. Section 3.6 presents the results and Section 3.7 concludes.

\subsection{Related Literature}

This paper is related to the literature on optimal inflation targets. Closely related is Coibion et al. (2011) who compute the optimal inflation target in New Keynesian DSGE models while taking into account the ZLB constraint. Calibrated for U.S., they show that the optimal inflation target is positive but less than $2 \% .^{3}$ They therefore argue that raising the inflation target above $2 \%$ is "too blunt an instrument to efficiently reduce the severe costs of zero-bound episodes". Unlike their work, this paper focuses on the role of countercyclical fiscal policy and in some sense complements their conclusion in that the results from this paper also suggest that an inflation target higher than $2 \%$ may not be warranted as long as countercyclical fiscal tools are available. An important difference from Coibion et al. (2011) is the model solution method: while they use a linearized solution under perfect foresight, this paper deploys a global solution in a fully stochastic setting which has the advantages of being able to capture nonlinear global dynamics and expectational effects associated with ZLB.

Another strand of related literature is fiscal-monetary interactions. This begins with the seminal work of Leeper (1991) who introduces different equilibrium concepts (monetary-led and fiscally-led) in DSGE models. Following this, a lot of studies have looked at jointly optimal monetary and fiscal policies in DSGE models (e.g. Schmitt-Grohe and Uribe (2006)).

\footnotetext{
${ }^{3}$ The literature on the optimal inflation target is quite big. Friedman's rule implies an optimal inflation level which is negative so as to target a zero nominal interest rate. Subsequent monetary models that feature money still point to an optimal inflation target which is negative (e.g. Khan et al. (2002), Schmitt-Groh and Uribe (2007)). Positive optimal inflation targets are obtained in models that feature downward nominal wage rigidity and the ZLB constraint. But in most of these studies, the optimal targets are small and below $2 \%$.
} 
Particularly relevant to this paper are those that study jointly optimal policies in the context of the ZLB constraint. For instance, Nakata (2013) shows that the optimal policy, in the context of a small New Keynesian DSGE model, is characterized by increased government expenditure at ZLB. This paper explores the role of additional state variables like price dispersion and government debt and highlight how these additional features drive the key results in the paper. In terms of modeling strategy, this paper is more similar to $\mathrm{Bi}$ and Kumhof (2011) who, instead of analyzing optimal policies, evaluate optimal fiscal and monetary rules.

The ZLB is an occasionally binding constraint which ideally requires global solution techniques. ${ }^{4}$ This paper extends the relatively few but growing literature that deploys global solution techniques to handle the occasionally binding ZLB constraint. Most of these studies consider a small monetary model on lines of Clarida et al. (1999). For instance, Billi and Kahn (2008) and Nakov (2008) use such models to study optimal monetary policy in the presence of the ZLB constraint. Fernandez-Villaverde et al. (2012) add more structural shocks and include additional model features like price dispersion. This paper builds on and extends the model in Fernandez-Villaverde et al. (2012) in two dimensions. First, the model in this paper features Ricardian and non-Ricardian households. Second, the model features a more elaborate fiscal sector with an endogenous fiscal rule that seeks to stabilize output and debt fluctuations. I use these additional model features to answer the questions set out in this paper: the significance of countercyclical fiscal policy and the role of government debt level.

Finally, this paper is related to the literature on trend inflation in DSGE models. Ascari (2004) and Ascari and Ropele (2007) show that positive trend inflation under less than full indexation can have non-trivial implications for monetary models. In particular, these papers highlight that firm pricing behavior becomes more forward looking as the trend

\footnotetext{
${ }^{4}$ For a discussion on alternative model solution techniques used in the literature to handle the ZLB constraint and the shortcomings associated with them, see Nakov (2008).
} 
inflation increases which then requires stronger monetary responses to inflation for ensuring determinacy. A key model feature that drives the results in this paper is partial indexation in the Calvo pricing scheme. In this regard, Cogley and Sbordone (2008) point out that once positive trend inflation is taken into account, full indexation which is often hardwired in DSGE models to match inflation persistence in the data, is no longer required. Along with their result, estimates of indexation from several studies are key elements of this paper.

\subsection{Model}

The model economy is populated by Ricardian and non-Ricardian households. The number of households in the economy is normalized to unity with the fraction of Ricardian households given by $(1-\nu)$. The government comprises of a monetary authority and a fiscal authority. The monetary authority chooses the inflation target and sets the nominal interest rate according to a Taylor rule truncated at ZLB. The fiscal authority sets government expenditure according to a fiscal surplus rule. Price setting follows a Calvo (1983) scheme with partial indexation to the steady state inflation.

\subsubsection{Households}

\section{Ricardian}

The period utility function for the representative Ricardian household is $U\left(c_{R, t}, l_{R, t}\right)$, where $c_{R, t}$ denotes real consumption and $l_{R, t}$ labor. ${ }^{5}$ The representative household enters period $t$ with $B_{t-1}$ units of nominal bonds which pay the gross nominal interest rate, $R_{t}$, between $t$ and $t+1$. During period $t$, the Ricardian household supplies labor to the intermediate good producers for which it receives wage income $w_{t} l_{R, t}$, where $w_{t}$ is the economy-wide real wage. Her labor income is taxed at a proportional constant rate $\tau .{ }^{6}$ In addition, the Ricardian household receives a lump-sum real transfer, $T_{t}$, from the fiscal authority and real dividend payments, $\Omega_{t}$, from the firms in the economy. The household allocates these

\footnotetext{
${ }^{5}$ I consider a cashless economy on the lines of Woodford (2003).

${ }^{6} \mathrm{~A}$ constant tax rate means that I am not specifying it as a fiscal instrument. I can also switch to the tax rate as the fiscal instrument instead of government expenditure. In that case, the former is variable and the latter constant.
} 
funds to consumption and nominal bond holdings. The household's budget constraint in real terms is:

$$
c_{R, t}+\frac{B_{t}}{p_{t}}=(1-\tau) w_{t} l_{R, t}+R_{t-1} \frac{B_{t-1}}{p_{t}}+T_{t}+\Omega_{t}
$$

The period utility function of the representative household is of type considered in Greenwood et al. (1988) (GHH henceforth). The representative household maximizes expected utility by choice of $c_{R, t}, l_{R, t}$, and $B_{t}$ subject to the budget constraint. The household's optimization problem is:

$$
\max _{\left\{c_{R, t}, l_{R, t}, B_{t}\right\}} E_{0} \sum_{t=0}^{\infty} \beta^{t} d_{t}\left\{\frac{1}{1-\gamma}\left(c_{R, t}-\psi \frac{l_{R, t}^{1+\vartheta}}{1+\vartheta}\right)^{1-\gamma}\right\}
$$

subject to (3.1). The parameter $\beta$ denotes the discount rate, $\gamma$ the risk aversion, and $\vartheta$ inverse of Frisch elasticity. The weight on leisure in the household's utility function is denoted by $\psi$. The preference shock $d_{t}$ follows an $\operatorname{AR}(1)$ process as follows:

$$
\log \left(d_{t}\right)=\rho_{d} \log \left(d_{t-1}\right)+\epsilon_{d, t} ; \quad \epsilon_{d, t} \sim N\left(0, \sigma_{d}\right)
$$

The preference shock is the only shock that drives model dynamics in this paper. This is to minimize on the number of state variables since the model is solved using global methods. Among the many business cycle shocks, I focus on preferences shock since they move output, inflation, and the nominal rate in the same direction. ${ }^{7}$ This allows me to simulate recession episodes with a binding ZLB constraint.

\footnotetext{
${ }^{7}$ In a standard New Keynesian DSGE model, productivity shocks, for instance, move output and nominal interest rate in opposite direction and hence, is less suitable for the purpose of the paper. That said, the results from this paper are quite general and will carry over to any shocks whose effects are qualitatively similar to those of preference shocks.
} 
The first order conditions for the Ricardian household's problem are:

$$
\begin{aligned}
\lambda_{t} & =d_{t}\left(c_{R, t}-\psi \frac{l_{R, t}^{1+\vartheta}}{1+\vartheta}\right)^{-\gamma} \\
\psi l_{R, t}^{\vartheta} & =(1-\tau) w_{t} \\
\lambda_{t} & =\beta E_{t}\left[R_{t} \frac{\lambda_{t+1}}{\pi_{t+1}}\right]
\end{aligned}
$$

where $\lambda_{t}$ is the Lagrange multiplier associated with the budget constraint of the Ricardian household. The gross inflation rate is defined as $\pi_{t} \equiv \frac{p_{t}}{p_{t-1}}$. With GHH preferences, Equation 3.4 shows that labor supply decisions depend only on the real wage rate.

The long run Fisher relationship between the level of inflation and the nominal rate can be derived by evaluating the bond pricing Euler equation (3.5) in the steady state. This results in $R=\frac{\pi}{\beta}$, which shows that steady state inflation determines steady state nominal rate. ${ }^{8}$ Thus, by controlling the inflation target (steady state inflation), the monetary authority can control the long run (steady state) nominal interest rate. This is the "room to manoeuvre" argument of Blanchard et al. (2010): raising the inflation target raises the long run nominal rate which then gives central banks more margin to cut rates when hit by adverse shocks.

\section{Non-Ricardian}

The period utility function of the representative non-Ricardian household is the same as that of the Ricardian household. The non-Ricardian household, however, does not have access to nominal bonds and hence, cannot save and borrow. ${ }^{9}$ Thus, her consumption, $c_{N, t}$, must be financed only by her net labor income, $(1-\tau) w_{t} l_{N, t}$. Note that the non-Ricardian household receives the economy wide wage, $w_{t}$, from her labor supply, $l_{N, t}$, and is subject to the same tax rate as the that of the Ricardian household. The budget constraint of the non-Ricardian household is:

\footnotetext{
${ }^{8}$ This of course assumes that the discount factor $\beta$ is a fixed structural parameter.

${ }^{9}$ Non-Ricardian households are modeled in different ways in the literature. In this paper, these are the rule-of-thumb consumers.
} 


$$
c_{N, t}=(1-\tau) w_{t} l_{N, t}
$$

The first order condition for the non-Ricardian household's problem, after substituting out for the Lagrange multiplier, can be written as:

$$
\psi l_{N, t}^{\vartheta}=(1-\tau) w_{t}
$$

\subsubsection{Final Good Producer}

A perfectly competitive final good producer aggregates the intermediate goods to produce the final good as:

$$
y_{t}=\left(\int_{0}^{1} y_{j t}^{\frac{\theta-1}{\theta}} d j\right)^{\frac{\theta}{\theta-1}}
$$

where $\theta$ is the elasticity of substitution across goods. The final good producer maximizes profit, taking as given the intermediate goods prices $p_{j, t}$ and the final good price $p_{t}$ which results in the following input demand function:

$$
y_{j, t}=\left(\frac{p_{j, t}}{p_{t}}\right)^{-\theta} y_{t}
$$

The aggregate price level is

$$
p_{t}=\left(\int_{0}^{1} p_{j, t}^{1-\theta} d j\right)^{\frac{1}{1-\theta}}
$$

\subsubsection{Intermediate Good Producers}

\section{Production}

There is a continuum of intermediate good producers, indexed by $j$, each of which produces a differentiated good $y_{j, t}$ using labor supplied by households:

$$
y_{j, t}=l_{j, t}
$$


The real marginal cost is the cost associated with producing one unit of output. In the case of the production function in this paper that depends only on labor, it equals the real wage rate. Thus,

$$
\xi_{t}=w_{t}
$$

\section{Price Setting}

Each intermediate good producer sets the price of its differentiated good according to a Calvo (1983) scheme that allows for partial indexation to steady state inflation which is also the inflation target. The price setting mechanism is as follows: each firm cannot reoptimize its selling price unless it receives a random signal. The constant probability of receiving such a signal is $(1-\phi)$. Thus, firm $j$ sets its price, $p_{j, t}^{*}$, that maximizes the expected profit for $l$ periods. However, with probability $\phi$, the firm $j$ must charge the price that was in effect in the preceding period partially indexed to the steady state gross rate of inflation, $\pi$. Thus, with probability $\phi$, the price charged by firm $j$ is given by:

$$
p_{j, t}=\pi^{\omega} p_{j, t-1}
$$

where $\omega \in[0,1]$ is the degree of indexation. ${ }^{10}$ At time $t$, if firm $j$ receives the signal to re-optimize, it chooses price $p_{j, t}^{*}$ that maximizes its discounted expected real total profit over the interval during which its price remains fixed. The optimization problem for firm $j$ is:

$$
\max _{p_{j, t}^{*}} E_{t} \sum_{l=0}^{\infty}(\beta \phi)^{l} \lambda_{t+l} \Omega_{j, t+l} / p_{t+l}
$$

subject to the demand function

\footnotetext{
${ }^{10}$ The Calvo indexation scheme used in this paper follows Yun (1996) and Christensen and Dib (2008) in that indexation is with respect to the steady state inflation. The literature has also considered indexation to lagged inflation (e.g. Christiano et al. (2005), Smets and Wouters (2007)). Indexation to lagged inflation adds an additional state variable in the model and is computationally very expensive for a global solution. The main results of the paper are, however, not dependent on the particular choice of the indexation scheme as long as it is partial and not full.
} 


$$
y_{j, t}=\left(\frac{p_{j, t}}{p_{t}}\right)^{-\theta} y_{t}
$$

and where firm $j$ 's nominal profit is given by

$$
\Omega_{j, t+l}=\left[\pi^{\omega l} p_{j, t}^{*}-p_{t+l} \xi_{t+l}\right] y_{j, t+l}
$$

The first order condition is:

$$
\frac{p_{j, t}^{*}}{p_{t}}=\frac{\theta}{\theta-1} \frac{E_{t} \sum_{l=0}^{\infty}(\beta \phi)^{l} \lambda_{t+l} \xi_{t+l}\left(\pi^{\omega l}\right)^{-\theta} \pi_{t, t+l}^{\theta} y_{t+l}}{E_{t} \sum_{l=0}^{\infty}(\beta \phi)^{l} \lambda_{t+l}\left(\pi^{\omega l}\right)^{1-\theta} \pi_{t, t+l}^{-(1-\theta)} y_{t+l}}
$$

where,

$$
\pi_{t, t+l} \equiv \begin{cases}\prod_{i=1}^{l} \pi_{t+i} & l>0 \\ 1 & l=0\end{cases}
$$

In a symmetric equilibrium, all intermediate good producers set the same price. Dropping the subscript $j$ from the optimal re-set price and defining $\pi_{t}^{*} \equiv \frac{p_{t}^{*}}{p_{t}}$, I can re-write the first order condition compactly as:

$$
\theta g_{1, t}=(\theta-1) g_{2, t}
$$

where $g_{1, t}$ and $g_{2, t}$ are auxiliary variables defined recursively as:

$$
\begin{aligned}
& g_{1, t}=\lambda_{t} \xi_{t} y_{t}+\beta \phi E_{t}\left[\left(\frac{\pi^{\omega}}{\pi_{t+1}}\right)^{-\theta} g_{t+1}^{1}\right] \\
& g_{2, t}=\lambda_{t} \pi_{t}^{*} y_{t}+\beta \phi E_{t}\left[\left(\frac{\pi^{\omega}}{\pi_{t+1}}\right)^{1-\theta} \frac{\pi_{t}^{*}}{\pi_{t+1}^{*}} g_{t+1}^{2}\right]
\end{aligned}
$$

The equation that governs the evolution of aggregate price can be written as:

$$
1=\phi\left(\frac{\pi^{\omega}}{\pi_{t}}\right)^{1-\theta}+(1-\phi) \pi_{t}^{* 1-\theta}
$$




\subsubsection{Government}

\section{Monetary Authority}

The monetary authority sets the nominal interest rate according to a Taylor rule truncated at ZLB as:

$$
R_{t}=\max \left\{Z_{t}, 1\right\}
$$

where,

$$
\frac{Z_{t}}{R}=\left(\frac{R_{t-1}}{R}\right)^{\rho_{r}}\left[\left(\frac{\pi_{t}}{\pi}\right)^{\rho_{\pi}}\left(\frac{y_{t}}{y}\right)^{\rho_{y}}\right]^{1-\rho_{r}}
$$

where, the variables without a time index, $t$, denote the respective steady states. The variable $Z_{t}$ is the unconstrained nominal interest. The parameter $\rho_{r}$ determines interest rate smoothing, while $\rho_{\pi}$ and $\rho_{y}$ are the weights on inflation and output stabilization respectively.

While solving the model, following Garcia and Zangwill (1981), the truncated Taylor rule in (3.22) is re-specified as:

$$
\begin{aligned}
& R_{t}=Z_{t}+\max \left\{\mu_{t}, 0\right\}^{2} \\
& R_{t}=1+\max \left\{-\mu_{t}, 0\right\}^{2}
\end{aligned}
$$

where, $\mu_{t}$ is an auxiliary variable. Specifying the truncated Taylor rule in this manner allows the use of gradient-based nonlinear solvers and facilitates computation. To see how this formulation works, consider the case where the unconstrained Taylor rule in (3.23) prescribes a gross interest rate $Z_{t}>1$. Then, Equations (3.24) and (3.25) result in the following:

$$
R_{t}=Z_{t} \text { and } \mu_{t}=-\sqrt{R_{t}-1}<0
$$


If, on the other hand, $Z_{t} \leq 1$, the zero lower bound constraint is enforced as follows:

$$
R_{t}=1 \text { and } \mu_{t}=\sqrt{R_{t}-Z_{t}}>0
$$

\section{Fiscal Authority}

The fiscal authority enters time $t$ with an amount of nominal debt denoted by $B_{g, t-1}$ for which it pays the nominal interest rate $R_{t-1}$. The fiscal authority also spends a real amount $g_{t}$. Part of the financing of these two government expenditure items is through the aggregate tax revenue, $\tau w_{t} l_{t}$, collected from the Ricardian and the non-Ricardian households. The fiscal authority can also borrow from the Ricardian households by issuing nominal bonds, $B_{g, t}$. The budget constraint of the fiscal authority in real terms is then given by:

$$
g_{t}+b_{g, t-1} \frac{R_{t-1}}{\pi_{t}}=\tau w_{t} l_{t}+b_{g, t}
$$

where $b_{g, t} \equiv \frac{B_{g, t}}{P_{t}}$.

The fiscal surplus, $f_{t}$, is defined as the negative of the change in real government debt as: ${ }^{11}$

$$
f_{t} \equiv-\left(b_{g, t}-\frac{b_{g, t-1}}{\pi_{t}}\right)
$$

The fiscal surplus rule is given by:

$$
f_{t}-f=\rho_{\tau}\left(y_{t}-y\right)+\rho_{b}\left(b_{t}-b\right)
$$

where, the variables without time index, $t$, represent the respective steady states. The parameters $\rho_{\tau}$ and $\rho_{b}$ control the extent to which the fiscal surplus endogenously responds to deviations of output and real debt from their respective steady states. ${ }^{12}$ In the remainder

\footnotetext{
${ }^{11}$ Following $\mathrm{Bi}$ and Kumhof (2011), the surplus defined in this way includes interest payments. An alternative approach is to define in terms of the primary surplus which excludes interest payments. In the context of the paper, this distinction is however trivial.

${ }^{12}$ The specification of the fiscal surplus rule is similar to the one in Bi and Kumhof (2011). Unlike their
} 
of this paper, I will refer to these two deviations as "output deviation" and "debt deviation" respectively. Specifying the fiscal rule in this manner delivers a mechanism in the model where the fiscal authority can stabilize the business cycle (output fluctuations) while ensuring fiscal sustainability (non-exploding debt).

While the fiscal surplus serves as the operational target, the fiscal instrument is taken to be government expenditure. That is, the fiscal authority endogenously adjusts the level of government expenditure that is necessary to achieve a given value of the fiscal surplus as pinned down by output and debt deviations from the fiscal surplus rule. To illustrate, suppose $\rho_{\tau}=1$ and $\rho_{b}=0$. When the output deviation is negative (due to adverse preference shocks), the fiscal surplus rule prescribes a reduction in fiscal surplus or, stated differently, an increase in fiscal deficits which is operationalized by increasing government expenditure. The increase in government expenditure, in turn, increases aggregate demand and helps stabilize the economy especially when the nominal interest rate is constrained at ZLB. Thus, in this paper, the primary channel through which fiscal policy affects the economy is via the demand side of the economy. ${ }^{13}$

\subsubsection{Aggregation and Market Clearing Conditions}

In equilibrium, aggregate demand of labor by intermediate good producers must equal their aggregate supply by Ricardian and non-Ricardian households. Thus,

$$
\int l_{j, t} d j=l_{t}=(1-\nu) l_{R, t}+\nu l_{N, t}
$$

Using the production function (3.11) and the demand (3.9) for each intermediate good, I can write:

rule which is specified in terms of ratios, the fiscal rule in this paper is specified in terms of levels. This makes the model more stable with GHH preferences. For a discussion on how GHH preferences fail to generate output and inflation persistence, see Dey (2014).

${ }^{13}$ This need not be always the case. For instance, if the fiscal instrument is taken to be the tax rate on labor income, then fiscal policy affects the economy via the supply side. 


$$
l_{j t}=\left(\frac{p_{j t}}{p_{t}}\right)^{-\theta} y_{t}
$$

This can be aggregated to yield an aggregate supply equation as follows:

$$
l_{t}=s_{t} y_{t} \Leftrightarrow y_{t}=\frac{l_{t}}{s_{t}}
$$

where, $s_{t} \equiv \int_{0}^{1}\left(\frac{p_{j t}}{p_{t}}\right)^{-\theta} d j$ captures the degree of price dispersion. Price dispersion evolves as:

$$
s_{t}=\phi\left(\frac{\pi^{\omega}}{\pi_{t}}\right)^{-\theta} s_{t-1}+(1-\phi) \pi_{t}^{*-\theta}
$$

Equations (3.31) and (3.32) highlight the effects of trend inflation $(\pi)$ on aggregate output through its effects on price dispersion. More precisely, Equation (3.31) shows that the effect of higher price dispersion, ceteris paribus, is to reduce aggregate supply of output and hence, aggregate output in equilibrium. And from Equation (3.32), one can see that the dynamics of price dispersion is dependent on trend inflation. More precisely, with less than full indexation $(\omega<1)$, an increase in trend inflation increases price dispersion. This is the welfare cost of inflation that the model primarily captures and is the cost against which the benefit of reduced incidences of ZLB episodes associated with a higher inflation target is compared. ${ }^{14}$

Aggregate demand in the economy comprises of consumption and government expenditure and is given by:

$$
y_{t}=c_{t}+g_{t}
$$

where $c_{t}$ denotes aggregate consumption and is given by:

\footnotetext{
${ }^{14}$ The literature has discussed other costs of inflation which are not captured in the model. These include distortions in cash holdings, distortions of the tax system, difficulties in financial planning etc. See Mishkin (2011) for an elaborate discussion.
} 


$$
c_{t}=(1-\nu) c_{R, t}+\nu c_{N, t}
$$

Finally, the market for nominal bonds clears as follows:

$$
B_{g, t}=(1-\nu) B_{t}
$$

\subsection{Calibration}

\subsubsection{Parameter Values}

The model is calibrated for quarterly frequency. The discount factor, $\beta$, is set as 0.99 to match the average real interest rate during the sample period. The share of non-Ricardian households is taken to be $11.84 \%$ which is the value estimated for the U.K. in Bhattarai and Trzeciakiewicz (2013). The risk aversion parameter $\gamma$ in the utility function is taken to be $1 .{ }^{15}$ The inverse Frisch elasticity of labor supply is 0.5 . The coefficient before leisure, $\psi$, is calibrated as 1.22 to ensure that one-third of the aggregate household's time is spent working in the steady state.

The parameter $\theta$ that measures the degree of monopoly power of intermediate good producers is set equal to 8 , implying a steady-state price markup of around $14 \%$. Regarding the Calvo pricing parameters, I pick values close to the estimates provided in Benati (2008) and Cogley et al. (2011) for the U.K. during the inflation targeting period. The Calvo probability parameter, $\phi$, is taken to be 0.7 . For the indexation parameter, $\omega$, I pick a value of 0.1. Such a choice which implies an almost lack of indexation is a key aspect of the inflation targeting regime in the U.K. as emphasized in Benati (2008).

\footnotetext{
${ }^{15}$ This is the same parameter value used in Fernandez-Villaverde et al. (2012). For a given choice of parameters in the fiscal and monetary rules, the policy function iteration routines are a bit sensitive to the choice of $\gamma$. For instance, when I choose $\gamma<1$ and given the baseline fiscal and monetary parameters, those routines would not converge. This is because smaller values of $\gamma$ make Ricardian households more sensitive to real interest movements. This makes their consumption demand to drop even more sharply at or near ZLB which, in the absence of a stronger fiscal stabilization, makes the policy function iteration routines to explode.
} 
Coming to the parameters in the Taylor rule, the gross steady state quarterly inflation is 1.005 thereby implying a net annual inflation target of $2 \%$ which is the current target adopted in the U.K. Interest smoothing parameter $\rho_{r}$ is chosen as 0.7 and the coefficient before output $\rho_{y}$ is 0.4 . I choose the coefficient before inflation $\rho_{\pi}$ as 3 . The parameter values in the Taylor rule are broadly in line with the estimates in Cogley et al. (2011). I choose a slightly larger value for $\rho_{\pi}$ because that is necessary to ensure determinacy for higher inflation targets. ${ }^{16}$ Also, I choose the coefficient before output to be a bit larger than Cogley et al. (2011) to generate a more reasonable probability of zero lower bound episodes without having to rely on really big shocks for the same.

To calibrate the fiscal parameters I proceed as follows: I choose the steady state government debt-to-GDP ratio and government expenditure-to-GDP ratio as $52.77 \%$ and $16.54 \%$ respectively. These are the average values during the sample period 2000-2013 for which quarterly government debt-to-GDP ratio data is available at Eurostat. By evaluating the government budget constraint in the steady state, these choices result in an average tax rate $\tau$ which equals $19.5 \%$. To the best of my knowledge, there is no study to guide the choice of parameter values for the coefficients in the fiscal surplus rule. In the baseline specification, the coefficient before output $\rho_{\tau}$ is set as 0.3 and that before debt $\rho_{b}$ as 0.5 . In the model, the coefficient $\rho_{\tau}$ controls the strength of fiscal response to stabilize output fluctuations. As highlighted later in Section 3.6, this response is weak when $\rho_{\tau}=0.3$. I, therefore, take this choice as the baseline against which the implications of much stronger fiscal responses are evaluated by choosing larger values of $\rho_{\tau}$. Choosing a positive value for the coefficient before debt gap, $\rho_{b}$, stabilizes government debt and ensures that the government is solvent.

The AR(1) coefficient in the law of motion of preference shocks is set as 0.8. The

\footnotetext{
${ }^{16}$ This is consistent with the result in Ascari and Ropele (2009) who show that a stronger coefficient on inflation is required to ensure determinacy with higher trend inflation. By choosing $\rho_{\pi}=3$, I can then use the same parameter value for different inflation targets thereby yielding a consistent scheme for model comparison.
} 
standard deviation of the shocks is calibrated as 0.023 . With this, the model when simulated under a $2 \%$ inflation target results in a $2.87 \%$ probability of hitting the zero lower bound, or once every about 9 years. ${ }^{17}$ The complete set of parameter values used in the baseline specification is provided in Table 3.1. The parameter values in alternative specifications of the model are in Table 3.2 .

\subsubsection{Discussion on Equilibrium}

As with all models that feature both a monetary authority and a fiscal authority, it is important to characterize the nature of equilibrium, whether it is monetary-led or fiscally-led (Leeper (1991)). In a monetary-led equilibrium, (a) the Taylor principle is satisfied so that the nominal rate responds more than one-to-one to movements in inflation, and (b) fiscal policy stabilizes government debt. This is also referred to as an active monetary and passive fiscal regime. In a fiscally-led equilibrium, on the other hand, monetary policy is passive while fiscal policy is active. As pointed out in Leeper (1991), for this class of models to be determinate, both monetary and fiscal policies cannot be active at the same time.

Against the backdrop of the theoretical underpinnings above, the analysis in this paper is confined to a monetary-led equilibrium. Accordingly, the parameters in the monetary and the fiscal rules are chosen so as to be consistent with a monetary-led equilibrium. Thus, the choice of the coefficient before inflation in the Taylor rule $\rho_{\pi}=3>1$ implies that monetary policy is active. Fiscal policy is set to be passive by choosing the coefficient before debt in the fiscal surplus rule $\rho_{b}=0.5>0$. Given these parameter values, the coefficient before output in the fiscal rule, $\rho_{\tau}$, is restricted to yield a determinate solution. ${ }^{18}$

\footnotetext{
${ }^{17}$ The shock size calibrated is much larger than the ones estimated in the literature. Two comments are in order here. First, it is plausible that such big shock sizes, which will not be picked up by studies that report "average" estimates during the Great Moderation period, are relevant in the context of the recent crisis episodes. Second, this paper focuses on the role of monetary and fiscal policies during ZLB episodes. Therefore, it is more important to generate ZLB spells that are quantitatively significant by appropriately calibrating the shock size rather than to focus on which shocks and with sizes that are empirically reasonable can result in those spells. The latter is a slightly different research question. See, for instance Amano and Shukayev (2009).

${ }^{18}$ Since the model is solved globally, the relevant determinacy criterion is global determinacy and not local determinacy. Local criteria like Blanchard and Kahn conditions are not sufficient to establish global determinacy. While global determinacy conditions have been developed for small stylized models (for instance,
} 
The choice of the equilibrium, whether monetary-led or fiscally-led, should ideally reflect the actual experience of the U.K. economy during the inflation targeting period. While estimates of Taylor rule coefficients from previous studies (e.g. Cogley et al. (2011)) and the current fiscal mandate that stresses on meeting statutory targets for fiscal deficits and government debt suggest a monetary-led equilibrium, fiscal policy has been arguably much more "active" during the crisis years (Aizenman and Pasricha (2013)). In other words, it is not very clear from existing work whether a monetary-led equilibrium best describes the entire 1992-2013 period, even though it seems be the case for majority of the times. Given this ambiguity, an ideal modeling choice for this paper would have been a regime switching model that switches between monetary-led and fiscally-led equilibria (Bianchi and Melosi (2013)). With this caveat in mind, this paper, nonetheless, makes an attempt to answer the questions set out in the paper in the specific case of a monetary-led equilibrium.

\subsection{Solution Method}

The complete set of equations that describe the equilibrium conditions among the model's endogenous variables is given in Appendix 1.1 This is a system of 21 equations in 21 endogenous variables. The model features three endogenous states: government debt $\left(b_{g, t-1}\right)$, nominal interest rate $\left(R_{t-1}\right)$, and price dispersion $\left(s_{t-1}\right)$. The exogenous state in the model is the preference shock $\left(d_{t}\right)$.

The zero lower bound constraint poses a nonlinearity which, under standard calibration of the model parameters, also happens to be far away from the steady states. This implies that standard perturbation methods, irrespective of the order of approximation, do not provide a satisfactory model solution. The goal in this paper is to solve the model in a fully stochastic setting and where agents are aware of the occasionally binding constraint associated with ZLB. For this, I deploy a global solution method, in particular the policy Benhabib et al. (2002)), extending those to the model used in this paper is not straightforward. 
function iteration algorithm of Coleman (1990). ${ }^{19}$ Solving the model globally in this manner allows me to explore nonlinear global dynamics and expectational effects associated with the ZLB constraint. ${ }^{20}$

The policy function iteration algorithm is implemented as follows:

1. Discretize States: The states are discretized around their steady states. Since price dispersion and the nominal interest rate cannot take values less than one, I choose a lower bound of 1 for these. The rest of the bounds are chosen iteratively such that they cover the state spaces when the model is simulated. The state space for the preference shock is discretized following Tauchen's method with lower and upper bounds taken to be 3.5 times the standard deviation of the shocks.

2. Initial Guess: For each node, start with an initial guess for these 3 policy rules: $\pi_{t}$, $g_{1, t}$, and $\lambda_{t}$. For the initial guess, I solve the model with an unconstrained Taylor rule using the first order perturbation solution in Dynare and use the policy rule as the initial guess.

3. Recursive Solution: Given these 3 policy rules, solve for the rest of the policy rules using the model's nonlinear equations except the ones that feature expectational terms.

4. Compute Expectations: Using current policy rules, compute variables in the next period interpolating wherever necessary. Then, compute the expectational terms that enter Equations 1.1.2, 1.1.8, and 1.1.9 using the conditional transition probabilities from Tauchen's method.

5. Update Policy Rule: Evaluate the complete set of nonlinear equations and update the policy guesses for $\pi_{t}, g_{1, t}$, and $\lambda_{t}$ via a root finding algorithm.

6. Iterate: Goto Step 3 and iterate until convergence. ${ }^{21}$

\footnotetext{
${ }^{19}$ I use the routines in Richter et al. (2013) for the policy function iteration.

${ }^{20}$ I illustrate in Appendix 1.2 that such effects are significant.

${ }^{21}$ For Step 3, wherever possible, I solve for the rest of the equations analytically given the 3 policy guesses.
} 


\subsection{Results}

This section presents three sets of results. First, I present the global solution with the occasionally binding ZLB constraint. Second, I compare and contrast two different policy interventions that help mitigate the effects of ZLB: (a) higher inflation target and (b) countercyclical fiscal policy. Third, I discuss how the initial level of government debt matters for countercyclical fiscal policy during ZLB episodes.

\subsubsection{Global Dynamics and Expectational Effects}

In this section, I discuss how the occasionally binding ZLB constraint results in nonlinearities in the dynamics of model variables. I begin with a general analysis of the transmission mechanism of preference shocks in the model. Thereafter, I extend the analysis to understand how the ZLB constraint affects the transmission mechanism giving rise to expectational effects and nonlinear global dynamics.

In the model, preference shocks have the effect of changing the effective discount rate for both Ricardian and non-Ricardian households. When hit by adverse preference shocks, Ricardian households reduce current consumption and save more. This has the effect of reducing aggregate consumption which, in turn, reduces aggregate demand. With sticky prices, the decline in aggregate demand works to reduce output in equilibrium. Furthermore, the decline in labor demand due to a decline in output results in lower wages, marginal costs, and hence inflation. In the case of non-Ricardian households, their labor supply and consumption decisions are not directly affected by preference shocks due the assumption of GHH utility in the model. ${ }^{22}$ Nonetheless, non-Ricardian labor and consumption decline in response to the general equilibrium effects of a decline in economy-wide output and wages which contributes to the already declining aggregate demand. The monetary authority re-

An analytical solution is, however, not available for all equations in which case I use a numerical nonlinear solver. In particular, I use the solver in Morini and Porcelli (2012). In Step 4, I use a linear interpolation scheme. The convergence tolerance is taken to be $10^{-5}$.

${ }^{22}$ With GHH utility functions, labor supply decision of households depends only on wage rate. And for a non-Ricardian household, consumption is only a function of her labor income. 
sponds to the decline in output and inflation by cutting the nominal interest rate. If the adverse preference shocks are big enough, the drop in the nominal rate can hit the ZLB constraint. Once the constraint binds, further monetary stimulus via nominal rate cuts is ruled out to stabilize output and inflation. This is the basic reason why the ZLB constraint is destabilizing in the model.

Under rational expectations and in a fully stochastic environment, agents take into account expectations of the future evolution of model variables while making their decisions. The ZLB constraint, by shaping these expectations, affects current decisions of agents and introduces an additional dimension of nonlinearity in the dynamics of model variables. In particular, expectations of future real interest rates are crucial in the model. When the nominal rate is at or near ZLB due to big adverse preference shocks, agents expect the real interest rate to increase because they are aware that inflation will decline. In this environment, Ricardian households further postpone current consumption in favor of savings, thereby reinforcing the collapse in aggregate demand. Such expectational effects, therefore, make the ZLB constraint even more destabilizing. Furthermore, they imply that these effects of the ZLB constraint should show up even before the nominal rate hits zero.

Of course, a nonlinear solution method is required to capture these global dynamics and expectational effects. ${ }^{23}$ The global solution method deployed in this paper is exactly designed for that. Figure 3.2 plots the policy rules of key model variables across the grids of preference shocks used in the global solution. ${ }^{24}$ These are from the baseline specification of the model. Shaded highlights regions where the ZLB constraint is binding. As the figure shows, the ZLB constraint is binding for big adverse preference shocks. The kink in the policy rule of the nominal interest rate at ZLB translates into kinks in the policy rules of the rest of the variables. Output, aggregate consumption, and inflation decline sharply in

\footnotetext{
${ }^{23}$ A linearized solution does not capture any of these effects and hence, understates the destabilizing effects of the ZLB constraint. This is established more concretely in Figure 10 where I compare the linearized solution method of Coibion et al. (2011) with the global solution used in this paper.

${ }^{24}$ All other state variables are fixed at grid points at or closest to steady states.
} 
the shaded region where ZLB binds. This is consistent with destabilizing nature of the ZLB constraint as discussed above. Furthermore, the curvature in these policy rules begins to show up even before ZLB binds. This corroborates the earlier point on the expectational effects associated with the ZLB constraint.

The ZLB constraint has fiscal implications as well. The policy rule of government borrowing shows that the government borrows more (less) with adverse (favorable) preference shocks. When hit by adverse preference shocks, Ricardian households forgo current consumption and save. In general equilibrium, these household savings equal government borrowing. Also, the policy rule of government borrowing exhibits a sharp upward kink in and around the shaded region where ZLB binds. This partly reflects the sharp increase in savings by Ricardian households around this region. The sharp rise in government borrowing is also due to the fact that the government's real interest payments on its past debt increase sharply thereby requiring the government to borrow even more to finance those payments. In the baseline specification, the fiscal response to stabilize output fluctuations is weak. The policy rule of government expenditure, that closely mirrors that of output, is consistent with the weak fiscal response.

In sum, the policy rules from the baseline specification, with a $2 \%$ inflation target and a weak fiscal response to output fluctuations, highlight that the ZLB constraint binds for big adverse preference shocks with destabilizing effects on macroeconomic variables. As discussed earlier in the calibration section, the ZLB constraint binds once in about every 9 years under the baseline specification subjecting the economy to those destabilizing effects. In the next section, I discuss two alternative policy interventions to maneuver the ZLB constraint and how they help stabilize the economy. 


\subsubsection{Maneuvering the Zero Lower Bound}

Policy Experiments: I discuss two policy interventions to maneuver the ZLB constraint. First, the monetary authority raises the inflation target to $4 \% .{ }^{25}$ Second, the fiscal authority pursues a countercyclical fiscal policy. I label these as Model A and Model B respectively. To illustrate how these policy interventions maneuver the ZLB constraint and help stabilize the economy, I compare the dynamics of model variables across these policy counterfactuals and the baseline specification during a ZLB episode. ${ }^{26}$ The ZLB episode is simulated by hitting the economy, which is initially at its steady state, with adverse preference shocks of size 2 s.d. in the first 4 periods. $^{27}$

Figure 3.3 presents the results. The solid blue line in the figure shows the model dynamics under the baseline specification. During the simulated episode, the ZLB constraint binds at 2 quarters after the impact of the initial shock and continues so for the next 8 quarters. Output, aggregate consumption, and inflation decline sharply consistent with the policy rules described earlier. Given the weak fiscal response in the baseline specification, government expenditure declines. On the other hand, government borrowing increases sharply which in part reflects the increase in savings by Ricardian households at ZLB. The sharp increase in government borrowing is also due to the increase in real interest payments on its past obligations and the decline in tax revenues at ZLB (Figure 3.4). ${ }^{28}$ I now discuss these model dynamics under the baseline specification with those under the two policy counterfactuals.

Higher Inflation Target: The dotted black lines in Figure 3.3 show the results when the

\footnotetext{
${ }^{25} \mathrm{~A} 4 \%$ inflation target is the one emphasized in Blanchard et al. (2010) and I use that to illustrate the effects of a higher inflation target.

${ }^{26}$ Because these policy counterfactuals are conducted using a structural model, they are consistent with the Lucas Critique. Of course, this assumes that the structural parameters in the DSGE model are truly structural. There are many papers in the literature that rigorously evaluate such an assumption, for instance Fernndez-Villaverde and Rubio-Ramrez (2007). The literature has, in particular, focused on the Calvo probability parameter. However, this is more of a serious issue for really high levels of inflation.

${ }^{27}$ Simulating the ZLB episode in this manner via a sequence of adverse shocks rather than one huge shock ensures that the simulation stays within the state grids used in the global solution.

${ }^{28}$ The former is due to the fact that real rates increase at ZLB and the latter is attributed to the decline in wages and labor.
} 
inflation target is raised to $4 \%$. With the higher inflation target, the Fisher relationship implies that the steady state (long run) nominal interest rate is also higher. Since the initial states in the simulated ZLB episode are taken to be the steady states, the monetary authority starts off with a higher nominal rate at the beginning of the ZLB episode. More specifically, this gives the monetary authority an additional "room to maneuver" of about $2 \%(8 \%$ minus $6 \%)$ in net annual terms. ${ }^{29}$ And as the dotted black lines show, the monetary authority indeed uses this extra room to further ease monetary policy in response to the adverse shocks. The additional monetary stimulus then ensures that the drops in output, aggregate consumption, and inflation are all smaller with respect to the baseline specification (thick blue lines). ${ }^{30}$ The improved macroeconomic stabilization, in turn, steers the nominal rate away from ZLB reducing the duration of the ZLB spell. With regard to the fiscal variables, tax revenues improve which help to reduce government borrowing compared with the baseline specification (Figure 3.4). All in all, these findings lend support to the point in Blanchard et al. (2010) who advocate a higher inflation target to maneuver the ZLB constraint during a deep recession.

Countercyclical Fiscal Policy: I now turn to countercyclical fiscal policy. Fiscal policy is specified to be countercyclical by choosing a higher coefficient on output deviations, $\rho_{\tau}$, in the fiscal surplus rule. For the purpose of comparability, this parameter value is chosen to be 1.4 such that the drop in the nominal rate during the simulated episode is roughly the same as was in the previous exercise with the higher inflation target of $4 \%$. In this manner, the extent to which ZLB presents a constraint during the simulated episode is roughly the same across Model A and Model B.

The dotted red lines in Figure 3.3 show the results. The most obvious difference with

\footnotetext{
${ }^{29}$ Given that most rate cuts are in terms of basis points, such a margin of $2 \%$ or 200 basis points is quite significant.

${ }^{30}$ These improvements are quantitatively significant. For instance, while output decline bottoms out at about $-13 \%$ in the baseline specification, it is only about $-8 \%$ with the higher inflation target. In addition, there is some improvement on the recovery horizon as well. However, that is minor and is most likely due to the fact that the model in this paper abstracts away from endogenous propagation mechanisms like habit formation and investment adjustment costs that are considered in medium scale DSGE models.
} 
the countercyclical fiscal policy is that government expenditure now increases in response to adverse shocks while it decreases in the other two specifications. The increase in government expenditure works to increase aggregate demand which, under sticky prices, works to increase equilibrium output, labor, wages, and inflation. The expansionary fiscal response, thus, wrests the drops in output and inflation and results in a much improved macroeconomic scenario with respect to the baseline specification. This, in turn, steers the nominal rate away from ZLB in the same manner as was with the higher inflation target. In the monetary-led equilibrium that is the focus in this paper, the fiscal surplus rule also stabilizes government debt. This, along with the fact that tax revenues improve with macroeconomic stabilization (Figure 3.4), explains why government borrowing is much smaller than the baseline specification despite having to finance the expansionary government expenditure.

The upshot of the foregoing analysis is that as much as a higher inflation target helps to stabilize business cycle fluctuations in the presence of the ZLB constraint, a carefully calibrated fiscal response presents as an alternative policy choice to achieve the same objective. Furthermore, in a monetary-led equilibrium, a countercyclical fiscal policy does not pose significant fiscal challenges for the government.

Higher Inflation Target vs. Countercyclical Fiscal Policy: I now compare the two policy interventions from the perspective of business cycle stabilization, welfare, and government financing.

Business Cycle Stabilization: Table 3.3(b) shows the standard deviation of key macroeconomic variables from model simulations across different specifications. ${ }^{31}$ The table shows a clear decline in the volatility of macroeconomic variables when either the inflation target is raised or when fiscal policy is countercyclical. These two policy interventions also result in a much smaller probability and duration of ZLB episodes (Table 3.4). This corroborates the stabilizing role of these policy interventions in the presence of the ZLB constraint. Be-

\footnotetext{
${ }^{31}$ These are based on model simulations with a simulation length of 50,000.
} 
tween the two policies, the countercyclical fiscal policy fares better than the higher inflation target as evident from the smaller volatilities in the former vis-a-vis the latter. Because the strength of the countercyclical fiscal response is picked in a rather adhoc fashion, these results should not be construed as establishing a universal superiority of countercyclical fiscal policy over higher inflation targets in stabilizing business cycle fluctuations (second moments) when confronted with the ZLB constraint. Nonetheless, they do highlight the point that a carefully calibrated fiscal response presents an alternative policy choice to higher inflation targets in this regard.

The analysis above suggests that fiscal policy has strong stabilizing effects on the model economy. Part of the reason lies in the calibration of the fiscal surplus rule which generates strong countercyclical movements in government expenditure. Part of the reason also lies in model features. The real effects of an increase in government expenditure depend on two opposite forces. The increase in aggregate demand works to increase equilibrium output. On the other hand, crowding-out effects on consumption pull output in the opposite direction. ${ }^{32}$ Crowding-out effects operate via two mechanisms in the model. First, monetary tightening in response to the expansionary fiscal policy crowds out Ricardian consumption. Second, the fiscal surplus rule implies that the government will adjust by reducing government borrowing. ${ }^{33}$ Since Ricardian households hold government debt, this imposes a negative wealth effect which then reduces their current consumption demand. Because of the assumption of GHH utility functions, such wealth effects do not apply to labor supply decisions of Ricardian households. If their labor supply were to depend on wealth effects, an expansionary fiscal policy would have resulted in an increase in labor supply thereby dampening the positive effects on wages. Thus, with GHH preferences, an expansionary fiscal policy has a much more pronounced positive effect on wages. This undoes some of the crowding out effects on Ricardian consumption. The presence of non-Ricardian house-

\footnotetext{
${ }^{32}$ Note that the model in this paper does not feature investment so that crowding-out effects only apply to consumption.

${ }^{33}$ Note that the tax rate is taken to be constant in this paper so that fiscal adjustment is via a reduction in government borrowing.
} 
holds in the model also contributes to strong fiscal effects. Unlike Ricardian households, non-Ricardian consumption demand is not subject to negative wealth effects. And their consumption demand simply responds positively to the increase in economy-wide wages and labor brought about by expansionary fiscal policy.

Welfare: The preceding analysis only looks at stabilizing business cycle fluctuations or second moments. I now compare welfare across the two policy interventions - an exercise that takes into account both first and second moment effects. The distinction is not trivial because a higher inflation target increases steady state price dispersion in the model. This, in turn, reduces steady state output and consumption which then works to reduce welfare. ${ }^{34}$ Such first moment effects are absent under the countercyclical fiscal policy. Figure (3.5) shows the distribution of price dispersion in relation to different inflation targets and Table 3.3(a) shows the means of the macroeconomic variables from model simulations. These results confirm the observations. The key model feature that drives these results is partial indexation in the Calvo pricing scheme. As the figure and the table further confirm, such effects disappear with full indexation (Model C).

Formally, I compute the unconditional welfare (i.e. present value of lifetime utility) of Ricardian and non-Ricardian households. ${ }^{35}$ For this, I simulate a long time series of the state variables of length 50,000 and then take the average of the value functions corresponding to these states for each type of household. Table 3.5 and Figure 3.6 present the results which show that the unconditional welfare under the higher inflation target (Model A) is lower than that under the countercyclical fiscal policy (Model B) for both Ricardian and nonRicardian households. However, with full indexation (Model C), the unconditional welfare under the higher inflation target improves. This illustrates the first moment effects of higher inflation target under partial indexation as discussed above. From a welfare perspective,

\footnotetext{
${ }^{34}$ By the same token, steady state labor also declines which then implies an increase in in steady state leisure. This works to increase welfare. But the effects on consumption dominate for overall welfare.

${ }^{35}$ Alternatively, one could also address welfare in terms of consumption equivalents. This is particularly relevant for comparing the magnitude of welfare gain or loss. Since the focus of this section is more on the sign of the welfare change rather than the magnitude, I analyze welfare in terms of lifetime utility.
} 
the main result here is that countercyclical fiscal policy is better than higher inflation target.

With respect to the baseline specification, the unconditional welfare under the countercyclical fiscal policy is, however, smaller for both Ricardian and non-Ricardian households thereby implying a welfare loss in an unconditional sense. While the earlier results from the specific ZLB episode suggest that countercyclical fiscal policy should be welfare improving (vis-a-vis the baseline), Table 3.5 shows that this need not be the case in an unconditional sense. To investigate further, I compare conditional welfare - welfare conditional on a given state. Figure 3.7 shows the difference in the conditional welfare of the Ricardian and nonRicardian households under the countercyclical fiscal policy (Model B) and the baseline model across different grid points of the preference shock. ${ }^{36}$ A positive (negative) value indicates a welfare gain (loss). As the figure shows, with respect to the baseline specification, Ricardian households are worse off under the countercyclical fiscal policy across all states of the preference shock. ${ }^{37}$ This is not surprising given that Ricardians are subject to crowding out effects as discussed earlier. For the non-Ricardian households, the result, however, is mixed. For adverse shocks, where the ZLB is likely to bind, countercyclical fiscal policy is welfare improving with respect to the baseline specification. However, this is not the case for favorable shocks. The result here, therefore, suggests that countercyclical fiscal policy, as a macroeconomic stabilization tool, is particularly valuable to Ricardians during periods of a deep recession associated with a binding ZLB constraint.

As mentioned above, the key model feature that discriminates the two policy interventions from a welfare standpoint is partial indexation in the Calvo pricing scheme. Because partial indexation has been established as a robust empirical feature not only for the U.K. and but also other advanced economies like the U.S., the difference in welfare consequences

\footnotetext{
${ }^{36}$ All other state variables are fixed at grid points at or closest to steady states.

${ }^{37}$ Figure 3.7 also shows the conditional welfare difference between the higher inflation target and the baseline specification. The welfare difference is all negative thereby implying a welfare loss with respect to the baseline. The welfare difference is also below that under the countercyclical fiscal policy which is in agreement with the result from the unconditional welfare exercise.
} 
across the two policy interventions is a robust result. ${ }^{38}$ In other words, while a higher inflation target has to contend with the adverse welfare consequences coming from first moment effects, it is not the case with countercyclical fiscal policy. This weakens the case for raising the inflation target to mitigate the effects of ZLB when countercyclical fiscal tools are available.

Government Financing: The final metric I use to compare the two policy interventions is from the perspective of government financing. In particular, I evaluate whether the countercyclical fiscal policy results in significant fiscal challenges for the government. For that, I compute the maximum government debt and fiscal deficit as a percentage of GDP from model simulations. As Table 3.6 shows, these fiscal numbers are admittedly higher under the countercyclical policy than the higher inflation target. However, the differences are minor. For instance, the maximum debt-to-GDP ratio is $59.6 \%$ under the countercyclical fiscal policy while it is $57.9 \%$ under the higher inflation target.

One reason why countercyclical fiscal policy does not result in high government debt and fiscal deficit numbers in the model is because by stabilizing the economy, countercyclical fiscal policy also results in improved tax revenues thereby easing the government budget constraint (Figure 3.4) ${ }^{39}$ Another reason is that the equilibrium considered in this paper is monetary-led, so that government debt is stabilized in the model. How much of these results change in a fiscally-led equilibrium is an important question which I leave for future research.

In conclusion, this section underscores the point that as much as a higher inflation target stabilizes business cycle fluctuations in the presence of the ZLB constraint, a carefully calibrated countercyclical fiscal policy is an alternative policy choice to meet the same objective. From a welfare perspective, a countercyclical fiscal policy is better than a higher inflation

\footnotetext{
${ }^{38}$ For the estimates of indexation in the U.K., see for instance Benati (2008) and for the U.S., see for instance Smets and Wouters (2007). In the case of the U.S., full indexation is also in conflict with the micro level evidence on price setting (Bils and Klenow (2004)).

${ }^{39}$ If for instance, the proportional tax is replaced by lump sum taxes, this will require the government to borrow more during ZLB episodes raising government debt and fiscal deficit numbers.
} 
target, because the latter reduces the long run output and consumption while the former is neutral in the long run. Furthermore, in a monetary-led equilibrium, countercyclical fiscal policy does not pose significant fiscal challenges for the government.

\subsubsection{Does the Initial Level of Government Debt Matter?}

So far, the upshot is that a countercyclical fiscal policy helps in mitigating the effects of the ZLB constraint thereby resulting in improved macroeconomic performance. This section evaluates how the initial level of government debt matters for the efficacy of countercyclical fiscal policy, particularly in the context of the ZLB constraint. For that, I deploy a similar event study as done earlier. In particular, I simulate ZLB episodes from different levels of initial government debt: low, steady state, and high. ${ }^{40}$ And then, I evaluate the dynamics of model variables in the simulated episodes under the countercyclical fiscal rule. Because the countercyclical fiscal rule steers the nominal rate away from ZLB in the earlier exercise (Figure 3.3), I choose a bigger shock size of 3 s.d. in this exercise. Figure 3.8 presents the results.

The stabilizing role of countercyclical fiscal policy stems from an increase in government expenditure during the ZLB episode. Therefore, key to analyzing the role of initial government debt lies in how it affects the expansionary response of government expenditure. In general, because the fiscal authority can always borrow more to finance its expenses, a higher level of initial government debt does not necessarily mean that the government expenditure is lesser vis-a-vis the case where the initial government debt is low. However, in a monetary-led equilibrium that must stabilize government debt, it is the case. The response of government expenditure in Figure 3.8 confirms this: government expenditure, even though expansionary, is lower when the initial government debt is higher. This then implies that the boost in aggregate demand due to the countercyclical fiscal rule is smaller when the initial government debt is higher. Accordingly, the drop in equilibrium output is more when the initial government debt is higher, as the figure confirms. This result

\footnotetext{
${ }^{40}$ The low, steady state, and high levels of government debt roughly correspond to $50 \%, 53 \%$, and $57 \%$ of GDP respectively. While I can choose a really high debt level (which infact helps in drawing a sharper inference), I restrict myself to a high debt level that is actually realized in model simulations.
} 
suggests that a higher level of initial government debt limits the scope and the efficacy of countercyclical fiscal policy during ZLB episodes. The theoretical result in this paper is also consistent with the empirical findings in Ilzetzki et al. (2013) who report lower fiscal multipliers for those countries with high government debt.

The initial level of government debt also matters for inflation. And here, the assumption of GHH utility function is crucial. As discussed in detail earlier, households' labor supply decisions are independent of wealth effects under GHH utility function. In particular, a decrease in labor supply that would have arisen due to a higher government debt induced bigger (positive) wealth effects has no bearing in determining wages in the model. Therefore, a lower aggregate demand with the higher initial government debt, for reasons outlined above, means that wages and hence, marginal costs also decline much more. ${ }^{41}$ This results in inflation declining more when the initial government debt is higher. The bigger drops in inflation and output (as discussed above) then mean that the nominal rate also declines much more when the initial level of government debt is higher. As a result, a higher level of government debt also increases the duration of the ZLB spell in the model (Figure 3.8).

With regard to consumption, the effects of a higher initial government debt are somewhat nuanced in the model. Ricardian consumption is subject to bigger (positive) wealth effects when the initial government debt is high. Thus, as Figure 3.9 shows, Ricardian consumption initially declines much less with the higher initial government debt. However, the general equilibrium effects of a bigger drop in wages and labor, due to the limited fiscal expansion on count of the higher government debt, offset some of these. Because such wealth effects do not apply to non-Ricardian households, the corresponding effects on their consumption are via wages and labor movements in the model. Accordingly, a higher government debt unambiguously implies that non-Ricardian consumption drops more in the simulated ZLB

\footnotetext{
${ }^{41}$ In terms of wealth effects, the polar opposite case is the type of utility function considered in King et al. (1988). Under this utility function, labor supply effects dominate labor demand effects so that wages decline much less with a higher level of government debt. Accordingly, the effects of a higher level of initial government debt on inflation are the opposite to the ones shown in Figure 3.8.
} 
episode. Due to the larger share of Ricardians in the model, Ricardian consumption response weighs more for the dynamics of aggregate consumption (Figure 3.8). But the important takeaway point in this exercise is that a higher level of initial government debt, by limiting the scope of expansionary fiscal response, adversely affects the non-Ricardians during ZLB episodes.

\subsection{Conclusion}

In the light of policy rates in most advanced economies now at or near ZLB, a recent monetary policy proposal is that central banks should pursue a higher inflation target that would give them more "room-to-manoeuvre" during deep recessions (Blanchard et al. (2010)). This paper evaluates the efficacy of such a proposal with an emphasis on the role of countercyclical fiscal policy. I use a New Keynesian DSGE model that features Ricardian and non-Ricardian households and where the government sector comprises of a monetary and a fiscal authority. I provide a global solution for the model in a fully stochastic setting and where agents are aware of the occasionally binding constraint associated with the zero lower bound.

The results from the model suggest that as much as a higher inflation target stabilizes business cycle fluctuations in the presence of the ZLB constraint, a carefully calibrated countercyclical fiscal policy is an alternative policy choice to meet the same objective. From a welfare perspective, a countercyclical fiscal policy is better than a higher inflation target, because the latter reduces the long run output and consumption while the former is neutral in the long run. Furthermore, in a monetary-led equilibrium, countercyclical fiscal policy does not pose significant fiscal challenges for the government. Thus, the scope for a countercyclical fiscal policy weakens the case for raising the inflation target as a means to mitigate the effects of the zero lower bound. The results from the paper also suggest that the efficacy of countercyclical fiscal policy during zero lower bound episodes depends on the initial level of government debt. In particular, a high initial level of government debt limits that efficacy. 
While the model used in this paper is rather stylized so that some caution is warranted, this paper highlights the important point that one needs to rigorously evaluate all available policy options as far as mitigating the effects of ZLB is concerned. In this regard, important extensions to the model will be useful. One important extension is to introduce fiscal implementation lags in the model. Another extension is to consider a regime switching model where the economy switches between monetary-led and fiscally-led equilibria on the lines of (Bianchi and Melosi (2013)). Using that framework, one can re-evaluate the results in this paper, particularly those related to government debt dynamics. To further explore the significance of government debt, one can also extend the model to include endogenous sovereign risk premiums (Corsetti et al. (2013)) and debt limits. I leave these extensions for future work. 


\subsection{Tables and Figures}

Figure 3.1: U.K. Macroeconomic Variables
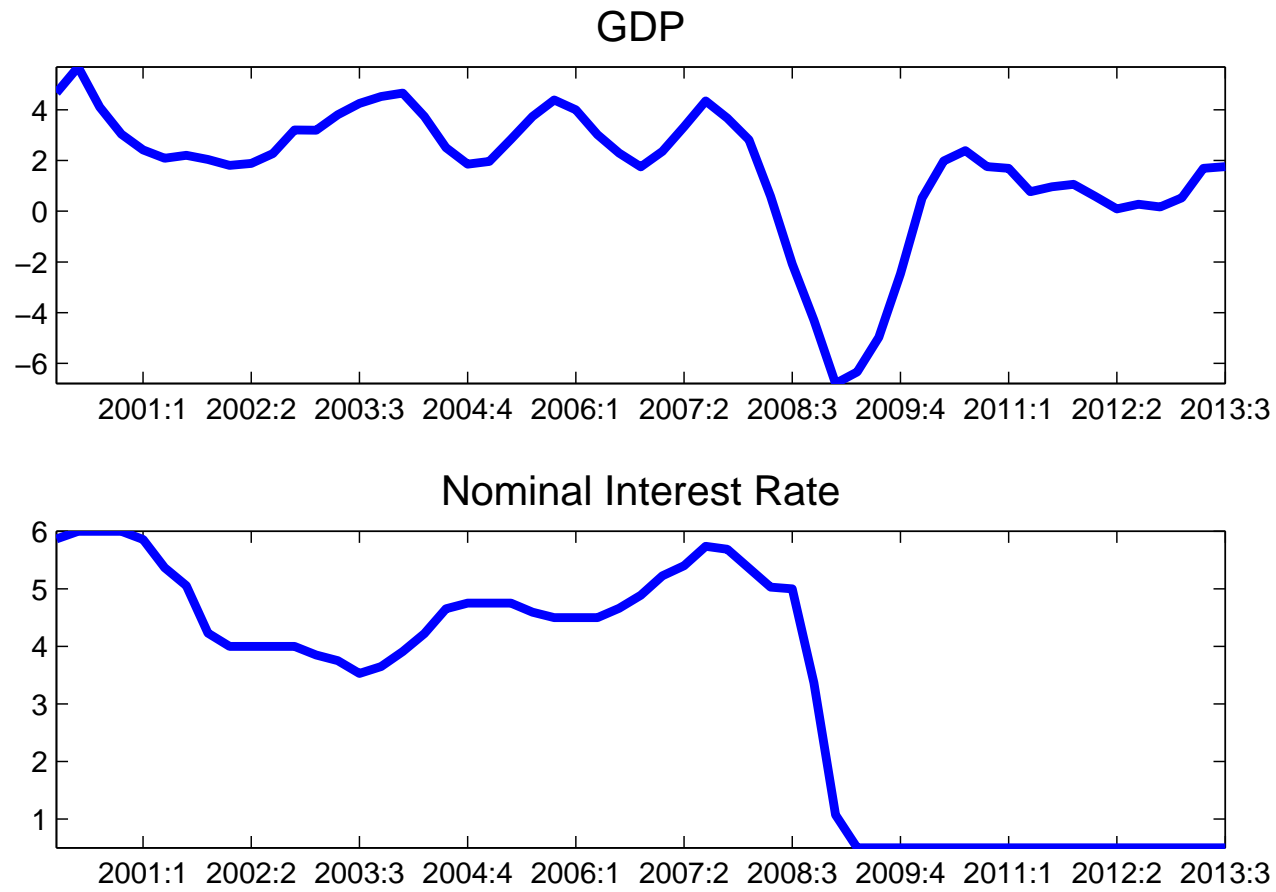

Govt. Debt to GDP Ratio

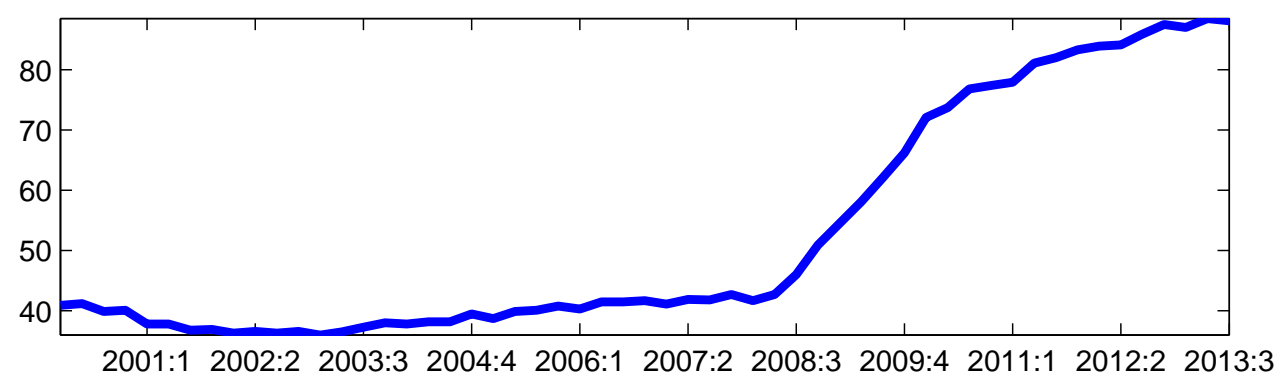

Note: The graph shows GDP (annual growth rates), the nominal interest rate (net annual), and government debt to GDP ratio for the U.K. All numbers shown are in percentages. 
Table 3.1: Baseline Parameter Values

\begin{tabular}{|l|c|c|}
\hline Definition & Parameter & Value \\
\hline Discount factor & $\beta$ & 0.99 \\
\hline Share of non-Ricardians & $\nu$ & 0.1184 \\
\hline Utility risk aversion & $\gamma$ & 1 \\
\hline Frisch labor supply & $\vartheta$ & 0.5 \\
\hline Labor preference & $\psi$ & 1.22 \\
\hline Mark-up & $\theta$ & 8 \\
\hline Calvo probability & $\phi$ & 0.7 \\
\hline Indexation & $\omega$ & 0.1 \\
\hline Gross inflation target & $\pi$ & 1.005 \\
\hline Interest smoothing & $\rho_{r}$ & 0.7 \\
\hline Taylor coefficient on inflation & $\rho_{\pi}$ & 3 \\
\hline Taylor coefficient on output & $\rho_{y}$ & 0.4 \\
\hline Govt. expenditure-to-GDP ratio & $\frac{g}{y}$ & 0.1654 \\
\hline Govt. debt-to-GDP ratio & $\frac{b}{y}$ & 0.5277 \\
\hline Tax rate & $\tau$ & 0.195 \\
\hline Fiscal coefficient on output & $\rho_{\tau}$ & 0.3 \\
\hline Fiscal coefficient on debt & $\rho_{b}$ & 0.5 \\
\hline AR(1) of preference shock & $\rho_{d}$ & 0.8 \\
\hline S.D of preference shock & $\sigma_{d}$ & 0.023 \\
\hline
\end{tabular}

Note: The table shows the parameter values chosen in the baseline specification of the model.

Table 3.2: Alternative Model Specifications

\begin{tabular}{|l|c|c|c|c|}
\hline Parameter & Baseline & Model A & Model B & Model C \\
\hline Inflation target & 1.005 & 1.01 & 1.005 & 1.01 \\
\hline Fiscal coefficient on output & 0.3 & 0.3 & 1.4 & 0.3 \\
\hline Indexation & 0.1 & 0.1 & 0.1 & 1 \\
\hline
\end{tabular}

Note: The table shows the parameter values chosen in alternative specifications of the model. Model A: higher inflation target of $4 \%$ with partial indexation. Model B: countercyclical fiscal policy. Model C: higher inflation target of $4 \%$ with full indexation. 
Figure 3.2: Policy Rules in the Baseline Specification
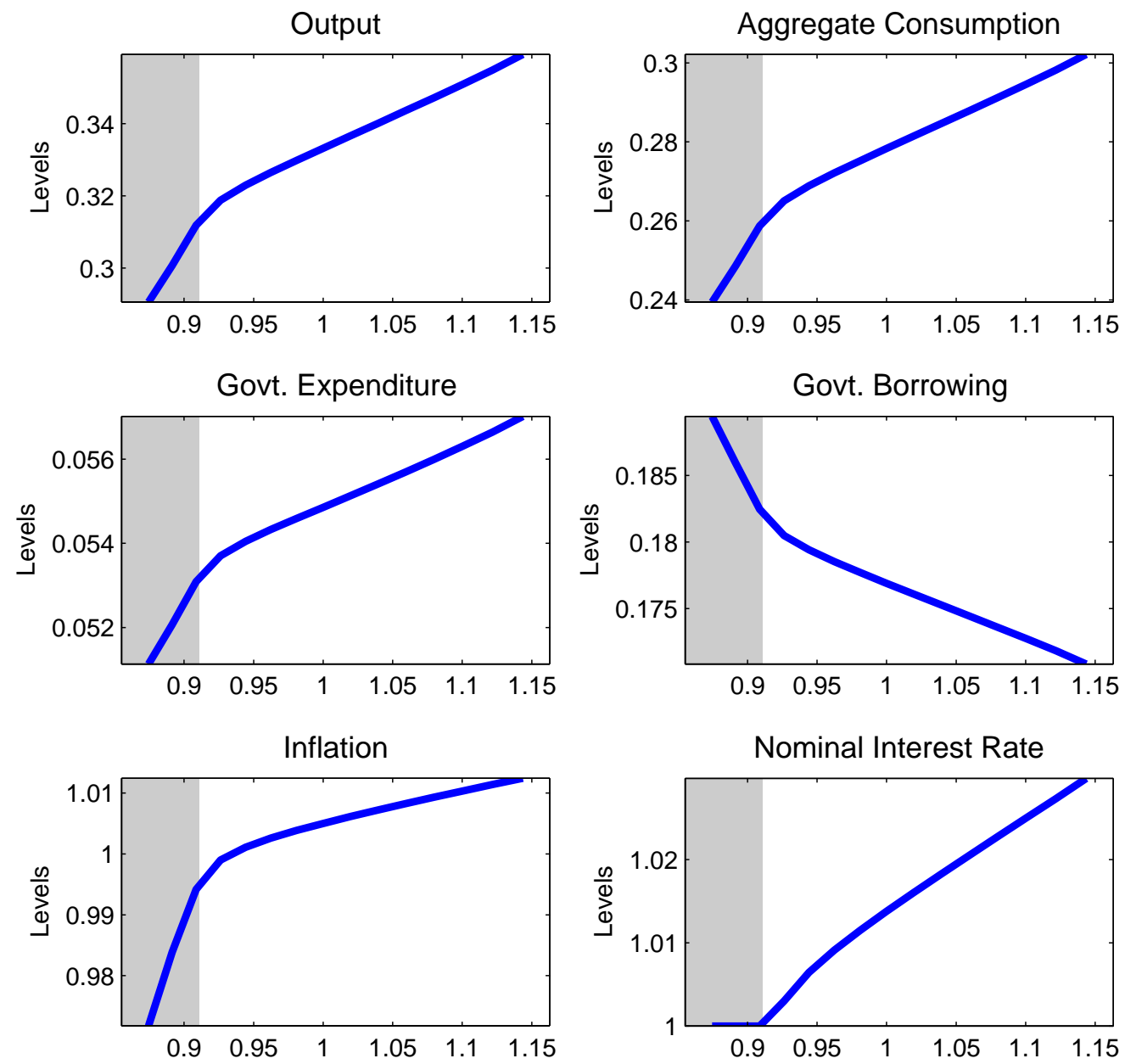

Note: The graph shows the policy rules at different grid points of the preference shock. These are from the baseline specification. All other state variables are fixed at grid points at or closest to steady states. Shaded highlight regions where the ZLB binds. 
Figure 3.3: Higher Inflation Target vs. Countercyclical Fiscal
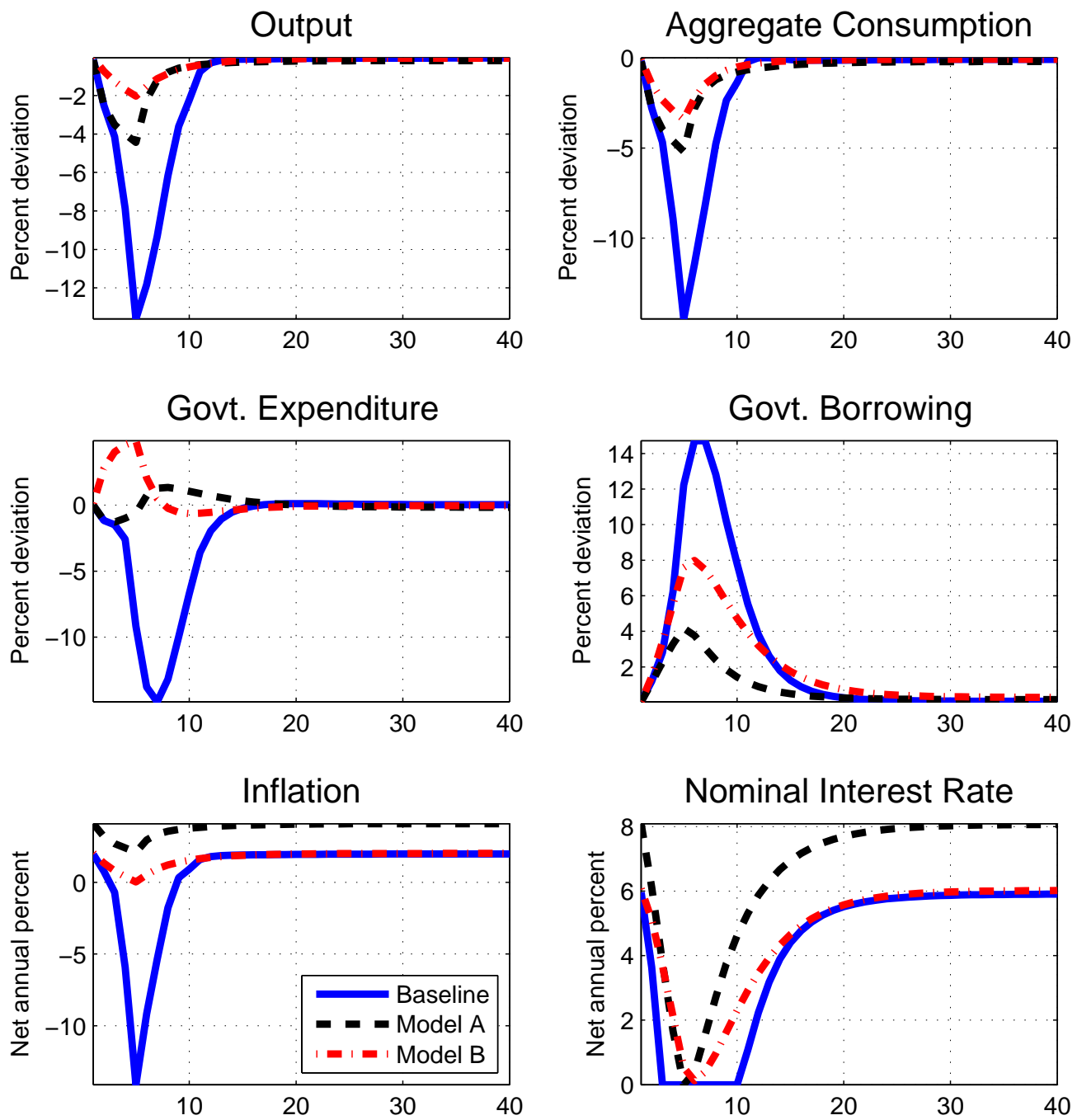

Note: The graph compares the dynamics of macro variables during a ZLB episode across these specifications: Baseline, Model A (higher inflation target of with partial indexation) and Model B (countercyclical fiscal policy). The ZLB episode is generated by hitting the economy, initially at its steady state, with adverse preference shocks of size 2 s.d. during the first 4 periods. 
Figure 3.4: Components of Govt. Budget Constraint
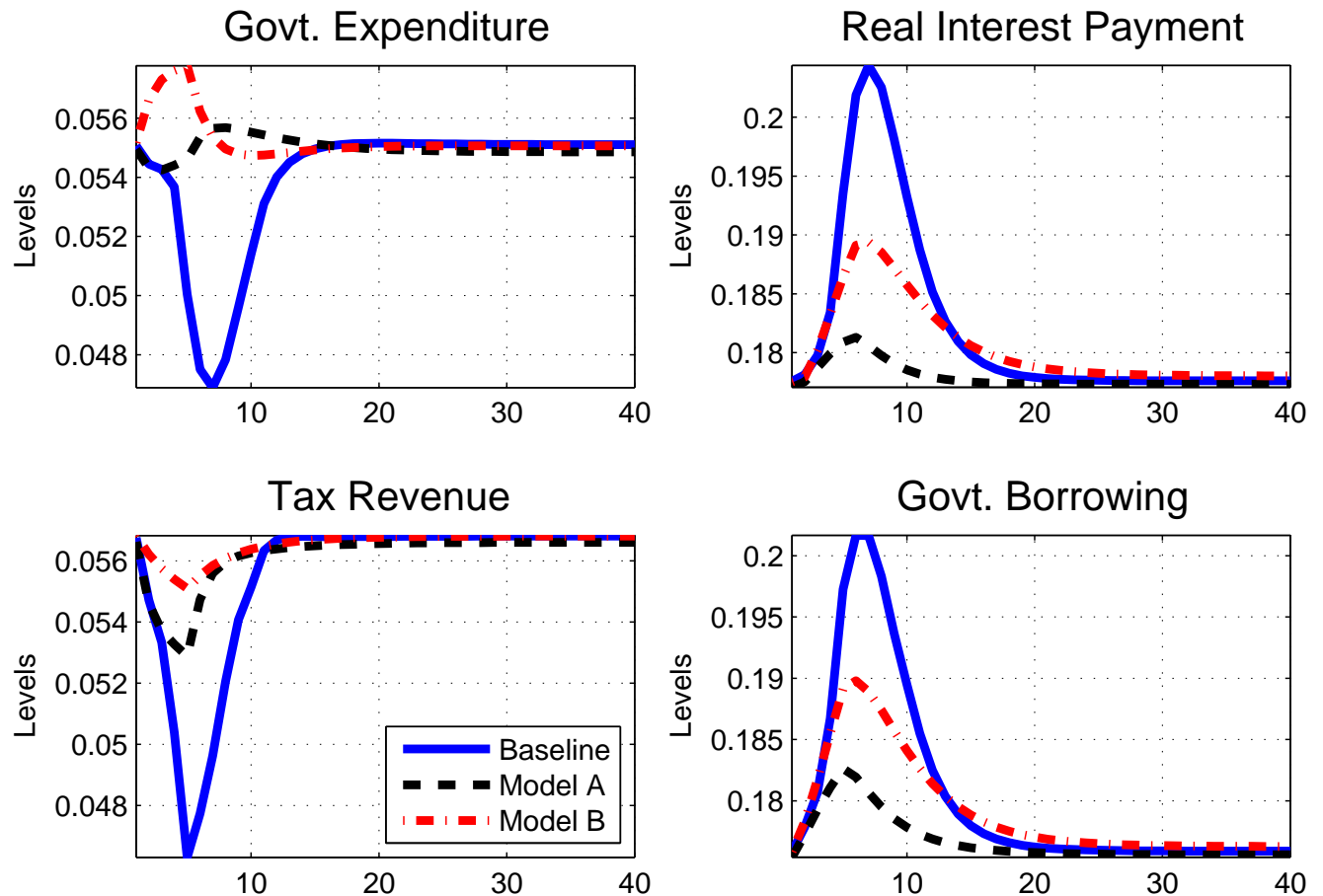

Note: The graph shows the dynamics of the components of the government budget constraint during a ZLB episode. The ZLB episode is generated by hitting the economy, initially at its steady state, with adverse preference shocks of size 2 s.d. during the first 4 periods. The top two figures are government expenditure items and the bottom two are the means by which those are financed. Model A: higher inflation target with partial indexation. Model B: countercyclical fiscal policy. 
Figure 3.5: Unconditional Distributions
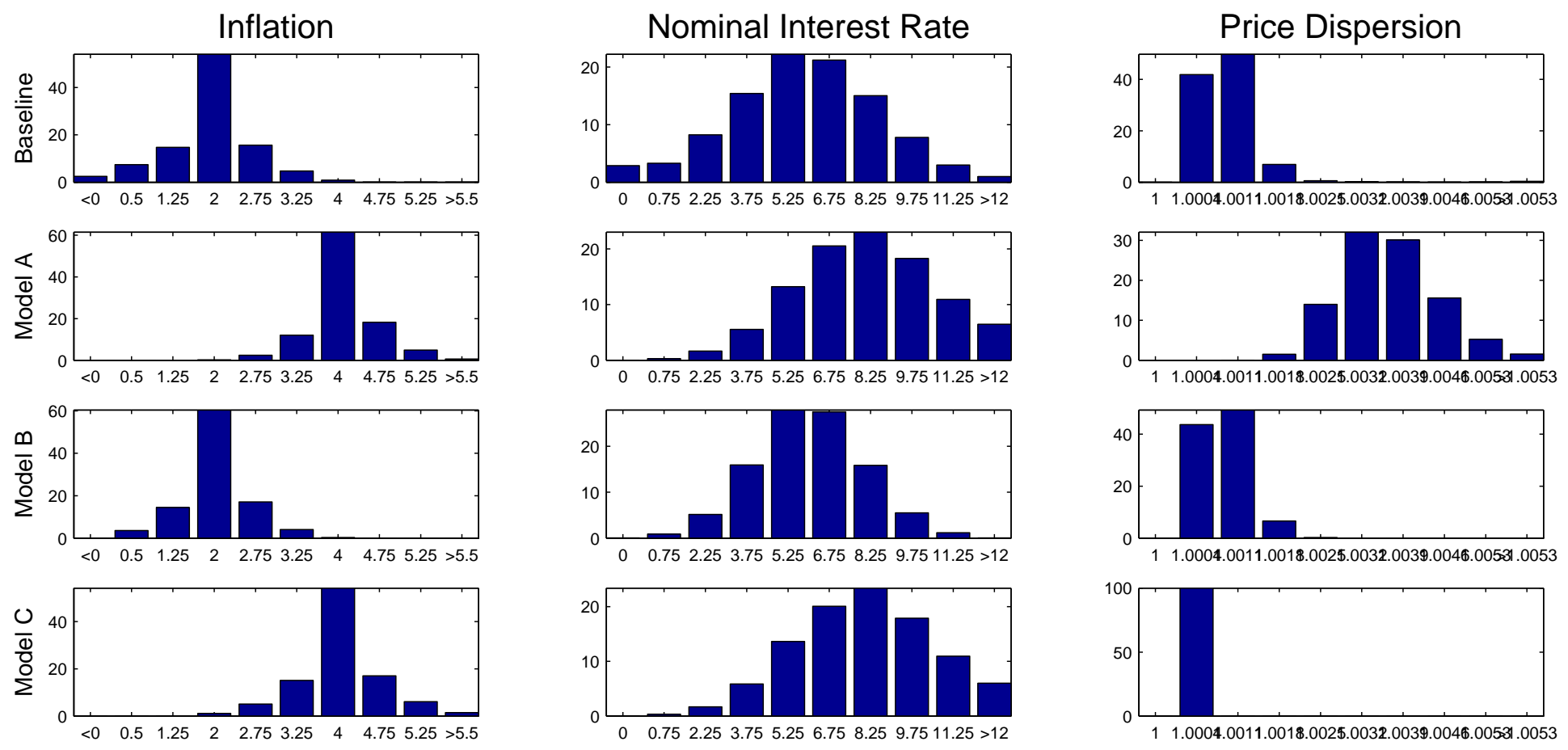

Note: The graph shows the frequency distributions (in percentage on Y-axis) of inflation, nominal interest rate, and price dispersion from model simulations across these specifications: Baseline, Model A (higher inflation target with partial indexation), Model B (countercyclical fiscal policy), and Model C (higher inflation target with full indexation). Inflation and nominal interest rate are in net annual rates while price dispersion is in gross quarterly levels. The results are based on simulations of length 50,000 with steady states of the baseline model as the starting point. 


\section{Table 3.3: Unconditional Moments from Model Simulations}

\section{(a) Mean}

\begin{tabular}{|l|c|c|c|c|}
\hline Model & Baseline & Model A & Model B & Model C \\
\hline Output & 0.3327 & 0.3317 & 0.3329 & 0.3331 \\
\hline Aggregate Consumption & 0.2777 & 0.2768 & 0.2778 & 0.278 \\
\hline Ricardian Consumption & 0.2835 & 0.2826 & 0.2836 & 0.2838 \\
\hline Non-Ricardian Consumption & 0.2344 & 0.2339 & 0.2346 & 0.2345 \\
\hline Aggregate Labor & 0.333 & 0.3329 & 0.3332 & 0.3331 \\
\hline Inflation & 1.0046 & 1.0102 & 1.005 & 1.0101 \\
\hline Nominal Interest Rate & 1.0146 & 1.0202 & 1.0151 & 1.0201 \\
\hline
\end{tabular}

\section{(b) Standard Deviation}

\begin{tabular}{|l|c|c|c|c|}
\hline Model & Baseline & Model A & Model B & Model C \\
\hline Output & 1.68 & 1.38 & 0.57 & 1.32 \\
\hline Aggregate Consumption & 1.83 & 1.59 & 0.94 & 1.51 \\
\hline Ricardian Consumption & 1.76 & 1.52 & 0.95 & 1.44 \\
\hline Non-Ricardian Consumption & 2.51 & 2.18 & 0.89 & 2 \\
\hline Aggregate Labor & 1.68 & 1.44 & 0.6 & 1.32 \\
\hline Inflation & 0.29 & 0.14 & 0.14 & 0.17 \\
\hline Nominal Interest Rate & 0.66 & 0.62 & 0.48 & 0.62 \\
\hline
\end{tabular}

Note: Table (a) shows the unconditional mean of macroeconomic variables from model simulations. Table

(b) reports the standard deviation of these variables as a percentage of the respective steady states. Model A: higher inflation target with partial indexation. Model B: countercyclical fiscal policy. Model C: higher inflation target with full indexation. The results are based on simulations of length 50,000 with steady states of the baseline model as the starting point. 
Table 3.4: Zero Lower Bound Episodes

\begin{tabular}{|l|c|c|c|c|}
\hline Model & Baseline & Model A & Model B & Model C \\
\hline Frequency & 2.87 & 0.03 & 0.06 & 0.04 \\
\hline Duration & 2.43 & 2.41 & 2.39 & 2.36 \\
\hline
\end{tabular}

Note: The table shows the frequency (in percentages) and average duration (in quarters) of zero lower bound episodes from model simulations.

Table 3.5: Unconditional Welfare

\begin{tabular}{|l|c|c|c|c|}
\hline Model & Baseline & Model A & Model B & Model C \\
\hline Ricardian & -653.01 & -654.50 & -653.15 & -652.41 \\
\hline Non-Ricardian & -807.16 & -807.86 & -807.18 & -807.17 \\
\hline
\end{tabular}

Note: The table shows the unconditional welfare of Ricardian and non-Ricardian households across model specifications. The unconditional welfare is obtained by simulating the value function of each type of household 50,000 times and then taking the average.

Table 3.6: Fiscal Variables

\begin{tabular}{|l|c|c|c|c|}
\hline Model & Baseline & Model A & Model B & Model C \\
\hline Govt. Debt & 79.4 & 57.9 & 59.6 & 57.6 \\
\hline Fiscal Deficit & 1.8 & 1.7 & 1.9 & 1.7 \\
\hline
\end{tabular}

Note: The table shows the maximum government debt and fiscal deficit as a percentage of GDP from model simulations. All of the above results are based on simulations of length 50,000 with steady states of the baseline model as the starting point. Model A: higher inflation target with partial indexation. Model B: countercyclical fiscal policy. Model C: higher inflation target with full indexation. 
Figure 3.6: Unconditional Welfare
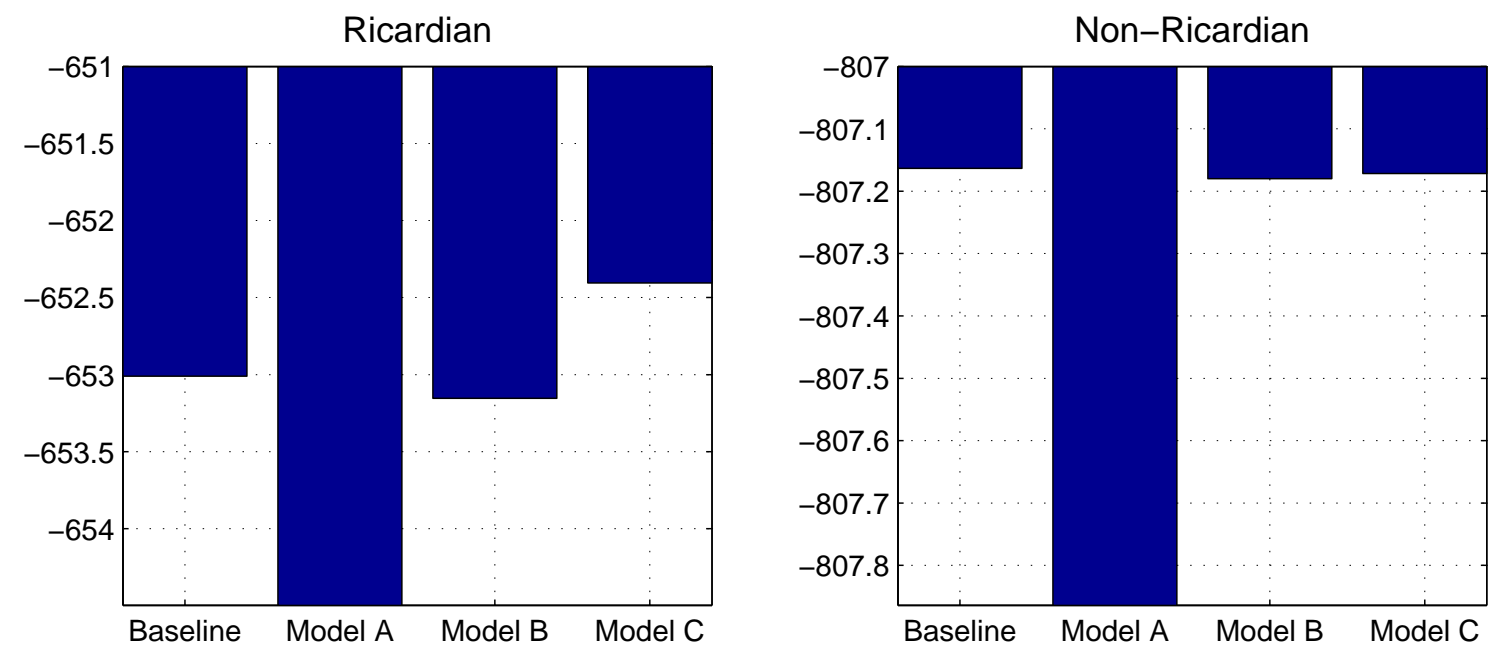

Note: The graph shows the unconditional welfare (Y-axis) of Ricardian and non-Ricardian households across model specifications. The unconditional welfare is obtained by simulating the value function of each type of household 50,000 times and then taking the average.

Figure 3.7: Conditional Welfare over Baseline Model
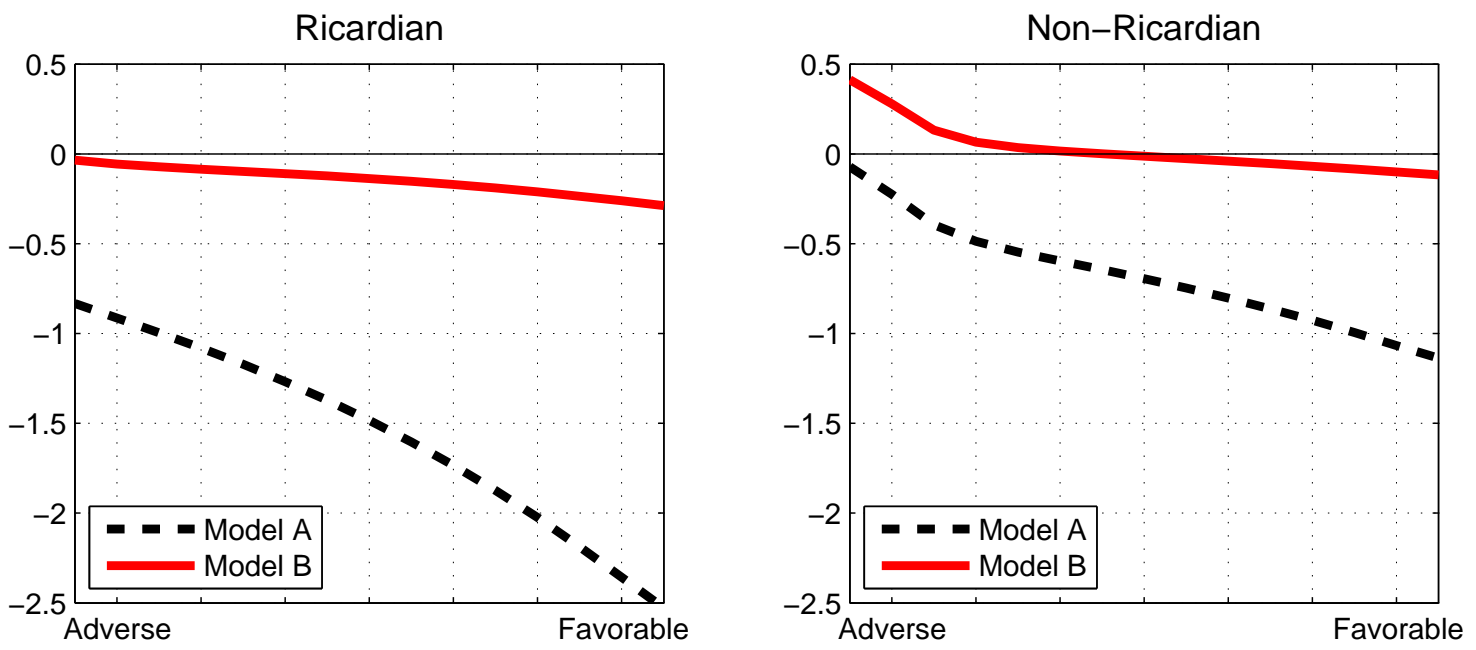

Note: The graph shows the difference in the conditional welfare (Y-axis) between each alternative model specification and the baseline model. A positive (negative) number indicates a welfare gain (loss). The conditional welfare shown is for different grids of preference shocks (X-axis), going from adverse (left) to favorable (right). All other state variables are fixed at grid points at or closest to steady states. 
Figure 3.8: Countercyclical Fiscal Policy for Different Levels of Initial Govt. Debt
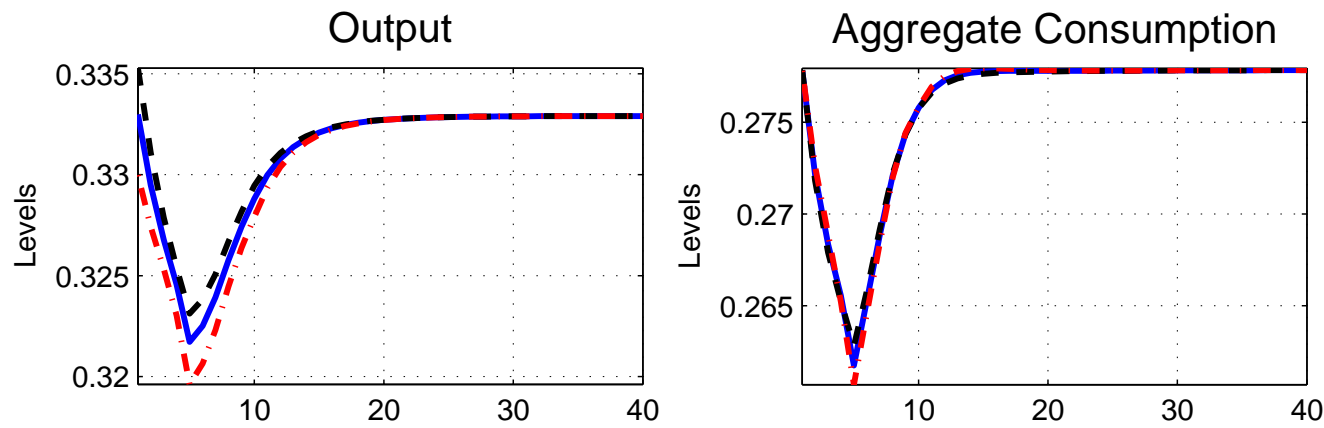

Govt. Expenditure

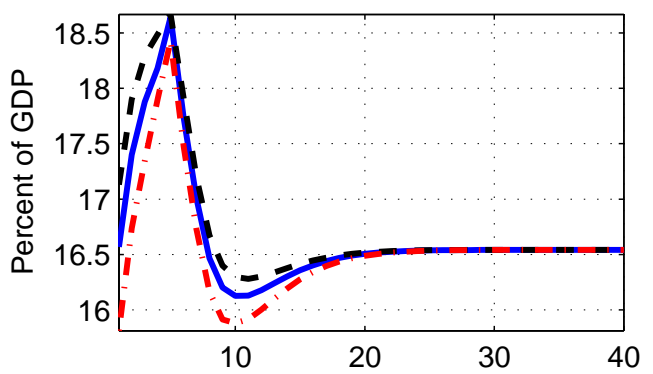

Govt. Borrowing
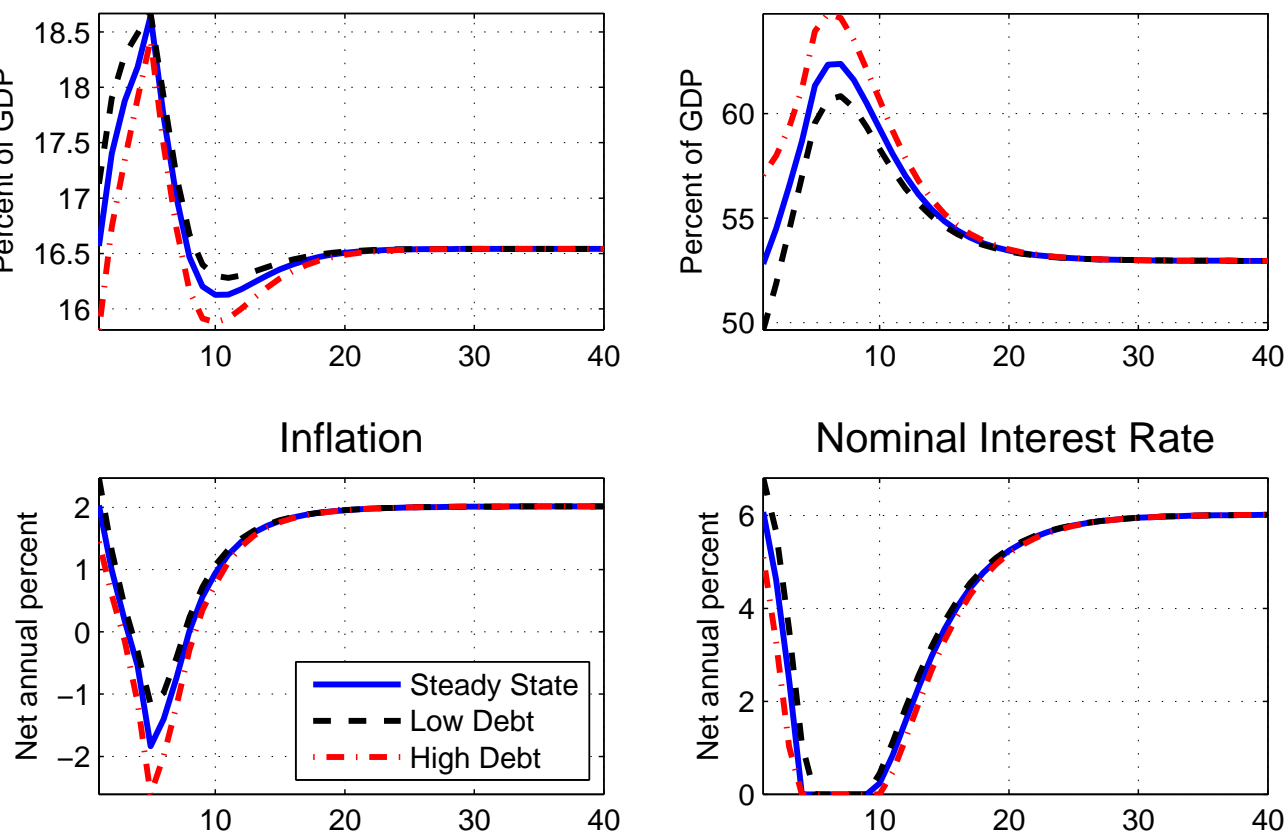

Note: The graph compares the dynamics of macro variables during ZLB episodes generated with different levels of initial government debt. These are from the specification with countercyclical fiscal policy (Model B). The initial levels of government debt considered are the steady state and debt levels lower and higher than the steady state. From these initial conditions, the ZLB episodes are generated by hitting the economy with adverse preference shocks of size 3 s.d. during the first 4 periods. 
Figure 3.9: Countercyclical Fiscal Policy for Different Levels of Initial Govt. Debt
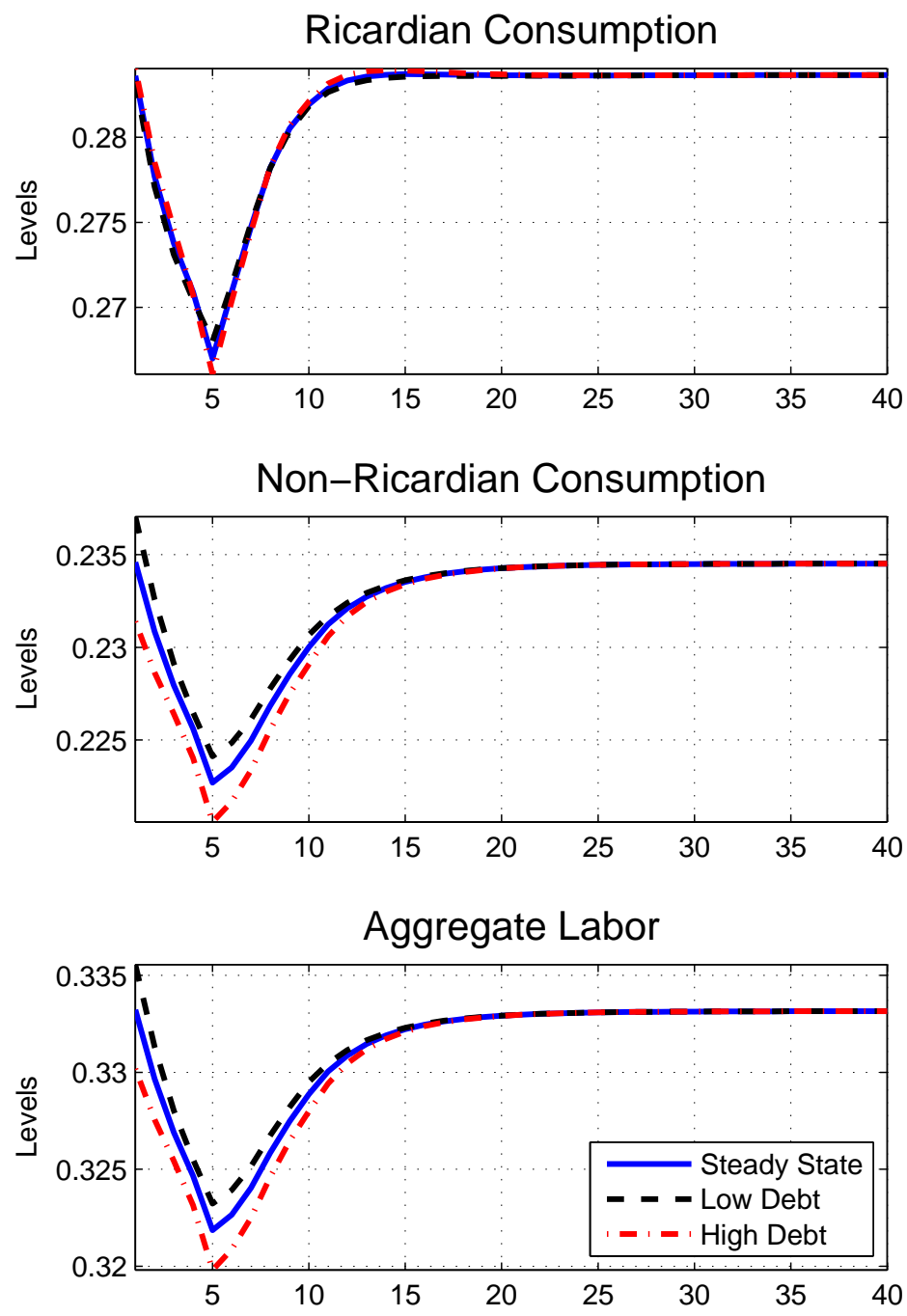

Note: The graph compares the dynamics of macro variables during ZLB episodes generated with different levels of initial government debt. These are from the specification with countercyclical fiscal policy. The initial levels of government debt considered are the steady state and debt levels lower and higher than the steady state. From these initial conditions, the ZLB episodes are generated by hitting the economy with adverse preference shocks of size 3 s.d. during the first 4 periods. 


\section{.1 Appendix}

\section{.1.1 Nonlinear Equations}

$$
\begin{aligned}
& \lambda_{t}=d_{t}\left(c_{R, t}-\psi \frac{l_{R, t}^{(1+\vartheta)}}{(1+\vartheta)}\right)^{-\gamma} \\
& \lambda_{t}=\beta E_{t}\left[R_{t} \frac{\lambda_{t+1}}{\pi_{t+1}}\right] \\
& \psi l_{R, t}^{\vartheta}=(1-\tau) w_{t} \\
& c_{N, t}=(1-\tau) w_{t} l_{N, t} \\
& \psi l_{N, t}^{\vartheta}=(1-\tau) w_{t} \\
& \xi_{t}=w_{t} \\
& \theta g_{1, t}=(\theta-1) g_{2, t} \\
& g_{1, t}=\lambda_{t} \xi_{t} y_{t}+\beta \phi E_{t}\left[\left(\frac{\pi^{\omega}}{\pi_{t+1}}\right)^{-\theta} g_{t+1}^{1}\right] \\
& g_{2, t}=\lambda_{t} \pi_{t}^{*} y_{t}+\beta \phi E_{t}\left[\left(\frac{\pi^{\omega}}{\pi_{t+1}}\right)^{1-\theta} \frac{\pi_{t}^{*}}{\pi_{t+1}^{*}} g_{t+1}^{2}\right] \\
& 1=\phi\left(\frac{\pi^{\omega}}{\pi_{t}}\right)^{1-\theta}+(1-\phi) \pi_{t}^{* 1-\theta} \\
& s_{t}=\phi\left(\frac{\pi^{\omega}}{\pi_{t}}\right)^{-\theta} s_{t-1}+(1-\phi) \pi_{t}^{*-\theta} \\
& \frac{Z_{t}}{R}=\left(\frac{R_{t-1}}{R}\right)^{\rho_{r}}\left[\left(\frac{\pi_{t}}{\pi}\right)^{\rho_{\pi}}\left(\frac{y_{t}}{y}\right)^{\rho_{y}}\right]^{1-\rho_{r}} \\
& R_{t}=Z_{t}+\max \left\{\mu_{t}, 0\right\}^{2} \\
& R_{t}=1+\max \left\{-\mu_{t}, 0\right\}^{2} \\
& g_{t}+b_{g, t-1} \frac{R_{t-1}}{\pi_{t}}=\tau w_{t} l_{t}+b_{g, t} \\
& f_{t}=-\left(b_{g, t}-\frac{b_{g, t-1}}{\pi_{t}}\right) \\
& f_{t}-f=\rho_{\tau}\left(y_{t}-y\right)+\rho_{b}\left(b_{t}-b\right) \\
& y_{t}=c_{t}+g_{t} \\
& y_{t}=\frac{l_{t}}{s_{t}} \\
& l_{t}=(1-\nu) l_{R, t}+\nu l_{N, t} \\
& c_{t}=(1-\nu) c_{R, t}+\nu c_{N, t}
\end{aligned}
$$




\section{.1.2 Additional Graphs and Tables}

Figure 10: Global vs. Linear Solution
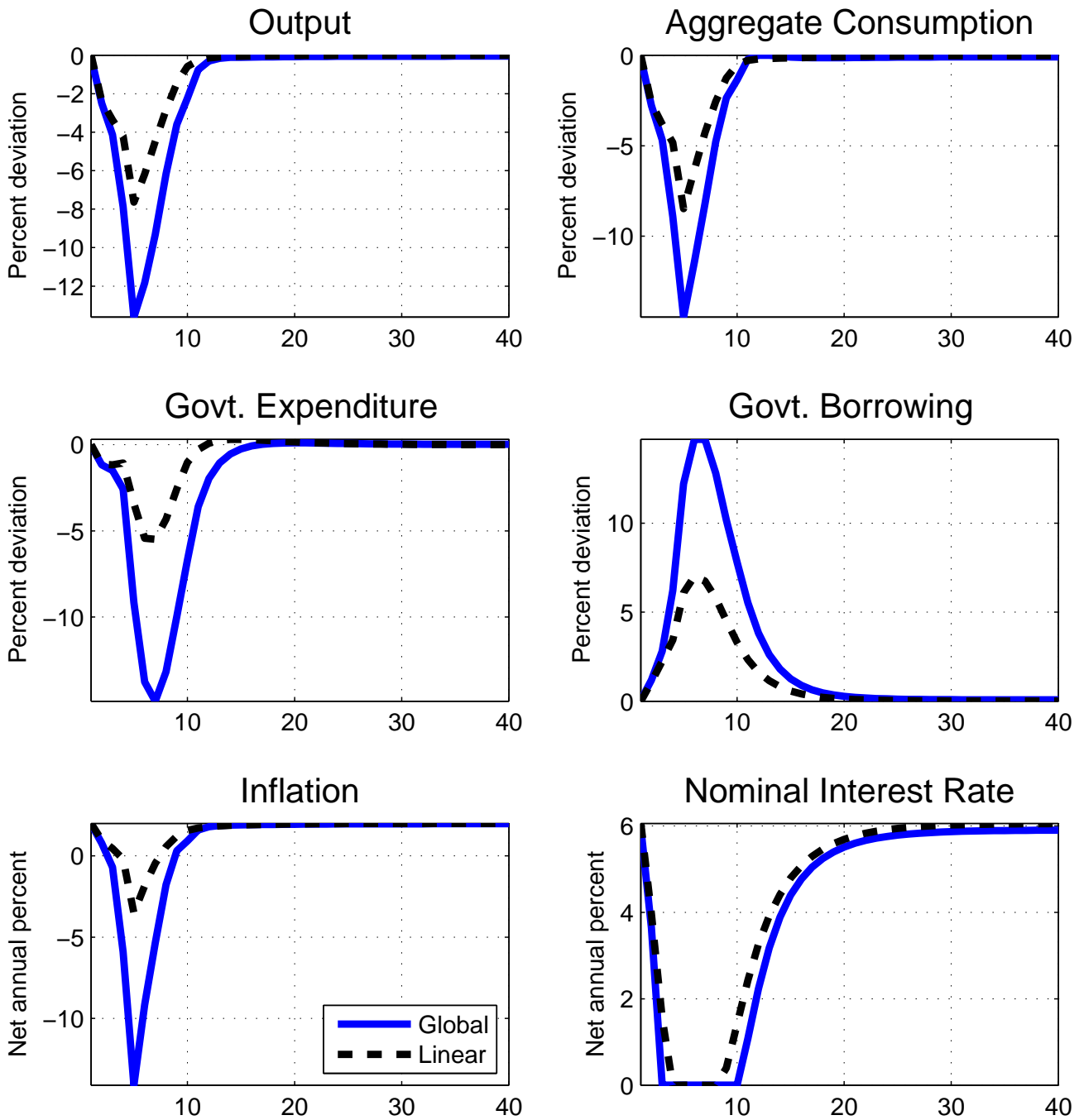

Note: The graph compares the dynamics of macro variables during a ZLB episode across the global and linear solution methods. These are from the baseline specification. The ZLB episode is generated by hitting the economy, initially at its steady state, with adverse preference shocks of size 2 s.d. during the first 4 periods. 


\section{Bibliography}

Adrian, T. and N. Boyarchenko (2013): "Intermediary Leverage Cycles and Financial Stability," Staff

Reports, Federal Reserve Bank of New York.

Adrian, T. And H. S. Shin (2009): "Prices and Quantities in the Monetary Policy Transmission Mechanism," International Journal of Central Banking, 5, 131-142.

Aizenman, J. and G. K. Pasricha (2013): "Net Fiscal Stimulus during the Great Recession," Review of Development Economics, 17, 397-413.

Amano, R. And M. Shukayev (2009): "Risk Premium Shocks and the Zero Bound on Nominal Interest Rates," Working Papers 09-27, Bank of Canada.

Ascari, G. (2004): "Staggered Prices and Trend Inflation: Some Nuisances," Review of Economic Dynamics, $7,642-667$.

Ascari, G. And T. Ropele (2007): "Optimal Monetary Policy under Low Trend Inflation," Journal of Monetary Economics, 54, 2568 - 2583.

_ (2009): "Trend Inflation, Taylor Principle, and Indeterminacy," Journal of Money, Credit and Banking, 41, 1557-1584.

Balke, N. S. (2000): "Credit and Economic Activity: Credit Regimes and Nonlinear Propagation of Shocks," The Review of Economics and Statistics, 82, 344-349.

Baumeister, C. And G. Peersman (2013): “Time-Varying Effects of Oil Supply Shocks on the US Economy," American Economic Journal: Macroeconomics, 5, 1-28.

Benfti, L. (2008): "Investigating Inflation Persistence across Monetary Regimes," The Quarterly Journal of Economics, 123, 1005-1060.

Benhabib, J., S. Schmitt-Grohe, and M. Uribe (2002): "Chaotic Interest-Rate Rules," American Economic Review, 92, 72-78. 
Bernanke, B. And M. Gertler (1989): “Agency Costs, Net Worth, and Business Fluctuations," American Economic Review, 79, 14-31.

Bernanke, B. S., J. Boivin, And P. Eliasz (2005): "Measuring the Effects of Monetary Policy: A Factor-Augmented Vector Autoregressive (FAVAR) Approach," The Quarterly Journal of Economics, $120,387-422$.

Bernanke, B. S. And M. Gertler (1995): "Inside the Black Box: The Credit Channel of Monetary Policy Transmission," Journal of Economic Perspectives, 9, 27-48.

Bernanke, B. S., M. Gertler, And S. Gilchrist (1999): "The Financial Accelerator in a Quantitative Business Cycle Framework," in Handbook of Macroeconomics, ed. by J. B. Taylor and M. Woodford, Elsevier, vol. 1 of Handbook of Macroeconomics, chap. 21, 1341-1393.

Bhattarai, K. And D. Trzeciakiewicz (2013): "Macroeconomic Impacts of Fiscal Policy Shocks in U.K. A DSGE Analysis," University of Hull, mimeo.

Bi, H. And M. Kumhof (2011): "Jointly Optimal Monetary and Fiscal Policy Rules under Liquidity Constraints," Journal of Macroeconomics, 33, 373-389.

Bianchi, F. And L. Melosi (2013): "Escaping the Great Recession," Working Papers 13-19, Duke University, Department of Economics.

Billi, R. M. And G. A. Kahn (2008): "What is the Optimal Inflation Rate?" Economic Review, 5-28.

Bils, M. And P. J. Klenow (2004): "Some Evidence on the Importance of Sticky Prices," Journal of Political Economy, 112, 947-985.

Blanchard, O., G. Dellariccia, And P. Mauro (2010): "Rethinking Macroeconomic Policy," Journal of Money, Credit and Banking, 42, 199-215.

Blanchard, O. And J. Simon (2001): "The Long and Large Decline in U.S. Output Volatility," Brookings Papers on Economic Activity, 32, 135-174.

Bordo, M. D. And J. G. Haubrich (2010): "Credit Crises, Money and Contractions: A Historical View," Journal of Monetary Economics, 57, 1 - 18, carnegie-Rochester Conference Series on Public Policy: Credit Market Turmoil: Implications for Policy April 17-18, 2009.

Borio, Claudio, C. F. And P. Lowe (2001): "Procyclicality of Financial Systems and Financial Stability," BIS Papers No.1.

Brunnermeier, M. K. And Y. Sannikov (2010): “A Macroeconomic Model with a Financial Sector," 2010 Meeting Papers 1114, Society for Economic Dynamics. 
(2014): "A Macroeconomic Model with a Financial Sector," American Economic Review, 104, 379421.

Caballero, R. J. and A. Krishnamurthy (1998): "Emerging Market Crises: An Asset Markets Perspective," NBER Working Papers 6843, National Bureau of Economic Research, Inc.

Calvo, G. A. (1983): "Staggered Prices in a Utility-maximizing Framework," Journal of Monetary Economics, 12, 383-398.

Campbell, J. Y. (2003): "Consumption-Based Asset Pricing," in Handbook of the Economics of Finance, ed. by H. M. Constantinides, G. M. and S. R, Amsterdam: Elsevier North-Holland.

Carter, C. K. And R. Kohn (1994): “On Gibbs Sampling for State Space Models,” Biometrika, 81, pp. 541-553.

Cespedes, L. F., R. Chang, And A. Velasco (2004): "Balance Sheets and Exchange Rate Policy," The American Economic Review, 94, pp. 1183-1193.

Christensen, I. And A. Dib (2008): “The Financial Accelerator in an Estimated New Keynesian Model," Review of Economic Dynamics, 11, 155 - 178.

Christiano, L. J., M. Eichenbaum, and C. L. Evans (2005): "Nominal Rigidities and the Dynamic Effects of a Shock to Monetary Policy," Journal of Political Economy, 113, pp. 1-45.

Clafessens, S., M. A. Kose, And M. E. Terrones (2012): "How Do Business and Financial Cycles Interact?" Journal of International Economics, 87, 178 - 190, symposium on the Global Dimensions of the Financial Crisis.

Clarida, R., J. Gal, And M. Gertler (1999): "The Science of Monetary Policy: A New Keynesian Perspective," Journal of Economic Literature, 37, pp. 1661-1707.

Clark, T. E. (2009): "Is the Great Moderation Over? An Empirical Analysis," Economic Review - Federal Reserve Bank of Kansas City, 94.

Cochrane, J. (2005): "Financial Markets and the Real Economy," Working Paper 11193, National Bureau of Economic Research.

Cogley, T., B. De Paoli, C. Matthes, K. Nikolov, and T. Yates (2011): "A Bayesian Approach to Optimal Monetary Policy with Parameter and Model Uncertainty," Journal of Economic Dynamics and Control, 35, 2186-2212.

Cogley, T. and T. J. Sargent (2005): "Drifts and Volatilities: Monetary Policies and Outcomes in the Post WWII US," Review of Economic Dynamics, 8, 262 - 302. 
Cogley, T. And A. M. Sbordone (2008): "Trend Inflation, Indexation, and Inflation Persistence in the New Keynesian Phillips Curve," The American Economic Review, 98, pp. 2101-2126.

Coibion, O., Y. Gorodnichenko, And J. Wieland (2011): "The Optimal Inflation Rate in New Keynesian Models: Should Central Banks raise their Inflation Targets in light of the ZLB?" Working Paper.

Coleman, W. J. (1990): "Solving the Stochastic Growth Model by Policy-Function Iteration," Journal of Business 6 Economic Statistics, 8, pp. 27-29.

Corsetti, G., K. Kuester, A. Meier, And G. Muller (2013): "Sovereign Risk, Fiscal Policy, and Macroeconomic Stability," The Economic Journal, 123, F99-F132.

Del Negro, M. (2003): "Discussion of Cogley and Sargent's "Drifts and Volatilities: Monetary Policies and Outcomes in the Post WWII U.S."," Working Paper 2003-26, Federal Reserve Bank of Atlanta.

Del Negro, M., M. P. Giannoni, And F. Schorfheide (2013): "Inflation in the Great Recession and New Keynesian Models," Staff Reports, Federal Reserve Bank of New York.

Dey, J. (2014): "Evaluating Monetary Policy under Preferences with Zero Wealth Effect: A Bayesian Approach," Journal of Economic Dynamics and Control, 38, 209 - 234.

Driessen, J. (2005): "Is Default Event Risk Priced in Corporate Bonds?" Review of Financial Studies, 18, $165-195$.

Elton, E. J., M. J. Gruber, D. Agrawal, And C. Mann (2001): "Explaining the Rate Spread on Corporate Bonds," The Journal of Finance, 56, 247-277.

Fernandez-Villaverde, J., G. Gordon, P. A. Guerrn-Quintan, and J. Rubio-Ramirez (2012): "Nonlinear Adventures at the Zero Lower Bound," Working Paper 18058, National Bureau of Economic Research.

Fernndez-Villaverde, J. And J. F. Rubio-Ramrez (2007): "How Structural are Structural Parameters?" Working Paper 13166, National Bureau of Economic Research.

Fisher, I. (1933): "The Debt-Deflation Theory of Great Depressions," Econometrica, 1, 337-357.

Garcia, C. And W. Zangwill (1981): Pathways to Solutions, Fixed Points, and Equilibria, Prentice-Hall.

Geanakoplos, J. (2009): "The Leverage Cycle," Cowles Foundation Discussion Papers 1715, Cowles Foundation for Research in Economics, Yale University.

Gertler, M. (1988): "Financial Structure and Aggregate Economic Activity: An Overview," Journal of Money, Credit and Banking, 20, 559-88. 
Gertler, M. And N. Kiyotaki (2010): "Chapter 11 - Financial Intermediation and Credit Policy in Business Cycle Analysis," Elsevier, vol. 3 of Handbook of Monetary Economics, 547 - 599.

Gilchrist, S., V. Yankov, And E. Zakrasjek (2009): "Credit Market Shocks and Economic Fluctuations: Evidence from Corporate Bond and Stock Markets," Journal of Monetary Economics, 56, 471 - 493.

Gilchrist, S. And E. Zakrajsek (2012a): "Credit Spreads and Business Cycle Fluctuations," American Economic Review, 102, 1692-1720.

- (2012b): "Credit Supply Shocks and Economic Activity in a Financial Accelerator Model," Rethinking the Financial Crisis, Russell Sage Foundation.

Gorton, G. (2009): "Information, Liquidity, and the (Ongoing) Panic of 2007," American Economic Review, $99,567-72$.

Graeve, F. D. (2008): "The External Finance Premium and the Macroeconomy: US Post-WWII Evidence," Journal of Economic Dynamics and Control, 32, 3415 - 3440.

Greenwood, J., Z. Hercowitz, and G. W. Huffman (1988): "Investment, Capacity Utilization, and the Real Business Cycle," The American Economic Review, 78, pp. 402-417.

Harrison, J. AND M. West (1997): Bayesian Forecasting and Dynamic Models, New York: SpringerVerlag.

He, Z. And A. Krishnamurthy (2011): "A Model of Capital and Crises," The Review of Economic Studies.

- (2013): "Intermediary Asset Pricing," American Economic Review, 103, 732-70.

Helbling, T., R. Huidrom, M. A. Kose, And C. Otrok (2011): "Do Credit Shocks Matter? A Global Perspective," European Economic Review, 55, 340 - 353, special Issue: Advances in International Macroeconomics: Lessons from the Crisis.

Ilzetzki, E., E. MendozA, And C. Vegh (2013): "How Big (Small?) are Fiscal Multipliers?" Journal of Monetary Economics, 60, 239-254.

ImBs, J. (2010): "The First Global Recession in Decades," IMF Economic Review, 58, 327-354.

Jacquier, E., N. G. Polson, And P. E. Rossi (1994): "Bayesian Analysis of Stochastic Volatility Models," Journal of Business $\& 5$ Economic Statistics, 12, pp. 371-389.

Kalemli-Ozcan, S., B. Sorensen, and S. Yesiltas (2012): "Leverage across Firms, Banks, and Countries," Journal of International Economics, 88, 284-298. 
Kannan, P. (2012): "Credit Conditions and Recoveries from Financial Crises," Journal of International Money and Finance, 31, 930-947.

Kashyap, A. K. And J. C. Stein (2000): "What Do a Million Observations on Banks Say about the Transmission of Monetary Policy?" American Economic Review, 90, 407-428.

Khan, A., R. King, and A. L. Wolman (2002): "Optimal Monetary Policy," Working Papers 02-19, Federal Reserve Bank of Philadelphia.

King, R., C. Plosser, and S. Rebelo (1988): "Production, Growth and Business Cycles: I. The Basic Neoclassical Model," Journal of Monetary Economics, 21, 195 - 232.

Kiyotaki, N. And J. Moore (1997): "Credit Cycles," Journal of Political Economy, 105, pp. 211-248.

Kose, M. A., C. Otrok, and C. H. Whiteman (2003): "International Business Cycles: World, Region, and Country-Specific Factors," American Economic Review, 93, 1216-1239.

- (2008): "Understanding the Evolution of World Business Cycles," Journal of International Economics, $75,110-130$.

Leeper, E. (1991): "Equilibria under Active and Passive Monetary and Fiscal Policies," Journal of Monetary Economics, 27, 129 - 147.

Meeks, R. (2012): "Do Credit Market Shocks Drive Output Fluctuations? Evidence from Corporate Spreads and Defaults," Journal of Economic Dynamics and Control, 36, 568 - 584.

Meh, C. A. And K. Moran (2010): "The Role of Bank Capital in the Propagation of Shocks," Journal of Economic Dynamics and Control, 34, 555-576.

MendozA, E. G. (2010): "Sudden Stops, Financial Crises, and Leverage," American Economic Review, 100, $1941-66$.

Mendoza, E. G. And M. E. Terrones (2008): “An Anatomy Of Credit Booms: Evidence From Macro Aggregates And Micro Data," NBER Working Papers 14049, National Bureau of Economic Research, Inc.

Merton, R. C. (1974): "On the Pricing of Corporate Debt: The Risk Structure of Interest Rates," Journal of Finance, 29, 449-70.

Mian, A. And A. Sufi (2010): "Household Leverage and the Recession of 200709," IMF Economic Review, $58,74-117$. 
Milcheva, S. (2013): “A Bank Lending Channel or a Credit Supply Shock?" Journal of Macroeconomics, $37,314-332$.

Mishrin, F. S. (2011): Monetary Policy Strategy: Lessons From The Crisis, European Central Bank, 67-118, Chapters.

Modigliani, F. And M. Miller (1958): "The Cost of Capital, Corporation Finance and the Theory of Investment," American Economic Review, 48, 261-297.

Morini, B. And M. Porcelli (2012): “TRESNEI, a Matlab Trust-Region Solver for Systems of Nonlinear Equalities and Inequalities," Computational Optimization and Applications, 51, 27-49.

Nakata, T. (2013): "Optimal Fiscal and Monetary Policy with Occasionally Binding Zero Bound Constraints," Finance and Economics Discussion Series 2013-40, Board of Governors of the Federal Reserve System.

Nakov, A. (2008): "Optimal and Simple Monetary Policy Rules with Zero Floor on the Nominal Interest Rate," International Journal of Central Banking, 4, 73-127.

Neely, C. J. (2004): "The Federal Reserve Responds to Crises: September 11th was not the first," The Federal Reserve Bank of St. Louis Review, 27-42.

Nunes, R. (2009): "Learning The Inflation Target," Macroeconomic Dynamics, 13, 167-188.

Peek, J., E. S. Rosengren, And G. M. B. Tootell (2003): "Identifying the Macroeconomic Effect of Loan Supply Shocks," Journal of Money, Credit and Banking, 35, pp. 931-946.

Perri, F. And V. QuAdrini (2011): "International Recessions," Working Paper 17201, National Bureau of Economic Research.

Potter, S. M. (2000): "Nonlinear Impulse Response Functions," Journal of Economic Dynamics and Control, 24, 1425-1446.

Primiceri, G. E. (2005): "Time Varying Structural Vector Autoregressions and Monetary Policy," The Review of Economic Studies, 72, 821-852.

Reinhart, C. And K. Rogoff (2009): This Time Is Different: Eight Centuries of Financial Folly, Princeton University Press.

Richter, A., N. Throckmorton, and T. Walker (2013): "Accuracy, Speed and Robustness of Policy Function Iteration," Computational Economics, 1-32. 
Schmitt-Groh, S. And M. Uribe (2007): "Optimal Inflation Stabilization in a Medium-Scale Macroeconomic Model," in Monetary Policy under Inflation Targeting, ed. by F. S. Miskin, K. Schmidt-Hebbel, N. L. S. Editor), and K. S.-H. (Se, Central Bank of Chile, vol. 11 of Central Banking, Analysis, and Economic Policies Book Series, chap. 5, 125-186.

Schmitt-Grohe, S. And M. Uribe (2006): Optimal Fiscal and Monetary Policy in a Medium-Scale Macroeconomic Model, MIT Press, 383-462.

Schneider, M. And A. Tornell (2004): "Balance Sheet Effects, Bailout Guarantees and Financial Crises," The Review of Economic Studies, 71, 883-913.

Sims, C. A. And T. Zha (2006): "Were there Regime Switches in U.S. Monetary Policy?" The American Economic Review, 96, pp. 54-81.

Smets, F. And R. Wouters (2007): "Shocks and Frictions in US Business Cycles: A Bayesian DSGE Approach," American Economic Review, 97, 586-606.

Stock, J. H. And M. W. Watson (2005): "Understanding Changes In International Business Cycle Dynamics," Journal of the European Economic Association, 3, 968-1006.

Stock, J. H. And M. W.Watson (2003): "Forecasting Output and Inflation: The Role of Asset Prices," Journal of Economic Literature, 41, 788-829.

TAYlor, J. (2007): "Housing and Monetary Policy," Housing, Housing Finance, and Monetary Policy, Federal Reserve Bank of Kansas City, 46376.

Uhlig, H. (2005): "What are the Effects of Monetary Policy on Output? Results from an Agnostic Identification Procedure," Journal of Monetary Economics, 52, 381 - 419.

Wheelock, D. C. And M. E. Wohar (2009): "Can the Term Spread Predict Output Growth and Recessions? A Survey of the Literature," Review, 419-440.

Woodford, M. (2003): Interest and Prices, Princeton University Press.

Yun, T. (1996): "Nominal Price Rigidity, Money Supply Endogeneity, and Business Cycles," Journal of Monetary Economics, 37, 345 - 370 . 